\title{
Mixed Reality A New Tool for Architecture
}

\author{
by \\ Balquis Attef
}

A thesis submitted to the Faculty of Graduate and Postdoctoral Affairs in partial fulfillment of the requirements for the degree of

\author{
Master of Architecture \\ in \\ M.Arch (Professional)
}

Azrieli School of Architecture \& Urbanism

Carleton University

Ottawa, Ontario

(C) 2019

Balquis Attef 



\section{INTRODUCTION}

For centuries, the architect was the person to oversee the design and the construction of a project from inception to completion, a master builder. Eventually, the complexity of projects required a higher level of specialization leading to the separation of the designer and the builder. ${ }^{1}$ Since the birth of Engineering Science in 1638 by Galileo, ${ }^{2}$ the structure was separated from aesthetics and from many other aspects in architectural thinking. ${ }^{3}$ In tandem, the separation worsened when the architectural field adopted the idea of "a site away from the site". In the past, knowledge and drawings were developed by professionals on construction sites. However, engineering laboratories and architecture workshops were later created to shift the work outside the construction site. While this was considered a good idea, eventually it led to an issue that can be summarized in one word - gaps. Lately, this problem had been addressed in the field and many professionals strive for solutions. Professionals in the architecture, engineering and construction fields (AEC) are suffering from knowledge and communication gaps that result from the lack of collaboration. Those clashes affect efficiency, safety and quality control of construction projects. The industry started to adopt technologies that facilitate and promote communication and collaboration among involved individuals. Collaborative relationships demand shared platforms of

\footnotetext{
${ }^{1}$ Antoine Picon and Martin Thom, French Architects and Engineers in the Age of Enlightenment (Cambridge: Cambridge University Press, 2009).

2 Prof. Joseph Dauben, "Galileo Galilei," Khan Academy, 2015.

${ }^{3}$ Philip Bernstein and Peggy Deamer, Building the Future: Recasting Labor in Architecture (New York: Princeton Architectural Press, 2008).
} 
communication, ${ }^{4}$ therefore, Building Information Modelling (BIM) documented a great success since its adoption in the mid-1980s.

3D modeling software made it possible to create and share detailed and accurate models quickly and inexpensively. Recently, however, the $3 \mathrm{D}$ visualization of complex systems has become increasingly difficult to communicate on 2D computer monitors. This paper investigates the adoption of Mixed Reality (MR) technology to bridge the gaps in the AEC field by merging the digital world with the physical environment. Instead of producing 3D models and viewing them as $2 \mathrm{D}$ representations, MR allows the user to align their 3D models onto the real world to evaluate. One can argue that this technology retrieves the idea of "on-site" design and construction: planning, drawing, and construction can all be done collaboratively on-site via MR headsets and MR remote collaboration.

The first chapter of the thesis posits a chronological order of some fundamental Human-Computer Interaction (HCI) approaches that significantly contributed to the development of mixed reality headsets. It also investigates two historical moments where mixed reality technology was envisioned through literature long before the technology allowed. The second chapter discusses architectural representations and the history of digital tools in architecture alongside the role they play in developing the industry. Then, the third chapter delves specifically into the mixed reality headset, Microsoft HoloLens, by discussing its nature, technical specifications, and its latest release. The chapter lists major AEC use cases of the HoloLens to date, and

\footnotetext{
${ }^{4}$ Philip Bernstein and Peggy Deamer, Building the Future: Recasting Labor in Architecture (New
} York: Princeton Architectural Press, 2008). 
proposes future AEC uses based on other industries' adoption of this technology. The fourth chapter examines the importance of collaboration and the role of MR technology in fostering greater collaboration between team members in the AEC industry. Since the architect is the person who brings all specialties together, it is the architect's role in implementing and developing new tools such as mixed reality to serve the industry. As a result, the fifth chapter describes the outcomes achieved when I worked in tandem with a Mixed Reality Enterprise, Arvizio, for their new software release that attains a smoother workflow for their AEC customers. 


\section{ACHNOLWEDGMENTS}

I am thankful for the opportunity to extend my sincere thanks to many individuals who belped my thesis becomes reality. Working on an evolving technology such as Mixed Reality was challenging, however, finding a way to properly thank all the people who have played a part in making this dream of mine come true is equally daunting.

I dedicate my work to my beloved parents, Dr. Omer Attef and Hana Noman who have always shown me love and support.

I would like to thank my supervisor Prof. Stephen Fai who supplied me with necessary resources and allowed me to shape my research thesis the way I saw fit.

Special thanks to the National Capital Commission for their constant support to young citizens.

Also, I would like to thank the entire team at Arvizio who work tirelessly on developing the technology and tools necessary to improve our field.

Special thanks to Alex Berlin, President and COO of Arvizio, who did not hesitate to support my research in all ways possible. I thank Eugene Belkin, Software Engineering Director, for his generosity in assisting me throughout the research by monitoring and sharing his knowledge.

With warmest thanks, Balquis 


\section{TABLE OF CONTENTS}

Introduction $\quad$ i

Acknowledgments iv

Table of Contents $\quad$ v

List of Illustrations vi vii

List of Appendices vii

\begin{tabular}{l|ll} 
CHAPTER 1 & The Essence of Mixed Reality: History Overview & 1
\end{tabular}

Vannevar Bush $\quad 2$

Ivan Sutherland 4

The Origin of Human Computer Interaction (HCI) 6

$\begin{array}{ll}\text { Remote Collaboration } & 10\end{array}$

\begin{tabular}{l|ll} 
CHAPTER 2 & Architectural Representations & 13
\end{tabular}

$\begin{array}{ll}\text { The History of Digital Tools in Architecture } & 14\end{array}$

The Role of Tools in the Architectural Profession $\quad 21$

Mixed Reality: A Tool or a Toy? $\quad 22$

\begin{tabular}{l|ll} 
CHAPTER 3 & Interpretation of the Nature of Mixed Reality & 26
\end{tabular}

$\begin{array}{ll}\text { What is Mixed Reality? } & 27\end{array}$

Mixed Reality Head-Mounted Devices $\quad 28$

Microsoft HoloLens Use cases in the AEC Industry 32

Mixed Reality Applications in Other Industries $\quad 34$

\begin{tabular}{l|ll} 
CHAPTER 4 & Towards a Harmonious Collaboration & 38
\end{tabular}

Master Builder: A Precursor $\quad 40$

The Origin of Collaboration $\quad 41$

Integrated Project Delivery in Canada 43

\begin{tabular}{l|ll} 
CHAPTER 5 & Implementations and Results & 46
\end{tabular}

Pilot Presentation with the National Capital Commission 48

Congregation des Servantes de Jésus-Marie $\quad 52$

Optimization Tool $\quad 53$

Conclusion: The Modern Master Builder $\quad 57$

Illustrations $\quad 61$

Appendix A: Key Terms $\quad 91$

Appendix B: List of Microsoft HoloLens 1 Applications 95

Appendix C: MR Studio Director Revit User Guide 101

Appendix D: MR Studio Director Wizard Guide 112

$\begin{array}{ll}\text { Bibliography } & 124\end{array}$ 


\section{LIST OF ILLUSTRATIONS}

Figure 1: As We May Think ............................................................. 2 source: "As We May Think." Life Magazine, October 1945.

Figure 2: The Memex ................................................................. 2 source: "As We May Think." Life Magazine, October 1945.

Figure 3: The Sketchpad ............................................................... 2 source: "Thumbnails for Alan Kay: Doing with Images Makes Symbols Pt 1 Return to Program Details.

Figure 4: The Sword of Damocles (viffingarrtual reality) .......................2 source: Ivan Sutherland, The Sword of Damocles, 1968.

Figure 5: Milgram Mixed Reality Spectrum..............................................2 source: Milgram and Kishino's Mixed Reality on the Reality-Virtuality Continuum, 1994.

Figure 6: Data Glove source: Virtual Technologies, Inc.

Figure 7: FingARtips . .2 source: Buchmaann Volkert, "Fing ARtips", 2004.

Figure 8: ClearBoard... source: Hirosbi Ishii and Minoru Kobayashi - NTT Human Interface Laboratories, 1993.

Figure 9: Descriptio Urbis Romae..........................................................2 source: Leon Battista Albertis Delineation of the City of Rome, "Descriptio Urbis Romae".

Figure 10: Meta 2 . .2 source: bttps:/ / wmw.metavision.com/

Figure 11: Magic Leap One source: https:/ / wnw.magicleap.com/

Figure 12: Microsoft HoloLens 1 2 
source: https:/ / wmw.microsoft.com/ bololens.

Figure 13: Microsoft HoloLens 2..................................................................2

source: bttps:/ / wmw.microsoft.com/ bololens.

Figure 14: Air Tap Gesture 2

source: https: / / docs.microsoft.com/ windows/ mixed-reality/gestures.

Figure 15: Bloom Gesture ..........................................................................2

source: https:/ / docs.microsoft.com/windows/mixed-reality/gestures.

Figure 16: Packard

source: Amy Frearson August, "V enice Architecture Biennale 2016",

Dereen Magarine, 2016.

Figure 17: Trimble XR10 with HoloLens 2.................................................2

source: Mobile World Congress, proceedings of Mobile World Congress, Barcelona (2019).

Figure 18: HoloLens RoomScanner. source: Matrix Inception.

Figure 19: Five Hills Health Regional Hospital 2 source: Graham Builds.

Figure 20: Mixed Reality in Real Estate and Design......................................2

Figure 21: Mixed Reality in Interior Design ....................................................2

Figure 22: Mixed Reality in Construction and Management............................2

Figure 23: Mixed Reality in Construction and Management............................. 2

Figure 24: Congregation des Servantes de Jésus-Marie...................................... 2 source: https:/ / ottawastart.com/ncc-buys-century-old-gatineau-convent/.

Figure 25: Congregation des Servantes de Jésus-Marie future uses.......................2

Figure 26: Wizard Constructor Tool... Error! Bookmark not defined.-86

Figure 27: Carleton Richcraft Hall Building..................................................... 2 


\section{LIST OF APPENDICES}

\section{Appendix A}

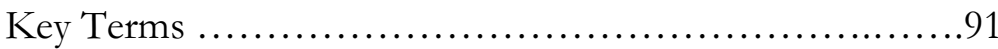

\section{Appendix B}

List of Microsoft HoloLens1 Applications..................95

\section{Appendix C}

MR Studio Director: Revit User Guide Release 3.0 ........101

\section{Appendix D}

MR Studio Director: Wizard Guide Release 3.0 ..........112 
CHAPTER 1

The Essence of Mixed Reality: History Overview 
The success of famous Human-Computer Interaction (HCI) products developed by companies are deeply rooted in academic/ institutional journals and literature. This chapter discusses two historical moments in which essays were published to popularize forward-thinking ideas. This exhibits a fundamental reason why some authors are more influential than others. Historically, planting the seed of ideas in people's imaginations through literature has proven to be a more successful method as opposed to producing real applications that are sometimes limited to finite technology. The chapter also posits a chronological order of some fundamental Human-Computer Interaction approaches that significantly contributed to the development of Mixed Reality Headsets.

\subsection{Vannevar Bush}

Figure 1, see As We May Think on page 62
At the end of World War II, Vannevar Bush wrote an influential article, As We May Think, which claimed that "there are signs of a change as new and powerful instrumentalities come into use." ${ }^{5} \mathrm{He}$ proposed a solution to what he considered the paramount challenge of the day: how information would be gathered, stored, and accessed in an increasingly information-saturated world. ${ }^{6}$ The vision in this article had a profound influence on the scientists and theorists responsible for the evolution of the personal computer and Internet, the key

\footnotetext{
${ }^{5}$ Vannevar Bush, "As We May Think," The Atlantic, July 01, 1945.

${ }^{6}$ Frank Biocca and Mark R. Levy, Communication in the Age of Virtual Reality (Florence: Taylor and Francis, 2013).
} 
Figure 2, see Memex on page 63 engineers at the Advanced Research Projects Agency (ARPA) - the Stanford Research Institute (SRI) XEROX P ARC, and many others. ${ }^{7}$

In his essay, Bush tries to imagine a new use and new future for the technologies people used at that time. He shared his musings on 3D images and his famous proposal for a machine called Memex, a hypermedia computer that would assist in the manipulation of ideas and allow professional workers to manage large amounts of data from different sources. Bush described Memex as a future device for individual use with intentional similarity with memory. ${ }^{8}$ The idea behind this machine was to augment our human memories and to manage information. In this ambitious conceptual device, the design was on the boundaries of available technology. In the same essay, Bush outlined his vision for a head-mounted camera that was in many ways a forerunner of today's augmented-reality devices:

"Let us project this trend ahead to a logical, if not inevitable, outcome. The camera hound of the future wears on his forehead a lump a little larger than a walnut. It takes pictures ... later to be projected or enlarged... It produces its result in full color. It may well be stereoscopic, and record with spaced glass eyes, for striking improvements in stereoscopic technique are just around the corner... One can now picture a future investigator in his laboratory. His hands are free, and he is not anchored. As he moves about and observes, he photographs and comments... If he goes into the field, he may be connected by radio to his recorder. As he ponders over his notes in the evening, he again talks his comments into the record. His typed record, as well as his photographs, may both be in miniature, so that he projects them for examination.",

As We May Think, is filled with thoughts and hypotheses that makes it a great example of someone with immense futuristic vision to

\footnotetext{
${ }^{7}$ Frank Biocca and Mark R. Levy, Communication in the Age of Virtual Reality (Florence: Taylor and Francis, 2013).

${ }^{8}$ Vannevar Bush, "As We May Think," The Atlantic, July 01, 1945.

${ }^{9}$ Vannevar Bush, "As We May Think," The Atlantic, July 01, 1945.
} 
advance technology, and in turn the way civilizations function. Bush didn't understand the technologies that were required at the time, because they hadn't been invented yet, instead, he understood and documented through literature the type of technology we need and the ways that we could put it to use to augment and to complement human intelligence.

\subsection{Ivan Sutherland}

Figure 3, see

Sketchpad on page 64
In 1963, Ivan Sutherland invented the Sketchpad that was directly influenced by the conceptual Memex envisioned by Vannevar Bush. This interactive computer-graphics program allowed users to visualize and control program functions becoming the foundation for computer graphics, computer operating system interactions, and software applications that are used in many facets of modern technologies. ${ }^{10}$ Sutherland's vision was articulated fully in his 1965 essay The Ultimate Display. He predicted the trajectory of technology towards virtual reality, augmented reality, head-mounted device, eye-tracking, voice recognition, haptics, gestural interaction, and holodeck. He foresaw many Mixed Reality capabilities that are known today in the $21^{\text {st }}$ century.

"The computer can easily sense the positions of almost any of our body muscles. So far only the muscles of the hands and arms have been used for computer control. There is no reason why these should be the only ones, although our dexterity with them is so high that they are a natural choice... Our eye dexterity is very high also. Machines to sense and interpret eye motion data can and will be built... Syllable voice input should not be ignored...In many cases the computer program needs to know which part of a picture the man is pointing at. The two-dimensional nature of pictures makes it impossible to order the parts of a picture by neighborhood. Converting from display coordinates to find the object pointed at is, therefore, a time-consuming process... the program really

\footnotetext{
${ }^{10}$ James Pyfer, "Sketchpad," Encyclopedia of New Media.
} 
Figure 4, see The Sword of Damocles on page 65

Figure 5, see Milgran Mixed Reality Spectrun on page 66

Key Terms, see Virtual Reality and Augmented Reality on page 92 needs to know which sub part of which part the man is pointing to. No existing display equipment computes the depths of recursions that are needed. New displays with analog memories may well lose the pointing ability altogether... The kinesthetic display might be used to simulate the motions of a negative mass. The user of one of today's visual displays can easily make solid objects transparent - he can "see through matter! "11

In 1968, with the help of his student Bob Sproul, Ivan Sutherland developed the first virtual reality head-mounted display system (HMD) - The $S_{\text {word }}$ of Damocles. This primitive user-interface device was invented for the purpose of experiencing computer-synthesized environments through head-mounted graphics displays. ${ }^{12} \mathrm{He}$ implemented some of the technologies and features predicted in The Ultimate Display, which inspired many researchers onward. He allowed the user to see the image rendered on a screen and the real world at the same time, making it possible to create an illusion of virtual objects existing in the real world. Some may argue that this attempt was the beginning of the augmented reality revolution, but the term itself was not introduced until 1992 by Thomas Caudell. He introduced a prototype of a see-through head-mounted display device that combines head position sensing and workplace registration systems to augment the visual field of the user with information necessary in the performance of their task. ${ }^{13}$ He coined this technology as "Augmented Reality." Later the term, Mixed Reality was introduced in 1994 by Professor Paul Milgram and Fumio Kishino. They created the Milgram Mixed Reality Spectrum that sought to explain the relationship of virtual reality and augmented reality. Similar to augmented reality, they define mixed reality environments where the

\footnotetext{
11 Ivan E. Sutherland, "The Ultimate Display," Proceedings of IFIP Congress, 1965, 506-508.

12 Woodrow Barfield and Thomas A. Furness, Virtual Environments and Advanced Interface Design (New York: Oxford University Press, 1995).

13 T.p. Caudell and D.w. Mizell, "Augmented Reality: An Application of Heads-up Display Technology to Manual Manufacturing Processes," Proceedings of the Twenty-Fifth Hawaii International Conference on System Sciences, 1992.
} 
real world and the virtual world objects are presented together on a single display. More details on acronyms queries in Chapter 3.

\subsection{The Origin of Human-Computer Interaction $(\mathrm{HCl})$}

\subsubsection{Two-Dimensional User Interface Technologies}

In his MIT Ph.D. thesis, Ivan Sutherland demonstrated what is now ubiquitous direct manipulation interface in his SketchPad project. He directly manipulated visible objects on the screen with a pointing device, a light-pen. ${ }^{14}$ It was used to manipulate objects by grabbing and moving them, changing size, and using constraints. ${ }^{15}$ With research on the SketchPad, the RAND Tablet was developed, it was one of the first products that used a handwriting recognition program, a GRAIL system (Graphical Input Language) that eliminated the use of a keyboard. This system smoothed out drawn shapes and rendered them on a large monitor in real time. Alan Kay, whose work for Xerox PARC resulted in many Apple innovations, described the experience as a remarkable system that felt like he "was sticking [his] hands right through the display". In 1965, light-pens were replaced by a cheaper alternative - the Mouse. Many of the current uses of the mouse were demonstrated by Doug Engelbart, a pioneer of human interaction with computers. His vision was used by Xerox PARC engineers to shape a better design of the mouse, employed by Xerox Alto - the first personal computer with a graphical interface. ${ }^{16}$ In 1968, another system was implemented at MIT's Lincoln Labs - AMBIT/G. This system employed, among other interface techniques, iconic

\footnotetext{
${ }^{14}$ Sutherland, I.E. "SketchPad: A Man-Machine Graphical Communication System," in AFIPS Spring Joint Computer Conference. 1963. 23. pp. 329-346.

${ }^{15}$ Sutherland, I.E. "SketchPad: A Man-Machine Graphical Communication System," in AFIPS Spring Joint Computer Conference. 1963. 23.

16 Brad A. Myers, "A Brief History of Human-computer Interaction Technology," Interactions 5, no. 2 (1998).
} 
representations, gesture recognition, dynamic menus, and selection of icons by pointing.

\subsubsection{Three-Dimensional User Interface Technologies}

Touchpad, mouse, keyboard or joysticks are input methods that traditionally define 2-dimensional user interface experiences. The key differences between 2D and 3D user interfaces are "direct interaction" and "3-dimensional spatial context." ${ }^{17}$ Bowman defines 3-dimensional user interface as a "user interface that involves 3D interaction." 18 Although some interactive computer systems display a virtual 3D space, the user may interact indirectly with this space (using a traditional mouse or a keyboard), making it a $2 \mathrm{D}$ user interface experience. However, if those traditional inputs (e.g. mouse inputs) are transformed directly into actions in the virtual space, it will be considered a 3D interaction. The user in a 3D user interface system gives spatial input that involves $3 \mathrm{D}$ position $(\mathrm{x}, \mathrm{y}, \mathrm{z})$ and/or orientation (yaw, pitch, roll). ${ }^{19}$ Whether it's a tracked hand-held device, the hand itself, or the use of the whole body and its senses; 3D interaction methods are used as portable spatial inputs that work from any location and by any user.

\section{Controllers:}

Unlike 2D user interfaces where the user interacts merely by manipulating 2D widgets, entering coordinate, or choosing items from a menu; the key technological enabler of 3D user interfaces is spatial tracking. The system must be able to “track the user's position, orientation, and/or motion to enable this input to be used for 3D

\footnotetext{
${ }^{17}$ Ernst Kruijff, Joseph J. LaViola, and Doug A. Bowman, 3D User Interfaces: Theory and Practice, ed. Doug A. Bowman (Boston, MA: Pearson Education, 2004).

${ }^{18}$ Ernst Kruijff, Joseph J. LaViola, and Doug A. Bowman, 3D User Interfaces: Theory and Practice, ed. Doug A. Bowman (Boston, MA: Pearson Education, 2004). 19 A. Bowman, "The Encyclopedia of Human-Computer Interaction, 2nd Ed.," The Interaction Design Foundation, https://www.interaction-design.org/literature/book/theencyclopedia-of-human-computer-interaction-2nd-ed.
} 
Key Terms, see Haptic Feedback on page 92 interaction." ${ }^{20}$ virtual reality and mixed reality controllers are used to allow users to interact with objects by picking up, moving, or pointing at an object. Inspired by video games joysticks, the built-in system of the controller aims to track the rotation and the position of the hand using external optical sensors to track its position. Controllers are also used for activities that cannot be done with our hands in real life. The controllers can be used to navigate around a virtual environment without moving the position of the body. This enables users to explore a virtual world that is bigger than the physical space they are in. Additionally, virtual reality controllers nowadays provide haptic feedback through vibration which increases the user's sense of immersion by resonating a real feeling.

\section{Eye-Tracking, Hand, and Speech Recognition}

As stated previously, Ivan Sutherland envisioned gestural interaction and the manipulation of "contents ... [by] merely point[ing] to the first and drag[ing] it over to the second." ${ }^{21} \mathrm{He}$ also focused on the importance of body parts and movements and that their dexterity should make them a "natural choice." 22 In his first virtual reality headset, Sword of Damocles, Sutherland introduced head tracking method. His attempt to use a body part was to present the user with a "perspective image which changes as he moves." ${ }^{23}$ With the available technology at the time, he knew it was difficult to measure the rotation of the eyeball (eye-tracking). He understood that the perspectival picture presented needs to change only when the user moves their head. Fast forward to today, we are presented with eye-tracking technology that takes device awareness to a new level. Its profound

\footnotetext{
${ }^{20}$ Doug A. Bowman, "The Encyclopedia of Human-Computer Interaction, 2nd Ed.," The Interaction Design Foundation, https://www.interaction-design.org/literature/book/theencyclopedia-of-human-computer-interaction-2nd-ed.

${ }^{21}$ Ivan E. Sutherland, "The Ultimate Display," Proceedings of IFIP Congress, 1965, 506-508.

22 Ivan E. Sutherland, "The Ultimate Display,"Proceedings of IFIP Congress, 1965, 506-508.

${ }^{23}$ Ivan E. Sutherland, "A Head-Mounted Three Dimensional Display," AFIPS '68, Fall Joint

Computer Conference, Part I, December 9, 1968.
} 
Figure 6, see Data Glove on page 67

Figure 7, see FingARtips on page 68 impact on 3D user interface experience enables the device (e.g. Mixed Reality Headset) to understand where users spend their most valuable resource -their attention.

While the human eye allows for optical observation, hands are our main means of interaction with objects in real life. Past research aimed to explore hand- and finger-based interaction in augmented and virtual reality interfaces, have contributed successfully to the mixed reality industry. It started with the invention of glove-based control interface - Data Glove. Researchers observed that hand gestures inspired by sign language can have intrinsic similarities to computer commands and interface experiences as a means of communication. ${ }^{24}$ Data glove (or finger trackers) detects contacts between the fingers while measuring joint angles. From physical kinetic measurements, developments on glove-based systems eventually shifted the researcher's focus to vision-based hand gesture recognition. In 2004, a research paper from the University of Canterbury presented techniques for freehand interaction with augmented reality content. ${ }^{25}$ They argued that freehand interaction would "not only enable natural intuitive interaction with virtual objects but also help to ease the transition between interaction with real and virtual objects at the same time."26 They focused their FingARtips project on presenting techniques to manipulate nearby objects using natural gestures such as grabbing, pressing, dragging and releasing for personal workspace or a conference table. ${ }^{27}$ A problem they faced occurred when attempting to distinguish near spaces and far spaces for hand-based interaction, they

\footnotetext{
24 Prashan Premaratne, "Historical Development of Hand Gesture Recognition," Human Computer Interaction Using Hand Gestures Cognitive Science and Technology, 2014.

25 Volkert Buchmann et al., "FingARtips," Proceedings of the 2nd International Conference on Computer Graphics and Interactive Techniques in Austalasia and Southe East Asia - GRAPHITE 04, 2004.

26 Volkert Buchmann et al., "FingARtips," Proceedings of the 2nd International Conference on Computer Graphics and Interactive Techniques in Austalasia and Southe East Asia - GRAPHITE 04, 2004.

27 Volkert Buchmann et al., "FingARtips," Proceedings of the 2nd International Conference on Computer Graphics and Interactive Techniques in Austalasia and Southe East Asia - GR APHITE 04, 2004.
} 
were only able to manipulate near objects. With today's technology, mixed reality head-mounted devices combine freehand gesture recognition, controllers, and eye-tracking for a smoother 3D user interface. Although this combination may seem intuitive and easy, some novice users disagree. Mixed reality gestures require basic training like any other new technology.

Elsewhere, recent devices feature speech recognition. Weinschenk and Barker, behavioural psychologists, define speech recognition as "the technologies that enable computers or other electronic systems to identify the sound of a human voice, separate that sound from noise in the environment, and accept the messages from the voice as input for controlling the system." 28 Aside from physical and visual tracking, speech recognition adds a new dimension of 3D user interface input method to mixed reality technology. It is explicit that almost any body part can be turned into a spatial input method by tracking it. This extends the capabilities of the user and allows data input to occur more naturally, precisely and efficiently.

\subsection{Remote Collaboration}

Computers are increasingly used to enhance collaboration between users. The enhancement of reality overlapped with synthetic images in mixed reality allows users to perform tasks easily and more efficiently. One of the great advantages of mixed reality technology is the ability to perform face-to-face conversation while collaborating on a realworld task. It allows users to look and interact with virtual objects while simultaneously being aware of the conversational cues of other users/participants. Throughout the years, a great effort was put into a remote collaboration that allows users to remotely participate in

\footnotetext{
${ }^{28}$ Weinschenk, S., Barker, D.T., 2000, Designing Effective Speech Interfaces, John Wiley
} and Sons, New York, NY, pp. 98-103. 
collaborative sessions and gain similar experience as face-to-face collaboration.

Figure 8, see

ClearBoard on page 69
One of the earliest attempts was shown in 1992 by the computer scientists, Hiroshi Ishii and Minoru Kobayashi, in their ClearBoard project. They learned that people feel difficulties to communicate in face-to-face conversations without eye contact because "eyes are as eloquent as the tongue" and they should be accounted for. ${ }^{29}$ They built a series of collaborative interfaces that metaphorically remove the seam between the images of the participants and the shared drawing images. Using surfaces made of large mirrors and video projection techniques, users can look directly at their workspace and see their collaborator directly behind it. ${ }^{30}$ Their focus on gaze awareness drove the future of remote collaboration in mixed reality. Now in 2019, Microsoft has revealed the most advanced remote collaboration feature that presents lifelike avatars with improved hand tracking and eye-tracking. The avatar mirrors the participant's physical arm, hand, and eye movements in a way that strongly resembles actual face-to-face collaboration. More on that in Chapter 3.

In recent years, there has been a rapid technological revolution born from the understanding of human-computer interaction (HCI). With much of the important work in HCI coming from research at universities and labs, they were later carried on by private industries. Over the years, HCI expanded to overlap with areas such as usercentered design, user interface design, and user experience design. According to John M. Carrol, author and founder of HCI:

"HCI has grown to be broader, larger and much more diverse than computer science itself. HCI expanded from its initial

\footnotetext{
${ }^{29}$ Hiroshi Ishii and Minoru Kobayashi, "ClearBoard," Proceedings of the SIGCHI Conference on Human Factors in Computing Systems - CHI 92, 1992.

${ }^{30}$ Hiroshi Ishii and Minoru Kobayashi, "ClearBoard," Proceedings of the SIGCHI Conference on Human Factors in Computing Systems - CHI 92, 1992.
} 
focus on individual and generic user behavior to include social and organizational computing, accessibility for the elderly, the cognitively and physically impaired, and for all people, and for the widest possible spectrum of human experiences and activities."

The concept of human-computer interaction popularized the new phase of innovation where the interaction between the computer and the user resembles a human-to-human experience. Now, HCI has expanded to focus on the widest possible spectrum of human experiences and activities rather than focusing solely on generic user behaviour. This approach means that technologies and devices are now developed around the user's needs, to enhance their abilities and productivity. Successful HCI technologies are those that allow untrained users to tailor the technology to their own needs and to allow professional users to invent new applications that would serve their discipline based on their understanding of their domain. 
CHAPTER 2

Architectural Representations 
"It is not about designing a building

using digital tools, but rather to

design a building that could not

have been either designed or build

without them."

Mario Carpo

The capacity of a distinct tool to carry ideas from conception to realization persists as an integral part of the architectural practice. ${ }^{31}$ For the past two centuries, drawing, in its many forms, had been the main tool of representation in architecture. Then, digital tools were introduced in the architectural profession and as a result, broadened the horizon of architectural representation, imagination, and production.

\subsection{The History of Digital Tools in Architecture}

Architectural representations experienced a major shift by the advent of digital technologies. Prior to the mid-1980s, analogic design "visual analogy, metaphor, and shape borrowing" ${ }^{32}$ was commonly used as an architectural representation. Beginning in 1960 and with Ivan Sutherland's Sketchpad, architectural representations began to be associated with the new computer technologies. This innovative system allowed the user to interact with the computer by creating, duplicating and storing drawings which allowed very large layouts; manual methods were not accurate, practical, or reliable to perform

31 Pari Riahi, "Expanding the Boundaries of Architectural Representation," The Journal of Architecture 22, no. 5 (2017).

32 Ellen Yi-Luen Do and Mark D. Gross, "Drawing Analogies: Supporting Creative Architectural Design with Visual References.," Proceedings of Association of Computer Aided Design In Architecture (ACADIA), 1995. 
similar tasks. ${ }^{33}$ The Sketchpad proved that "computers can be used not just for engineering and repetitive drafting but interactively by designers and potentially artists in the concept creation and innovation stage." ${ }^{34}$ The architectural researcher, Roberto Bottazzi, interprets the Sketchpad as a system that marked a historic benchmark for digital design and exemplified how digital tools migrated from military to civilian uses, "The invention of Computer-Aided Design (CAD) should be seen as one of the products from the conversion of military technologies, developed during the Second World War to commercial uses as needed by the US government in order to capitalize on the massive investments made." ${ }^{35}$ Unlike earlier computer applications, Sketchpad was interactive. Many would argue that modern CAD systems trace their roots back to Sutherland's Sketchpad, however, the term Computer-Aided Design was coined years prior to the invention of the Sketchpad; by MIT in 1959. The Mechanical Engineering Department and Electronic Systems Laboratory of the Electrical Engineering Department of MIT collaborated on a project sponsored by the US Air Force, to explore the possibilities for a 'Computer-Aided Design'. ${ }^{36}$ Thus it is evident that Sutherland did not intend to create a computer-aided design system, but rather a computer-aided drawing/drafting system. According to Bottazzi, Sutherland realized the design potential later, "designing objects with a computer was essentially different from hand drafting. The step-by-step formal logic of emerging software could not have been fully exploited without also changing the way in which objects were conceived. The ambition was for both architecture design process and representation to radically

\footnotetext{
33 Ivan E. Sutherland, "Sketchpad a Man-Machine Graphical Communication System," Simulation 2, no. 5 (1964).

${ }^{34}$ Cadazz, "CAD Software - History of CAD CAM," CAD Software History CAD CAM Computer Aided Design, 2004, http:// cadazz.com/cad-software-history.htm.

35 Roberto Bottazzi, "Digital Architecture Beyond Computers," 2018.

36 Steven Anson Coons, "An Outline of the Requirements for a Computer-aided Design System," AFIPS '63 (Spring), May 1963.
} 
merge traditional practices with the advantages afforded by computation." 37

Moreover, in the last two decades, both theorists and practitioners in the architectural field have been analyzing the paradigm shift brought by the digital revolution. The historian, Mario Carpo, interprets it in his book The Alphabet and the Algorithm as a shift from "identicality to variability." ${ }^{38}$ Carpo argues that there are two instances of identicality that shaped architectural modernity; Leon Battista Alberti's invention of architectural design and the Industrial Revolution. In Alberti's theory, "a building is an identical copy of the architect's design", he developed a specific numerical system for notation to ensure that both the design of the building and the building itself would be identical. Builders were using instructions/ notations made by the architect which identifies the architect as the author of the drawings, thus, the author of the building. This system of notational identicality gave a form of ownership and authorship to the architect.

\begin{abstract}
"Consequently, a building and its design can only be notationally identical: their identicality depends on a notational system that determines how to translate one into the other. When this condition of notational identicality is satisfied, the author of the drawing becomes the author of the building, and the architect can claim some form of ownership over a building which in most cases he does not in fact own, and which he certainly did not build indeed, which he may never even have touched."
\end{abstract}

Figure 9, see Descriptio Urbis Romae on page 70
Alberti's small book entitled Descriptio Urbis Romae contained the famous digital map of Rome where he used simple mathematical

\footnotetext{
${ }^{37}$ Roberto Bottazzi, "Digital Architecture Beyond Computers," 2018.

${ }_{38}$ Mario Carpo, The Alphabet and the Algorithm: Form, Standards and Authorship in times of

V ariable Media (Cambridge, MA: MIT Press, 2011), 23.
} 
tool to record information from his survey of Rome, thus allowing anybody to redraw the resulting map of the city. ${ }^{39}$ By translating the drawing into numbers rather than words - digitizing - Carpo identifies Alberti's research as one of the most original results in image-making technologies. "Alberti's "do-it-yourself" map of Rome curiously resonates with the logic and functions of today's digital mapping and geographic information systems." 40 This digitized system of polar coordinates is very similar to today's 3D CAD software that Carpo described as "... a set of three coordinates that locate each point in a three-dimensional space." ${ }^{41}$

The equally significant factor that encouraged the paradigmatic rise of identicality, in Carpo's opinion, is the Industrial Revolution and the mass production of standardized goods. This revolution proved to be a momentous shift in history for having made the technical infrastructure needed to create massive industrial standardization. As an example of industrial products, Carpo posits that:

"Printed books are a quintessentially industrial product. They are mass-produced. Mass production generates economies of scale, which makes them cheaper than manuscript copies. They are standardized... and the new architectural books in print (manuals, treatises, pattern books, etc.) changed the course of architecture first and foremost because of the printed images they contained. Before the invention of print, manual copies of drawings were famously untrustworthy, and as a result, images were seldom used, or altogether avoided, whenever precise copies were required. In such cases, nonvisual. Media (alphabetical or alphanumerical) were deemed safer. For centuries in the classical tradition (from antiquity to the Middle

\footnotetext{
${ }^{39}$ Mario Carpo and Francesco Furlan, eds., Leon Battista Albertis Delineation of the City of Rome (descriptio Urbis Romae), trans. Peter Hicks (Tempe, AZ: ACMRS, Arizona Center for Medieval and Renaissance Studies, 2007).

${ }^{40}$ Mario Carpo, The Alphabet and the Algorithm: Form, Standards and Authorship in times of Variable Media (Cambridge, MA: MIT Press, 2011), 57.

${ }^{41}$ Mario Carpo, The Alphabet and the Algorithm: Form, Standards and Authorship in times of

Variable Media (Cambridge, MA: MIT Press, 2011), 33.
} 
Ages to the early Renaissance) most architectural descriptions were verbal, not visual."

In architectural design, mass production of architectural elements resulted in "dumb structural design and a waste of building material." 42 Therefore, according to Carpo, the modern power of identicality came to an end with the rise of digital technologies because all that is digital is "variable". Digital technologies can certainly be used to make identical copies, however, they made it possible to envisage "new generation of mass production" where they are used to "design and build digital variable objects, rather than making three-dimensional copies" ${ }^{43}$ Mass customization manufacturing techniques combines the personalization of custom-made products and the low cost associated with mass production. ${ }^{44}$ Bottazzi investigates in his book the definition of mass-customization using B. Joseph Pine's ideas published in his 1992 book Mass Customization: The New Frontier in the Business Competition:

"the idea that computer-controlled machines were no longer bound to the logic of serialization and could produce endlessly different objects without-theoreticallyadditional cost. Mass-customized objects can be tailored to fit specific needs or personal taste and require a greater degree of coordination between design and manufacturing."

On the ground of this, digital technologies replaced concepts such as identicality, mass production, and authorship by similarity, mass customization, and open design. In one of his lectures at Princeton University, Antoine Picon discussed the open source movement in architecture: in the digital world, one of the fundamental features is the desire of a largely shared creativity, to popularize architecture design culture, and to associate people to be understanding of architecture

\footnotetext{
42 Mario Carpo, The Alphabet and the Algorithm: Form, Standards and Authorship in times of Variable Media (Cambridge, MA: MIT Press, 2011), 104.

${ }^{43}$ Mario Carpo, The Alphabet and the Algorithm: Form, Standards and Authorship in times of Variable Media (Cambridge, MA: MIT Press, 2011), 39

44 "What Is Mass Customization? Definition and Meaning," BusinessDictionary.com.
} 
and its production. ${ }^{45}$ Digital technologies have proven to perform tasks that are impractical or impossible to be done by a human. Computers are able to process complex tasks within seconds because they are based on Artificial Intelligence (AI) rather than human intelligence. According to Carpo in The Second Digital Turn, the computers search and the human sorts: The human mind structures and sorts data to make it smaller, more functional and understandable; where a computer, searches very fast that often sorting is unnecessary. This "artificial" intelligence made it possible to create, sort, and share large data.

Even though 3D printing, computer numerical control (CNC) significantly closed the gap between customized and scandalized construction $^{46}$, there was a call for new methods of fabrication. There was a search for "common language between design and execution" 47 and from that, a new generation of software arose, Building Information Modelling (BIM), marking a very important moment of digital design tools.

At the end of the 1980s, the CAD tool led to new architectural representation technology of three-dimensional objects, BIM. ${ }^{48}$ This tool allows for architectural representation that can integrate comprehensive building information and virtually display objects in three dimensions observable from any point and angle (e.g. Autodesk Revit). This tool brought a unique meaning to the field of AEC (architecture, engineering, and construction):

"With the gradual and increasing interest of new geometry spaces, where the plans that define it abandon their usual

\footnotetext{
45 Antoine Picon, "The Ownership Revolution, Digital Culture and the Transformation of Architectural Practice and Ideals" (lecture, Princeton University School of Architecture), 2016.

${ }^{46}$ Lee Xia Sheng and Dr.Mohd Faris Khamidi, "Digital Adaptive Mass Customization for Building Design, Construction, and Performance," January 3, 2018.

${ }^{47}$ Mario Carpo, Digital Turn in Arcbitecture 1992-2012: AD Reader (Somerset: Wiley, 2013).

48 Deke Smith, "An Introduction to Building Information Modeling," BuildingSMART

Alliance (National Institute of Building Sciences), January 01, 2007.
} 
orthogonal nature and become a game of multiple relationships that can ultimately lead to a single connected surface (with the ability to adopt infinite variations), the traditional representation systems are no longer satisfactory to translate and communicate the complexity inherent to these kinds of spaces." 49

Despite the complexity of building systems, projects are easier to control and deliver through BIM. Using BIM, project's information can either be accessed individually by a building's specialist or together with clients, stakeholders, or team's specialists for collaborative work. In recent years, CAD programs have integrated new generative processes to improve and enlarge digital design and representation tools and merged with Human-Computer Interactions (HCI). ${ }^{50}$

Unlike the approximation techniques of reality found in traditional architectural representations - such as sketches, renderings, or printed photomontages - the evolution of immersive technologies in architecture enabled the representation of virtual environments that delivered intense experiences of space to the user. By walking through a virtual space, the user's capabilities of understanding architectural spaces improved. Now, it is not sufficient for the user to be 'projected' into the architectural space, nor for the specialist to merely roam and observe. Users strive for more. Now, it is imperative for the user to interact with the space, “...to play with its geometry, change it, reform it, reorganize it and, by doing so, since a new reality has appeared ahead of him, to rethink any possible moves that he had formerly thought" 51 . In other words, the user demands Mixed Reality.

Key Terms, see Hologram on page 93
Mixed Reality with its concept of hologram, brings a new relationship between the real world and the virtual world where the

\footnotetext{
${ }^{49}$ Miguel B. Carreiro and Pedro D. Pinto, "The Evolution of Representation in Architecture," Future Traditions, Regional International Workshop, 2013.

${ }^{50}$ Miguel B. Carreiro and Pedro D. Pinto, "The Evolution of Representation in Architecture," Future Traditions, Regional International Workshop, 2013.

${ }^{51}$ Miguel B. Carreiro and Pedro D. Pinto, "The Evolution of Representation in Architecture," Future Traditions, Regional International Workshop, 2013.
} 
Key Terms, see Cloud Computing on page 93 barrier between the two realities fades, allowing them to share the same environment. Mixed reality “... will probably, among diagrams, prevail one day as a decision tool and the common architecture methodology of space definition." 52

In addition, mixed reality and similar technologies allow for cloud computing and collaboration. Carpo argues that "in recent years the networked environment has evolved from earlier, most monodirectional information technologies to fully symmetrical, bidirectional information framework." 53 Cloud-BIM integration is considered to be the second generation of building information management (BIM) development that produces another wave of change across the construction industry. ${ }^{54}$

\subsection{The Role of Tools in the Architectural Profession}

Architectural design can be approached and described by means of tools and cultural techniques deployed in the design process. ${ }^{55}$ In his book Tools for Ideas, Gänshirt, Senior Associate Professor in the Department of Architecture at Xi'an Jiaotong-Liverpool University, established gesture and language as the primary design tools that led to the development of other tools such as sketch, schematic outline, design drawing, perspective view, and the model as visual tools. ${ }^{56}$ Architects talk, write, draw, and present their ideas through language and gestures. Gänshirt appraises the danger of tools: design tools are considered the only instruments to communicate the architect's thoughts, ideas and visions, and the danger of any tool is the possibility

\footnotetext{
52 Miguel B. Carreiro and Pedro D. Pinto, "The Evolution of Representation in Architecture," Future Traditions, Regional International Workshop, 2013.

53 Mario Carpo, The Alphabet and the Algorithm: Form, Standards and Authorship in times of Variable Media (Cambridge, MA: MIT Press, 2011), 113.

${ }^{54}$ Johnny Wong et al., A Review of Cloud-Based BIM Technology in the Construction Sector (Journal of Information Technology in Construction, 2014).

${ }^{55}$ Christian Gänshirt, Tools for Ideas: Introduction to Architectural Design (De Gruyter, 2012).

${ }^{56}$ Christian Gänshirt, Tools for Ideas: Introduction to Architectural Design (De Gruyter, 2012).
} 
to falsify those ideas. ${ }^{57}$ The nature of each architectural tool is different - every tool has its own rules, purpose, limitations, and possibilities, therefore, the architect needs to know the tools' nature to use them to their fullest. The main idea of this research paper is not to evaluate whether a tool performs better than the other, but to explore the nature of each tool, to understand the relationship between tools, and to know when and how to use them simultaneously. The capacity of tools to carry ideas from conception to realization persists as an integral part of architectural practice; they maintain their role as the intermediary between thoughts and actions. ${ }^{58}$ Every design tool serves as a means of exploration and communication. A tool helps the architect explore the feasibility of an idea before communicating it with another architect, stakeholder, or client. The most important relationship a tool serves is the architect-engineer-construction worker relationship; therefore, the industry benefits from adopting a new tool to fill limitation gaps of existing tools. Architecture is constantly confronting the implementation of new tools and technologies. An effective architectural tool must allow simultaneous connection with other tools.

\subsection{Mixed Reality: A Tool or a Toy}

When new technologies are introduced, they are often misunderstood as toys due to the "fun factor" contributed to the consolidation of this idea. Mixed Reality is one of the latest digital technologies adopted by the AEC field. As a headset, it promises to help professionals with computer interface, however, according to Simon Yorke, an Advanced Design Technologist at Aurecon:

"Lots of AEC (Architecture, Engineering, and Construction) offices have these headsets and are keen

\footnotetext{
${ }^{57}$ Christian Gänshirt, Tools for Ideas: Introduction to Architectural Design (De Gruyter, 2012).

58 Pari Riahi, "Expanding the Boundaries of Architectural Representation," The Journal of Architecture 22, no. 5 (2017).
} 
to acquire the latest technologies, but they are generally neglected in a room somewhere - staff are either too scared to try it or even worse, they feel the technology is not relevant to their jobs." ${ }^{59}$

Currently, many of AEC offices persist with a 30-plus-year-old interface where the only output is a two-dimensional screen and the input is a keyboard and/or a mouse. Building Information Modeling (BIM) solutions and 3D modeling capabilities have already enhanced information sharing and dynamic workflows in AEC, but the most forward-thinking AEC firms are leveraging immersive technologies such as Virtual Reality and Mixed Reality.

What prevents the adoption of digital tools, in particular, mixed reality? One reason is that mixed reality is considered to be a new technology under development, and it could disturb the current system and process of a company. This costly tool has not fully proven to improve a firm's workflow and business decisions. Another reason highlighted above by Yorke is the improper use of mixed reality headsets. Thus, how can new technologies be assessed as tools? And how can architects contribute to this shift? Oxford dictionary defines a toy as "an object, especially a gadget or machine, regarded as providing amusement for an adult" ${ }^{60}$; and a tool as "a device or implement, used to carry out a particular function and to help perform a job." ${ }^{61}$ To be considered a tool, a device has to extend our abilities and to help us overcome obstacles in the field, otherwise, it is merely an amusement device, a toy. In recent years, mixed reality has been

\footnotetext{
59 Simon Yorke, "Blending Realities in AEC Using Immersive Experiences" (speech, Autodesk University, Las Vegas, July 13, 2018).

${ }^{60}$ Oxford Dictionaries, s.v. "toy," accessed January 22, 2019, https://en.oxforddictionaries.com/definition/toy.

${ }^{61}$ Oxford Dictionaries, s.v. "tool," accessed January 22, 2019, https://en.oxforddictionaries.com/definition/tool.
} 
proven to be a dependable tool; it fills the gap between digital drawings and physical models.

In her essay, the architect Charlotte Hendriks, argues that drawings and digital models do not have the ability to thoroughly test the design at early stages. ${ }^{62} \mathrm{~A}$ quick physical model bridges the impasse and uncovers possibilities and weaknesses that sketches or digital models do not efficiently show. However, physical models are time-consuming and cannot travel as easily as digital models and drawings. Mixed reality fits perfectly in this gap between physical and virtual architectural representation; it enables users to project digital models into the physical space and to test the feasibility of the design anytime and anywhere. Mixed reality uses the best of the two tools (physical and digital) and merges them together to create an architectural representation that accurately projects reality and communicates design.

In recent years, mixed reality started to be defined as a tool for AEC enterprise users rather than regular consumers. On February 24, 2019, Microsoft unveiled the next generation version of mixed reality headsets, HoloLens 2. It was defined as a corporate tool not a consumer device, Microsoft's director of communications, Greg Sullivan, says:

"If I buy a HoloLens 2 today and bring it home for my son to play games, it's difficult for it to pay for itself very quickly. But in the case of our commercial customers if they can do things they couldn't before or extend the expertise of people around the world then it's a lot easier to justify, and the return on investment for a commercial customer is so

\footnotetext{
${ }^{62}$ Charlotte Hendriks, "The Physical Architectural Model: The Architect's Most Important Tool" (reading, The Architecture of the Interior, 2015).
} 
profound that these things pay for themselves very quickly, which is not necessarily the case in the consumer scenarios."

In the previous release of HoloLens in 2015, Microsoft had stressed gaming and the potential of the device to shape consumer interactions with technology. However, the new release of HoloLens 2 shifted the industry's philosophy of mixed reality technology. Microsoft brought a number of business partners to prove the potential use of the device in various fields specifically architecture, engineering, and construction fields.

Adopting new technologies in architectural design, mixed reality or other emerging technologies increases production in our industry by reducing design cost, improving communication and collaboration, and creating new methods of architectural conceptions. The following chapters will test corporations promise that "new digital tools liberate creative forces that technology and society had long constrained, enabling the expression of nonstandard individualities, differences, and variations that older technologies could not support, and older societies would not tolerate." 63

${ }^{63}$ Mario Carpo, The Alphabet and the Algorithm: Form, Standards and Authorship in times of Variable Media (Cambridge, MA: MIT Press, 2011), 111. 
CHAPTER 3

\section{Interpretation of the Nature of Mixed Reality}




\subsection{What is Mixed Reality?}

What is mixed reality (MR), and how is it different from other immersive experiences like virtual reality (VR) and augmented reality (AR)? Since virtual reality came first, experts are often in agreement when they attempt to define it. Its characterization is based on the hardware and graphical aspects: It is a fully-virtual, fully-immersive simulation experience where the user wears a head-mounted device and carries controllers to navigate. However, this is not the case with augmented reality (AR) and mixed reality (MR). While there are prominent applications for these technologies, there are no universally agreed-on definition for MR and AR.

In one of the recent research papers on this topic, What is Mixed Reality? published at the CHI Conference on Human Factors in Computing Systems Proceedings 2019, the authors conducted interviews with ten AR/VR experts from academia and industry, as well as a literature survey of 68 papers. ${ }^{64}$ Many experts see mixed reality as a synonym for augmented reality; some consider mixed reality distinct from augmented reality in the sense that mixed reality enables walking into, interacting with, and manipulating, a 3-dimensional virtual objects whereas augmented reality does not; others consider augmented reality as a technology that merely overlays 2 -dimensional digital information on the real world like Google Glass; some do not even attempt, or want, to specify what mixed reality is. Moreover, some experts bound mixed reality to specific hardware (e.g. Microsoft HoloLens) and others expressed regret over the fact that the term is used for 'marketing purposes nowadays': "Microsoft was one of the

\footnotetext{
${ }^{64}$ Maximilian Speicher, Brian D. Hall, and Michael Nebeling, "What Is Mixed Reality," 2019.
} 
first companies who pushed mixed reality as a new technology, with HoloLens, then expanding to a range of Windows Mixed Reality devices, along with the Mixed Reality Toolkit to build applications for these devices." ${ }^{\prime 5}$ In fact, it is a matter of time that one device will be able to do it all; switch from reality to another, from full virtuality to full reality. Since an agreed upon definition does not exist and for the purpose of maintaining a consistent terminology throughout this paper, the term mixed reality $(M R)$ will be used in favor of angmented reality $(A R)$ to describe the merging of the virtual world and the real physical world.

\subsection{Mixed Reality Head-Mounted Devices}

Current smartphones from Apple and Android became AR/MRcapable devices. However, while there are some outstanding use cases for mobile AR/MR such as Pokemon Go and Ikea Interior Design application, the real future is in head-mounted devices. A body-worn device has the potential to perceive the world because it shares the same point of view as the user, this is particularly true for devices worn on the head. As humans receive most of their sensory input via the head, it is a particularly interesting body location for simultaneous sensing and interaction as well as cognitive assistance, ${ }^{66}$ consequently, this research paper focuses on the application of mixed reality head mounted devices (HMD). There are three main companies that have pursued manufacturing of mixed reality HMD: Meta, Magic Leap, and Microsoft HoloLens.

\footnotetext{
${ }^{65}$ Brandon Bray and Matt Zeller, "What Is Mixed Reality? - Mixed Reality," Mixed Reality | Microsoft Docs, March 2018.

${ }^{66}$ Andreas Bulling et al., "Eyewear Computing - Augmenting the Human with Head-

Mounted Wearable Assistants," Dagtsubl Seminar 16042, January 2016.
} 
Figure 10, see Meta 2 on page 71

Figure 11, see Magic Leap One on page 72

Key Terms, see Lightpack on page 93

Key Terms, see Facets on page 93
1. Meta

Founded in Silicon Valley, California in 2013. After launching the first version of its product in late 2014, the company announced its follow-up headset, Meta 2, in 2016. Although, Meta2 plugs into computer's video port, with sensor input and image processing being handled by the connected PC's processors. ${ }^{67}$ While the Meta 2 design was bulky and tethered to a computer, the device was very comfortable with a wide field of view (compared to Magic Leap One, and HoloLens1). On January 2019, Meta assets were sold to an unknown company after months-long financial struggle caused by Trump administration's trade war with China. ${ }^{68}$

\section{Magic Leap}

Headquartered in Florida, the company was founded in 2010. Their first product, Magic Leap One, MR headset was launched in August 2018. Similar to Meta 2, the device is also tethered, not to a computer, but to the waist by a Lightpack that provides power and handles data processing. ${ }^{69}$ Although this external device disappointed some customers, it allowed the MR headset to remain lightweight while processing heavy models: Magic Leap One can process 3x more facets than Microsoft HoloLens. The primary source of input for the Magic Leap One is the hand controller.

${ }^{67}$ Meta. "Meta 2 Development Kit- Launch Video". Filmed [March 2016]. YouTube video, 4:02.

68 Adi Robertson, "AR Headset Company Meta Shutting down after Assets Sold to

Unknown Company," The Verge, January 18, 2019.

69 "Magic in the Making," Magic Leap, https://www.magicleap.com/. 


\section{Microsoft HoloLens}

Figure 12, see HoloLens 1 on page 73

Figure 13, see HoloLens 2 on page 74
The HoloLens is the highest profile mixed reality headmounted device on the market. ${ }^{70}$ This standalone head worn built-in holographic computer device was launched in 2015. With a collection of sensors and cameras, the HoloLens is constantly scanning the space around the user and updating a 3D mesh of that area in what is referred to as a spatial map. This spatial map allows the HoloLens to interact with the space around it in ways never seen before its existence. ${ }^{71} 72$ The primary source of input for the HoloLens is hand-gesture and voice control. The HoloLens 1 has a limited field of view and its weight can become noticeable after wearing it for an extended period of time. Moreover, the built-in HPU (Holographic Processing Unit) limits the number of facets that could be processed through the HoloLens, forcing the user to optimize their models.

Many of these complaints were resolved with the reveal of the second generation of the device. Microsoft unveiled HoloLens 2 at the MWC 2019 conference in Barcelona. Although the device has not launched yet, it promises great features such as: the new Azure Kinect sensor, eye tracking technology, entirely new display system, built-in speakers, the ability to flip the display up so that it is easier to see what you are working on, an 8-megapixel front-facing camera, more than

\footnotetext{
70 "HoloLens 2-Overview, Features, and Specs | Microsoft HoloLens," -Overview, Features, and Specs | Microsoft HoloLens.

${ }^{71}$ Alex Kipman. “Windows HoloLens Full Presentation”. Filmed [March 2015]. YouTube video, 24:53.

72 "HoloLens 2-Overview, Features, and Specs | Microsoft HoloLens," -Overview, Features, and Specs | Microsoft HoloLens.
} 
Figure 14-15, see Air Tap and Bloom on page 75 doubled field of view, haptic feedback, instinctual interaction, and a more powerful holographic processor. ${ }^{73}$

The first generation of HoloLens used hand gestures as the primary input method. These gestures consist of two core component gestures - Air tap and Bloom. ${ }^{74}$ These discrete gestures must be done correctly for the HoloLens 1 to recognize, thus, require a practice by the primitive user. HoloLens 2 introduces an improved articulate hand tracking that encompasses more than simple hand gestures. Users are able to naturally "manipulate holographic buttons and objects just like in the real world." ${ }^{75}$ In addition, the HoloLens 2 supports eye-tracking with internal cameras, the device can recognize where the user is looking without head movement. For example, during a repair process, an engineer can scroll down instructions with their eyes while simultaneously using their hands to repair the broken machine. HoloLens 2 was built to target enterprise customers, not consumers. It is designed with "instinctual interaction" language that does not require tremendous training, instead, it naturally assists users and supports their natural gestures.

\subsection{Microsoft HoloLens Use Cases in the AEC Industry}

Mixed reality has shown great potential in the AEC field with the first generation of Microsoft HoloLens. It has been utilized for site

\footnotetext{
${ }^{73}$ Satja Nadella, "Microsoft Keynote HoloLens 2," in Mobile World Congress, proceedings of Mobile World Congress, Barcelona (2019).

${ }^{74}$ Rwinj, "Gestures - Mixed Reality," Mixed Reality | Microsoft Docs. https://docs.microsoft.com/en-us/windows/mixed-reality/gestures.

75 Satja Nadella, "Microsoft Keynote HoloLens 2," in Mobile World Congress, proceedings of Mobile World Congress, Barcelona (2019).
} 
productivity to provide precise alignment of holographic data on site. Microsoft asserts that HoloLens enabled workers to save time by efficiently visualizing, conveying and interacting with complex BIM models; improve communication by collaborating with remote stakeholders; and increase engagement and buy-in among diverse stakeholders. Trimble is considered the market leader in innovative digital technologies that transform the way the AEC industry works. ${ }^{76}$ In the past four years, they have partnered with Microsoft to focus on Mixed Reality and innovate software that brings actionable insights to fields and job sites. In construction, those solutions are used for workflows like quality assurance, training, visualization of 3dimensional constructible BIM models, off-site manufacturing and prefabrication and fabrication. Trimble believes that mixed reality is no longer a "futuristic technology, nor a gimmick to get more clients [...] it is a real working technology that is adding value to the field every day." 77 Their software, Trimble Connect is a "cloud-based construction management solution that acts as a collaboration hub for AEC projects. It can read files from many different sources - Autodesk Revit, Tekla Structures, SketchUp and more - then be used to coordinate models and manage projects through change orders, to do lists and RFIs (request for information)." 78

In 2016, Trimble worked with Greg Lynn, owner of Greg Lynn FORM and professor of architecture and urban design at the University of California, Los Angeles School of the Arts and

\footnotetext{
${ }^{76}$ Satja Nadella, "Microsoft Keynote HoloLens 2," in Mobile World Congress, proceedings of Mobile World Congress, Barcelona (2019).

${ }^{77}$ Satja Nadella, "Microsoft Keynote HoloLens 2," in Mobile World Congress, proceedings of Mobile World Congress, Barcelona (2019).

78 "AEC Magazine. Mixed Reality: HoloLens on the Construction Site.," AEC Magazine, 2018.
} 
Figure 16, see Packard on page 76
Architecture, who was selected to represent the United States at the 2016 Venice Biennale. Greg envisioned a drastic redesign of a Packard Plant that has been abandoned for half a century. He used the Microsoft HoloLens with Trimble's powerful mixed-reality technology to visualize and navigate the holographic design of the Packard space at a low cost. At early design stages, Greg was also able to evaluate his complex design in the 3-dimensional world from the convenience of his workspace in California.

Trimble Connect software has an impact on other customers as well. They are working with Consolis, a concrete prefab manufacturer, to explore a solution that will enable workers assembling complex concrete constructions to see 3-dimensional models and plans in front of them while working, instead of moving back and forth between printed plans or on-screen models. ${ }^{79}$ In a recent conference, the president of Trimble, Roz Buick, recounted an incident with their client who was working on a building project in Colorado. The construction team used the HoloLens to validate the HVAC heating and cooling system before installing, and suddenly discovered a clash between mechanical and plumbing systems. This happened despite months of coordinating the mechanical, electrical and plumbing models on a computer screen in the office. The issue was only discoverable by viewing the systems via HoloLens which saved the team time and money by discovering the conflict before the construction phase of the project.

In MWC Barcelona, Microsoft launched the HoloLens Customization Program that allows users to customize HoloLens 2 to meet all their

\footnotetext{
${ }^{79}$ Mark Sutton, "Mixed Reality Brings New Dimension to Construction," Leading Technology, June 19, 2018, http:/ / www.itp.net/617346-mixed-reality-brings-newdimension-to-construction.
} 
Figure 17, see Trimble XR10 on page 77 specific needs. During the same event, Trimble, one of Microsoft partners, announced Trimble XR10 with HoloLens 2, a new hard hat solution designed for field workers operating in safety-controlled environments. ${ }^{80}$

"The system has the same technical benefits of HoloLens 2 but with new construction workflow features to empower the worker in the field to do their work right the first time and using advanced Trimble software for design and construction. XR10 lets architects, engineers and constructors to bring the 3D constructible model detail and process all the way from the office to the field and on to the tool." $\$ 1$

\subsection{Mixed Reality Applications in Other Industries}

See Appendix $B$ on page 95 .
Since its launch in 2015, many companies and partners have used Microsoft HoloLens in various gaming, research, and educational applications. Microsoft has stressed the potential of the HoloLens to shape consumer interactions with technology, however, with HoloLens 2, Microsoft shifted their focus to businesses. With the help of Microsoft website, Podcast, and HoloLenUserCases blog and personal research, a detailed list was conducted in Appendix $B$ to capture Microsoft HoloLens 1 applications and use-cases in reverse

\footnotetext{
${ }^{80}$ Roz Buick, "Microsoft Keynote HoloLens 2," in Mobile World Congress, proceedings of Mobile World Congress, Barcelona (2019).

${ }^{81}$ Roz Buick, "Microsoft Keynote HoloLens 2," in Mobile World Congress, proceedings of Mobile World Congress, Barcelona (2019).
} 
chronological order. Some of these applications are not fully developed and were mainly designed to entertain consumers.

In the following section, two applications from Appendix $B$ are analyzed to be converted into applications that can benefit the AEC field.

Figure 18, see HoloLens RoomScanner on page 78

Key Terms, see Point Cloud on page 94

\section{HoloLens RoomScanner}

It is a free application published in 2017 by Matrix Inception. It allows users to capture full 3-dimensional models of rooms using Microsoft HoloLens as a stand-alone device for capturing, processing, and visualizing 3-dimensional models of rooms. This application has been used to share room scans with other users and join them remotely via a virtual "Hallway of Doors", then allowing the avatar to view your room. While it does feel like a game, it is a room-scanning process that constructs a realworld 3-dimensional mesh model that could compete with similar AEC methods such as point clouds. In recent years, AEC fields have started to adopt 3-dimensional laser scanning as a method to document the built environment. These scans produce heavy point clouds that can be converted to mesh models through a time-consuming process called Surface Reconstruction. HoloLens RoomScanner can be easily imagined as a replacement to the laser-scanning in the near future. The user can scan any space merely by gazing and walking around, then a detailed mesh model will simultaneously be generated, 
and the user will be able to identify unscanned areas and fix them instantly.

\section{Cambridge Consultants "X-Ray Vision"}

This surgical system prototype equips surgeons with the possibility to see inside of a patient in real time while operating through minimally invasive openings. When surgeons wear the HoloLens, they are instantly provided with records and operating information along with a 3-dimensional model of the patient's organs aligned to their body during the operation. The system uses MRI and CT scans to create a 3-dimensional image with different automatically color-coded organs. Surgeons can tap on irrelevant organs to disappear, thus, focusing on vital areas. The system is also equipped with sensors that warn surgeons when they are too close to a nerve, resulting in a safer and controlled operation. Such precision is also required in the construction field especially during renovations. Many partial demolitions have failed because workers cannot visualize what is behind existing walls such as structural columns or HVAC system. Imagine a system where a 3-dimensional model of the existing space can be modeled from 2-dimensional drawings and stored for future needs. When renovation work is required, workers upload the 3-dimensional model into the HoloLens headset and simultaneously demolish and construct while the headset warns the worker if they get too close to a pipe or a structural column for instance.

Adopting applications similar to the proposed above are not far from

reality. Many developers and partners with Microsoft are striving to provide enterprise solutions. With HoloLens 2, Microsoft is only 
focusing on industries, therefore, the device will rapidly develop to accommodate the needs of every industry. Most of Microsoft's partners are focused on the AEC field and promise astounding solutions for their clients. 
CHAPTER 4

Towards a Harmonious Collaboration 
Architects and engineers have learned to work together, not everywhere, not always, but sometimes, and that has made possible some very fine buildings. It has also changed things, and the message will go on spreading until it will no longer be possible for architects and engineers not to work together as a team.

Peter Rice, 1989

In the first year of architectural studies, I was introduced to several distinctive buildings, one that stood out for its remarkable story was the Sydney Opera House. This building overcame major obstacles, thus deserved to be considered one of the iconic buildings of the $20^{\text {th }}$ century. As Peter Murray states in The Sa';ga of the Sydney Opera House: "... the two men [the architect and the engineer] — and their teamsenjoyed a collaboration that was remarkable in its fruitfulness and, despite many traumas, was seen by most of those involved in the project as a high point of architect/engineer collaboration." ${ }^{\prime 2}$ The design of the Sydney Opera House was one of the first examples of the use of computer-aided design $C A D$ to design complex geometries. Although Ove Arup's engineering team was in Australia and Jørn Utzon's architecture team was in Hellebaek, Denmark; the collaboration between the two teams conducted design techniques that

Key Terms, see Blobitecture Movement on page 94 later influenced the Blobitecture movement and many architects like Frank Gerry. The biggest renowned challenge in the design of the Sydney Opera House was the roof. After months of remote discussion with engineers, Utzon solved many of the difficulties of constructing the shells by converting them to spherical geometry. The search for a

82 Peter Murray, "The Saga of Sydney Opera House," 2003. 
solution withheld several failed attempts, however, both teams had faith in one another. In 1960 along with the client, Sydney Opera House Executive Committee (SOHEC), the New South Wales State Government decided to take greater control of the project. Although, today the building is loved, in 1966 the pressure reached its climax with the criticism received from the local press and from politicians trying to control the costs and speed of the construction, thus leading to Utzon's resignation. ${ }^{83}$ Despite the challenges, the architecture team and the engineering team managed to overcome them by proper collaboration for the sake of the building. Sommer explains: "the willingness of the engineers to expand the limits of problem-solving by moving towards the principle of 'total design,' that is to say, the integration of all design and construction processes for the sake of the project as a whole" ${ }^{\prime 4}$ This story has a significant influence in sensing the importance of collaboration between specialists, despite the pressure received from the outside world.

\subsection{Master Builder: A Precursor}

Computer technology has not just transformed the way we use spaces and buildings but our methods of working and our skills. The profession of architect and engineer became increasingly isolated from one another during the course of the $18^{\text {th }}$ century after maintaining very close links since the time of the Renaissance. ${ }^{85}$ Today, the existence of intense dialogue and collaboration between these

\footnotetext{
83 Peter Murray, "The Saga of Sydney Opera House," 2003.

${ }^{84}$ Degenhard Sommer, Herbert Stöcher, and Lutz Weisser, Ove Arup \& Partners: Engineering the Built Environment (Basel: Birkhäuser Verlag, 1994).

85 Antoine Picon and Martin Thom, French Architects and Engineers in the Age of

Enlightenment (Cambridge: Cambridge University Press, 2009).
} 
disciplines is more important than ever. The beginning of this century has been characterized by extraordinary innovations in auxiliary techniques and the computerization of design and construction, creating a situation where almost any imaginable shape can be analyzed and built. ${ }^{86}$ Moreover, the most efficient and successful architectural tools are those that optimize the architect-engineer-construction manager's relationship. The importance of this relationship was previously highlighted by a market analysis conducted by Gartner Dataquest in 2001, who showed that in the AEC design world,

"collaboration typically involves the interactions among the architects, building owners, building operators, facilities managers, construction professionals, contractors, civil and structural engineers, and materials suppliers. The AEC design environment is characterized by its reliance on a great many disparate collaborating parties spread across many different organizations. Virtually every person... belongs to a separate external organization. The need for collaborative practices to span numerous organizations is vital but is presently dependent mostly on non-technology-enabled media."

Since 2001, the industry has moved past "non-technology-enabled media" for collaboration in an attempt to better manage construction projects. This desire has constantly been leading firms to implement next-generation collaboration tools and integrate technologies that are shown to effectively save money and time while improving knowledge management.

\subsection{The Origin of Collaboration}

Before diving into the technological tools for harmonious collaboration between disciplines, one should understand the

\footnotetext{
86 Alejandro Larena, proceedings of Origin of the Collaboration between Engineers and Architects in Great Britain in the Thirties, 2006.
} 
psychological difference between AEC professionals. Architects, engineers, and construction managers conceive differently. The mental act of conception, as it applies to architectural design, involves the creation of a mental picture using an architectural tool. A conceptual process can be defined as a "pattern of thought that may be personal and intuitive, or based on the rules of the industry." ${ }^{87}$ Furthermore, education plays a significant role in shaping future practitioners. Since engineering and architecture emerged as separate professions from the Master Builder, students of different AEC disciplines have been educated in isolation from each other. According to Pressman:

"Many academic programs still produce students who expect they will spend their careers working as heroic, solitary designers. But integrated practice is sure to stimulate a rethinking of that notion. Pedagogy must focus on teaching not only how to design and detail, but also how to engage with and lead others, and how to collaborate with the professionals they are likely to work with later." 88

Some institutions separate Architecture, Engineering, and Construction Management departments by housing them in separate schools, faculties, or even separate campuses. Sharing knowledge across these academic silos is a challenge that must be overcome in order to produce qualified graduates who will be best positioned to drive the industry forward. ${ }^{89}$

Despite the revolution of digital technologies, there are some challenges, questions, and areas of ambiguity that only education might

\footnotetext{
${ }^{87}$ Mark Hewitt, "Representational Forms and Modes of Conception; an Approach to the History of Architectural Drawing," Journal of Architectural Education 39, no. 2 (1985).

88 Pressman, A. (2007), "Integrated Practice in Perspective: A New Model for the Architectural Profession”, Architectural Record, May 2007. http://archrecord.construction.com/practice/projDelivery/0705proj-3.asp

${ }^{89}$ Jennifer A. Macdonald, "A Framework for Collaborative BIM Education Across the AEC Disciplines," proceedings of 37th Annual Conference of the Australasian Universities Building Educators Association (AUBEA), The University of New South Wales, Australia (2011).
} 
solve. There is a great need for academic institutions to acknowledge the role of harmonious collaboration in the digital world. Workshops and laboratories should be equipped with the latest technologies and with staff who can train faculty members and students in the use of technologies. Merged classes of engineering and architectural students can be created to implement knowledge through collaborative work on projects that mimic real-life challenges. These are some ideas that force us to think of the great potential lost in many educational institutions, where the main loser is the AEC industry. According to Redshift Autodesk,

"various architects and engineers were interviewed from large firms such as SOM, Gensler, and ARUP for the case studies in Collaborations in Architecture and Engineering. When they were asked to rank the most important criteria in hiring employees, surprisingly, design talent and skill didn't make the top of the list, but rather "the ability to collaborate." 90

\subsection{Integrated Project Delivery in Canada}

Construction is a major industry in Canada, employing more than 1.4 million men and women. According to the Canadian Construction Association, close to $\$ 300$ billion was invested in construction in 2018 . One out of thirteen workers employed in Canada earns a living in the construction industry, and 36 percent of the construction labour force works in Ontario. Therefore, the need for the best construction delivery method is more important than ever. There is a new approach introduced by the American Institute of Architects in 2007 designed to unlock the true power of collaboration, Integrated Project Delivery (IPD). It is a project delivery approach that "integrates people, systems,

\footnotetext{
${ }^{90}$ Devinee Fitzgerald, "Architecture vs. Engineering: Collaborate Despite Differences [Updated]," Redshift EN, June 12, 2018.
} 
Figure 19, see Five Hills Health Regional Hospital on page 79

Key Terms, see Big Room on page 94 business structures, and practices into a process that collaboratively harnesses the talents and insights of all participants to optimize project results, increase value to the owner, reduce waste, and maximize efficiency through all phases of design, fabrication, and construction." "91 Building Information Modeling (BIM) is one of the most powerful and important tools supporting IPD; it is a tool, not a project delivery method. Despite the complexity of building systems, BIM assists AEC specialists to easily access, control, and modify construction projects anywhere and from any device.

The first IPD project in Canada was the Five Hills Health Regional Hospital in Moose Jaw, Saskatchewan. Completed in 2015, the building was delivered on time and $\$ 30$ million under budget. ${ }^{92}$ According to Art Winslow, director of lean and IPD at Graham Construction, a Big Room was used to put all main participants in one space to work together on a regular basis to eliminate silos and improve communication;

"participants included owners, architects, construction company representatives, consultants, sub-contractors and municipal building code officials. Doctors, nurses and former patients were also sometimes present... [We] designed the building with them. When you involve end-users in the design of the building, they own it." 93

The Big Room framework has proven to improve trust, communication, and collaboration amongst stakeholders. ${ }^{94}$ The

\footnotetext{
91 AIA National and AIA California Council, "2007 Integrated Project Delivery: A Guide," 2007.

92 Mary Baxter, "IPD Shaping the Future of Canadian Construction Project Delivery Constructconnect.com," Daily Commercial News, September 15, 2017.

${ }^{93}$ Nate Hendley, "Lean Construction Puts down Roots in Canada with Graham Construction," February 22, 2017.

94 Tyler Lehtinen and Anne Kokkonen, "Collaboration and Contracts in Integrated Project Delivery - Exploring the Roles of Owners and Architects," proceedings of CO-CREATE 2013 - The Boundary-Crossing Conference on Co-Design in Innovation (2013).
} 
problem lies in the demand for physical presence and face-to-face dialogues between participants; a more interactive, stimulating experience is required; such as mixed reality. It encourages a higher-level collaborative workflow in contrast with burdensome traditional processes by bringing people together in a single virtual space to talk, sketch, design, and visualize together from anywhere in the world without ever boarding a plane or leaving their office. Mixed reality breaks down distance and language barriers. With the BIM tool, they enhance virtual collaboration and strengthen both the design process and the generated outcomes.

In summary, professionals in the AEC fields do not conceive in the same way, and the presence of various tools in the field allows for better conception. "Presence of BIM meant moving from a culture of litigation and fragmentation to one of information sharing, collaboration, and integrated project delivery." ${ }^{95}$ For architects and engineers, collaboration can be a collision, however, BIM coupled with powerful simulation tools, such as mixed reality is fostering greater collaboration between team members. This convergence significantly impacts how the AEC disciplines are working today, and how they anticipate working in the future.

\footnotetext{
${ }^{95}$ Benedict D. Ilozor and David J. Kelly, " Building Information Modeling and Integrated Project Delivery in the Commercial Construction Industry: A Conceptual Study," Journal of Engineering, Project, and Production Management 2, no. 1 (2012).
} 
CHAPTER 5

Implementations and Results 
In July 2017, Microsoft created the Mixed Reality Partner Program where they enable and support digital agencies, systems integrators, and solution providers who are committed to building mixed reality solutions for their clients. ${ }^{96}$ As of 2019, there are 150 partners across the globe; 60 of them in North America and 9 of them are headquartered in Canada. Many of those Canadian partners focus on the use of mixed reality technology in marketing, retail, mobility, health, defense and security, earth science and civil aviation. In this research, I worked in tandem with Microsoft's partner, Arvizio: An Enterprise Mixed Reality founded in 2016 and headquartered in Ottawa, ON. Arvizio is one of the few Canadian companies that focus solely on the use of mixed reality in the AEC field. Their platform combines advanced 3D visualization, real-time collaboration and data integration in a single comprehensive solution. They support a wide range of spatial data formats, optimize complex 3D models and enable multi-location, multi-user collaboration via Microsoft HoloLens with live audio, video and 3D holographic content. ${ }^{97}$ In addition, they have recently partnered with Autodesk to improve mixed reality workflow for AEC users.

Arvizio worked for years to build a platform for AEC users with only software developers and scientists in their team. As a future architect, my objective is to participate in Arvizio's new release of MR studio

\footnotetext{
96 "Join the Mixed Reality Partner Program | Microsoft HoloLens," Join the Mixed Reality Partner Program | Microsoft HoloLens.

97 "The Arvizio Platform," Front Page, https://www.arvizio.io/our-platform-2/.
} 
Director 3.0 launching May 2019. In this chapter, I will discuss HoloLens implementations using Arvizio's MR Studio Director software and my involvement in its new release.

\subsection{Pilot Presentation at the National Capital Commission (NCC)}

\section{Objective}

To introduce mixed reality technology to the Canadian Crown corporation, the National Capital Commission (NCC) for future adoption to their workplace. The presentation demonstrated the use of MR in different aspects of AEC industries: real estate and design, construction and management, and interior design. This demonstration was held on October 12, 2018, at the NCC Headquarters at 40 Elgin Street, Ottawa, ON. Invitees were stakeholders from different NCC departments including Architecture and Engineering, IT, Facilities Management, Capital Planning, and Real Estate Management.

Co-hosts from Arvizio:

Alex Berlin: President \& COO

Borys Vorobyov: Ph.D. CTO

Eugene Belkin: Ph.D. Software Engineering Director

\section{Attendees from the NCC: (alphabetical order)}

Bill Leonard: Director of Real Estate and Facilities Management Christopher Hetherington: Chief of Commercial property management David Royo: Property management Officer Geoffrey Frigon: Chief of Agricultural and residential property management. Luc Turpin: Chief of Facilities and material management. Matthew McIntyre: Manager of 3D Modelling. Matthew Sonier: Manager, Commercial Construction 
Michel Biagé : Director, IT and Geomatics Services and Chief

Information Officer

Nathalie Thibault: Senior Manager, Projects and Business

Analysis.

Rita Tadi: Chief Architect

Zachary Jenner: Manager of Commercial Construction

\section{Preparation:}

Prior to the demonstration, I studied the Technology Acceptance Model (TAM) theory to predict the NCC's reaction when presented with new technology. TAM proposes that the individuals' behavioural intention to adopt a new technology is determined both by perceived ease of use, defined as "the degree to which a person believes that using a particular system would be free of effort" and perceived usefulness, defined as "the degree to which a person thinks that using a particular system would enhance his or her job performance". ${ }^{98} \mathrm{I}$ extracted three factors that were predicted to influence the decision about how and when this technology will be used: the benefit of use, the risk of use, and the technology factor.

\section{Benefit of Using}

The technology acceptance literature argues that expected or perceived benefits from using technology typically drive the adoption. ${ }^{99}$ Perceived usefulness is the most important benefit in understanding the consumers' adoption of Microsoft HoloLens. Mixed Reality is proven to be a useful tool for professionals completing tasks and for the general public with little to no experience. As discussed in Chapter 3, Microsoft is currently leading the market and strives to adopt the

\footnotetext{
${ }^{98}$ Fred D. Davis, "Perceived Usefulness, Perceived Ease of Use, and User Acceptance of Information Technology," MIS Quarterly 13, no. 3 (1989): 319-340.

99 Timothy Hyungsoo Jung and Tom Dieck M. Claudia, Augmented Reality and Virtual Reality: Empowering Human, Place and Business (Cham: Springer International Publishing, 2018).
} 
latest technologies to provide the smoothest MR experience to its users. The NCC is managing major projects in the city, thus, they are constantly in the public eye. With mixed reality's capabilities in remote collaboration, tracking progress, validating BIM models; mixed reality can help the NCC preserve time and budget.

\section{Risk of Using}

Perceived technology risk has various aspects: financial, time loss, technology performance, physical, and privacy risks. ${ }^{100}$ A government institution client like the NCC may fear that public's money and time are invested in purchasing a new technology that may not improve their work; as a developing technology, it may fail to perform as expected. Moreover, like any headset, the HoloLens may have a physical risk associated with it. Physical risk refers to the risk of personal injury after using the technology. Some HoloLens 1 users complain about the uneven distribution of the headset's weight, causing back pain when worn for a long period of time. These risks were addressed during the presentation to sustain transparency.

\section{Technology Factor}

For all the magic it creates, the HoloLens is a high-powered device that has typical processing limitations. It is an untethered, selfcontained device that does not support large BIM models; a timeconsuming optimization process is often required to keep models below 300,000 facets. Furthermore, this sensitive device does not work efficiently at night or on sunny days. However, many of these

\footnotetext{
100 Mauricio S. Featherman and Paul A. Pavlou, "Predicting E-services Adoption: A Perceived Risk Facets Perspective," International Journal of Human-Computer Studies 59, no. 4 (2003).
} 
disadvantages were resolved in the release of HoloLens 2 that occurred post the NCC's pilot presentation.

Figure 20, see Mixed Reality in Real Estate and Design on page 80 .

Figure 21, see Mixed Reality in Interior Design on page 81 .

Figure 22, see Mixed Reality in Construction and Management on pages 82 83.
Results:

In the first demonstration: Mixed Reality in Real Estate and Design targeting Real Estate Management and Architecture groups; participants were able to place a new building on Confederation Square War Memorial across 40 Elgin street. They were able to visualize a new construction and discuss its location from the comfort of their office. Groups, Real Estate, in particular, discussed the potential of using this technology in placing designs on site and visualizing their feasibility to surrounding buildings, especially heritage.

In the second demonstration: Mixed Reality in Interior Design, we targeted the Facilities and Material Management group. At the time of the presentation, the NCC was undergoing the first phase of a major workplace refit project. This project was delayed for years due to management and financial issues. Facilities were asked to involve employees in the vision of their workspace design. However, since many employees were unable to visualize a modern functional environment, the NCC decided to create a showroom to allow employees to reimagine the space with new furniture. Furthermore, the project went through a tender call and was expected to be completed in January 2019. As a result, we included the showroom in the NCC mixed reality demonstration by overlaying the proposed showroom design on its actual location and encouraged participants to visualize and annotate the new furniture before it arrives.

In the third demonstration: Mixed Reality in Construction and Management, we targeted Facilities and Material Management and Architecture groups. we placed 40 Elgin Workplace Modernization initial floor design on the table and encouraged stakeholders to discuss, 
measure and annotate. In addition, the HVAC system of the Mezzanine space (where the demonstration was hosted) was modeled and aligned into space, allowing participants to have an x-ray vision experience and examine systems behind ceilings.

As an outcome of this presentation, the NCC deemed the adoption of mixed reality by purchasing Microsoft HoloLens and Arvizio's software. On November 2018, the NCC requested an estimation for a 2-year software subscription from Arvizio. At the time, Microsoft HoloLens was out of stock in preparation for the HoloLens 2 release, as a result, the NCC purchase was temporarily stopped. HoloLens 2 will be available for purchase Summer of 2019. However, I continued working in partnership with the NCC and Arvizio to further examine mixed reality on ongoing NCC projects.

\subsection{Congregation des Servantes de Jésus-Marie}

Figure 23, Congregation des Servantes de JésusMarie on page 84 .
The Congregation des Servantes de Jésus-Marie renovation project is a significant project in the NCC portfolio at the moment. On March 2017, the NCC acquired this century-old building located on 210 Lauirer Street in Gatineau, Quebec as part of its commitment to enhancing public access to the Ottawa River shoreline. ${ }^{101}$ The NCC presently owns the lands and premises adjacent to the property. The surrounding lands are known as Jacques-Cartier Park, one of the Capital's main event parks, which offers picturesque views of the

\footnotetext{
${ }^{101}$ Exploring New Uses for the Monastery Lands at 210 Laurier: Monastery Public Consultation Report, report, National Capital Commission (2018).
} 
Figure 23, Congregation des Servantes de JésusMarie future uses on pages 85-87.
Ottawa River and Rideau Falls. ${ }^{102}$ The property is located within the park and is the last property that would complete public ownership of these waterfront lands. The 82-room monastery has become too large for the congregation's 42 sisters, and they have decided to move to a new location that better suits their current needs. However, they will remain at the convent until 2020 to organize their move, while providing time for the NCC to develop a plan for the future use of the building. ${ }^{103}$ In this sensitive project, many stakeholders are involved including NCC executive directors and CEO, city planners, engineers, geotechnical along with the Priest, the Sisters, and the public.

The NCC held a public consultation to ascertain the preferences of stakeholders and members of the public regarding potential uses of the monastery. In response, suggested future uses were modeled and uploaded into the HoloLens and aligned on site for visualization. These photos will be presented to the NCC Executive Management Committee (EMC) meeting in early May 2019.

\subsection{Optimization Tool}

As discussed earlier, one of the major processing limitations of the HoloLens is its performance with complex BIM models. Due to the processor and power constraints, the HoloLens has diminished the capacity for graphics rendering. Practically, the HoloLens can read up to 600,000 polygons, however, the polygon counts that perform well

\footnotetext{
102 Heather Thompson. "Submission for FHBRO Evaluation: Convent - Congrégation Servantes de Jésus-Marie.”(Ottawa, ON : NCC 2017), 2.

103 "NCC Buys Century-old Gatineau Convent · OttawaStart.com," OttawaStart.com, November 26, 2016.
} 
are in the range of 200,000-400,000. A solution for that is to optimize BIM models. MR Studio Director tool Wizard Constructor is a model optimization solution that is developing to be more automated for its users. While working with Arvizio, I focused on Revit users as the endusers of this tool. Optimizing BIM models start with the exported Revit model.

Revit is the ultimate software for AEC professionals. It is specifically designed to support building information modeling (BIM) workflows. Arvizio is always striving to accomplish a smooth and user-friendly workflow for Revit users. On October 30, 2018, Arvizio announced the release of Revit Plug-In for MR Studio ${ }^{\text {TM }}$ mixed reality software platform. The MR Studio Revit plug-in provides an information-rich transfer of models between Revit and MR Studio Director while preserving geometry, textures and associated metadata for a compelling mixed reality sharing experience. ${ }^{104}$ The user is now able to efficiently export models and assets between Revit to MR Studio while preserving the relevant geometry, textures, details, and associated metadata in order to craft fully-featured mixed reality (MR), augmented reality (AR), or virtual reality (VR) experiences. Revit models can also be viewed simultaneously with point cloud data, and in augmented reality rather than flattened onto a 2D screen. Arvizio's Revit plugin enables 1:1 scale interaction, overlay of Revit models and point clouds, automatic scaling and aligning with the real world, and persistent annotations.

This Revit integration allows firms to improve the design process by more accurately view their models, document key milestones, and

104 "The Arvizio Platform," Front Page, https://www.arvizio.io/our-platform-2/. 
See Appendix $C$ on page 101.

Figure 25, see development stages of the Wizard Constructor Tool on pages 88-89.

Figure 26, see Carleton Richcraft Hall Building in MR experience on page 90 .

See Appendix $D$ on page 112. collaboratively communicate progress to project stakeholders. Users are given a Revit User Guide Appendix $C$ to prepare their model before exporting it using Arvizio's Revit plugin. This ultimate guide will help the user optimize Revit models before exporting. However, further optimization may be required through MR Studio Director using the Wizard Constructor Tool.

In the previous release of the Wizard Constructor Tool, imported model objects were grouped by the number of facets/ polygons, making it difficult for users to prioritize groups for optimization. Therefore, we included an automated name grouping feature extracted from Revit "category name" such as: floor, duct, structural column, etc. Furthermore, we encountered that one group may include both low facets complexity and high facets complexity objects and when optimized, some details are lost. Thus, we separated objects by complexity levels: Now the user can choose to optimize "floor high complexity" group, "floor medium complexity" group, and "floor low complexity" group. In addition, we included facets counter/ indicator that refreshes simultaneously when the user is optimizing.

A Revit model of the Carleton Richcraft Hall Building produced by Carleton Immersive Media Studio (CIMS) was used to test out the optimization tool. Initially, the model consisted of approximately 6 million polygons, however, we successfully reduced it to 486,560. The model was separated into horizontal sections allowing the user to turn on and off layers and accurately examine each floor.

On the other hand, we prepared a Wizard Optimization Guide Appendix $D$ that outlines a step-by-step guide to the optimization tool. We asked an Arvizio client, Impact Industrial in Calgary, to test the tool for feedback. Currently, the developing team is fixing minor 
bugs, and the tool will be released in the MR Studio Director 3.0 May 2019. 
CONCLUSION

The Modern Master Builder 
The intent of this research was to determine the ways an architect can develop mixed reality technology as a tool to better serve the AEC industry, however, many questions were raised on why it is the architect's role to lead this discussion? There are many factors that impacted and transformed their role in the design and construction of the built environment. As master builders, they were the ultimate controllers of the building process. Architects were hired by owners to design, craft, and control the construction process by directing craftsmen. Sometimes, they were also the curators. Buildings would always have an architect looking after and protecting it whether construction or restoration was needed or not. Today, architects in the United States are only involved in $5-10 \%$ of the building industry projects. ${ }^{105}$ The increased technical complexity and the associated risk management have led to a gradual erosion of the role of the architect in favor of project and construction management models. Authorship is challenged because the structure of the profession is changing. ${ }^{106}$ Today, control over a project comes with legal and financial responsibilities. Generally and for various reasons, architects particularly in North America - are not ready to make this shift and take on this liability. However, many argue that we must shift the discourse from one of control to one of collaboration.

105 "U.S. Bureau of Labor Statistics," U.S. Bureau of Labor Statistics, https://www.bls.gov/ooh/architecture-and-engineering/architects.htm. 106 Antoine Picon, "The Ownership Revolution, Digital Culture and the Transformation of Architectural Practice and Ideals" (lecture, Princeton University School of Architecture), 2016. 
With digital technologies rapidly changing our daily lives, the questions related to the role and responsibilities of the architect are changing as well. ${ }^{107}$ Some fear that adopting new technological tools will deprive architects of their "remaining" role, others argue that new technological tools are touted as an opportunity to expand the architect's ability to solve technical problems, to deliver accurate plans, and to exhaust every possible imaginative angle. ${ }^{108}$ This debate has been widely aired within the profession when CAD, digital fabrication, and BIM were first introduced. Generally, tools are not the solution; its how we use them and to what end. I would argue that the primary end in our industry is collaboration. In that sense, as an evolving technology, mixed reality could be shaped to serve the profession for the future that promises to be more complex. The question is, should architects take on the role of shaping mixed reality tools to better serve the practice of architecture and the construction industry more broadly?

While the exact role of the architect of today is in transition, the architect remains as the storyteller, the one bringing all specialties together. Regardless of the current role of engineers, constructors, and stakeholders, no one is currently trained to assume this part of the architect's traditional role. While this research thesis was about investigating a new tool for architecture, the architect's voice is the most important tool. While developers and computer scientists build digital tools, it is the architect's role to bring it to the industry. Some

\footnotetext{
107 Antoine Picon, "The Ownership Revolution, Digital Culture and the Transformation of Architectural Practice and Ideals" (lecture, Princeton University School of Architecture), 2016.

108 Philip Bernstein and Peggy Deamer, Building the Future: Recasting Labor in Architecture (New York: Princeton Architectural Press, 2008).
} 
of the criticism for the digital tools is that architects were not involved in the process: how can someone design a solution for problems they are not fully aware of? The architect has an ethical responsibility to have a thoughtful opinion on digital tools, and as an extension, to assist in developing them. 
LIST OF ILLUSTRATIONS 


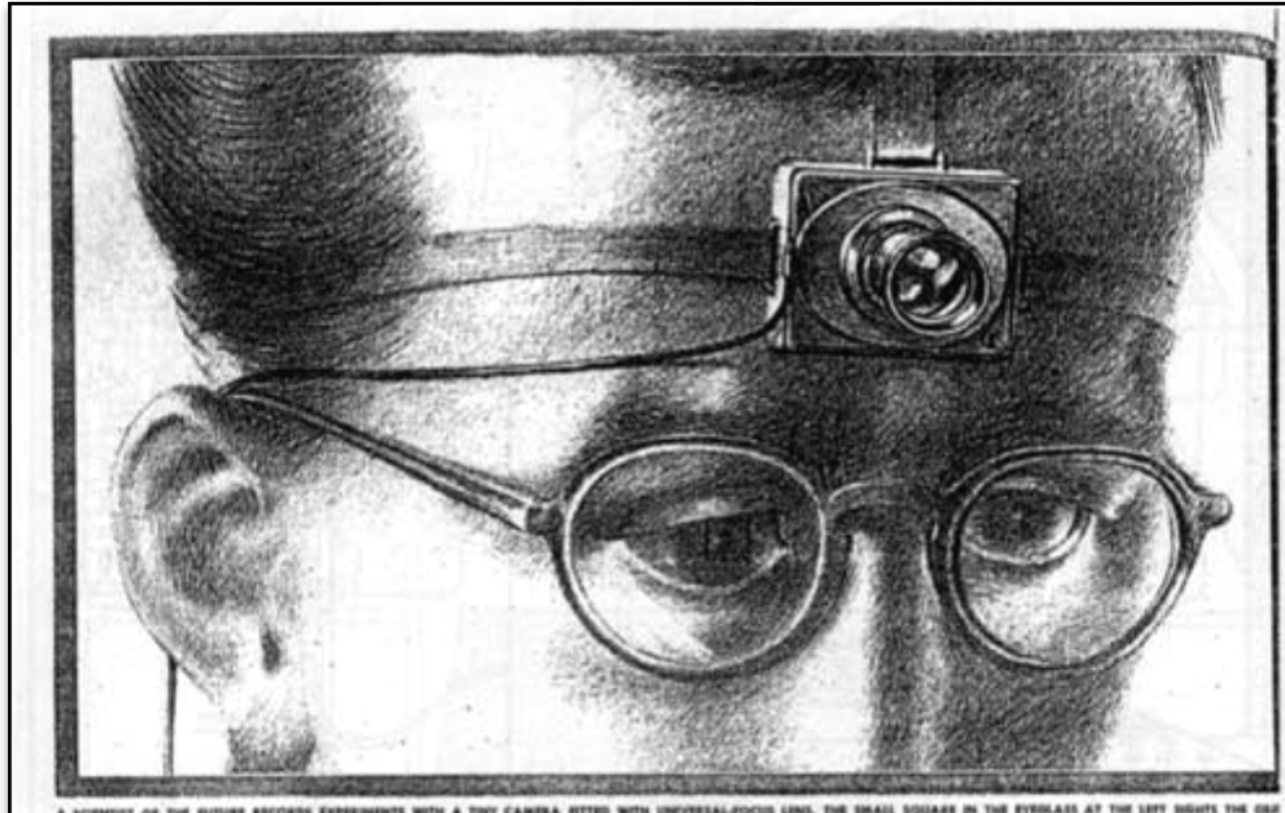

\section{AS WE MAY THINK}

A TOP U.S. SCIENTIST FORESEES A POSSIBLE FUTURE WORLI IN WHICH MAN-MADE MACHINES WILL START TO THINI bY VANNEVAR BUSH

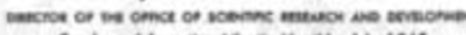

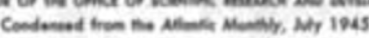

This ha not heen a nciegtine' war; it has lees a war in which all have hot

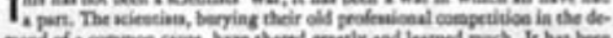

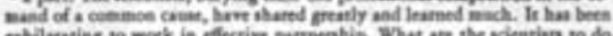

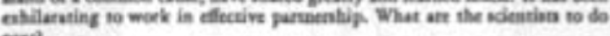
axis

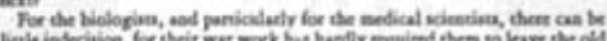

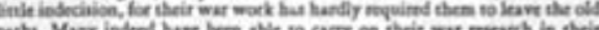

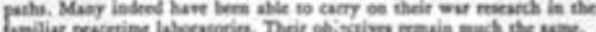

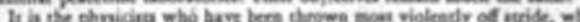

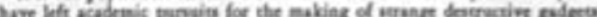

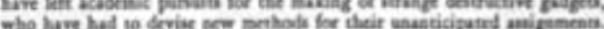

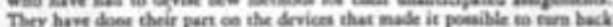

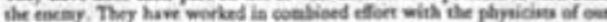

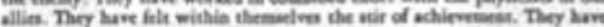

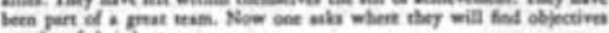
monily of dear has.

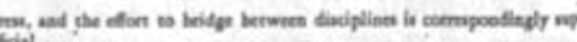

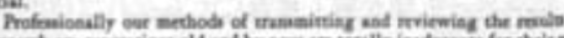

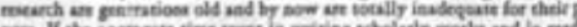

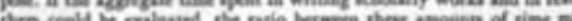

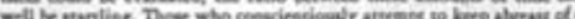

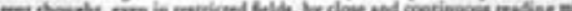

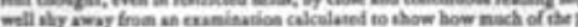

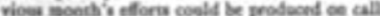

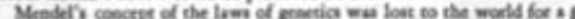

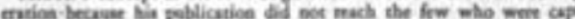

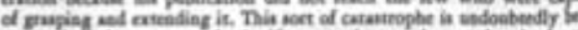

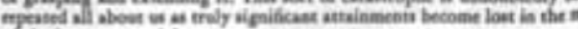

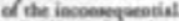

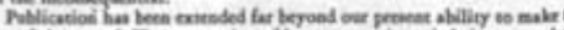

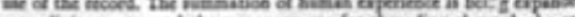

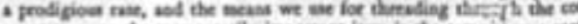

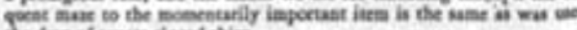

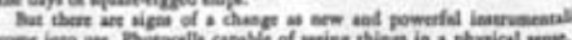

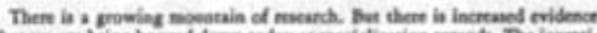

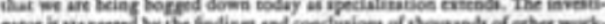

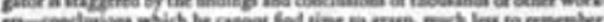

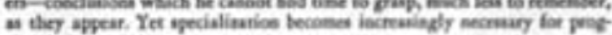

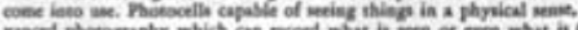

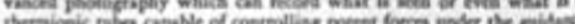

112

rLIFE」1945年9月10日曾に特萧をれた IAS WE MAY THINK」のベージ

'LLFE, 1945\%9月10日早上り引用

'AS WE MAY THINK, From the Atlantic Monthly, July 1945

Figure 1: As We May Think 


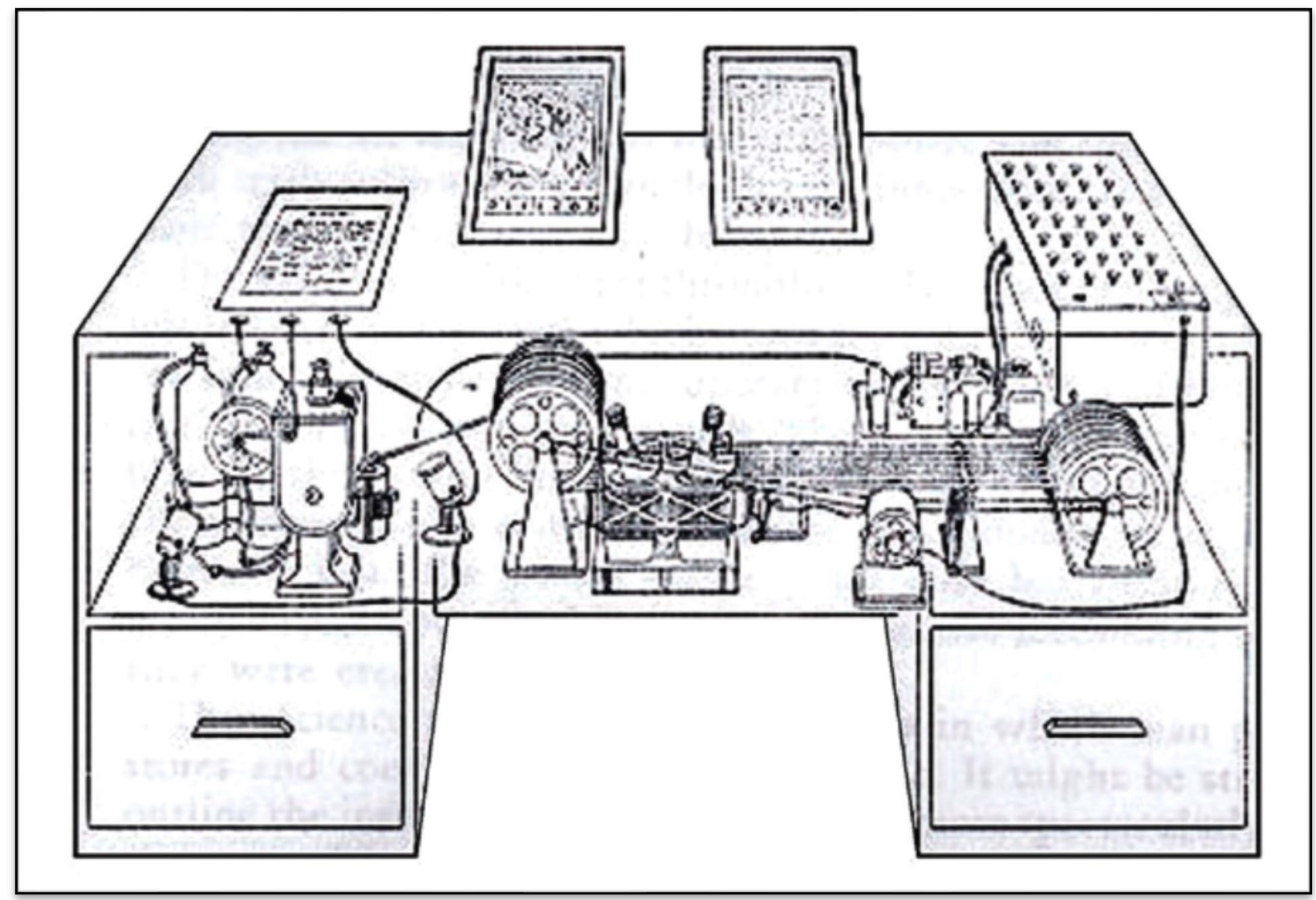

Figure 4: The Memex 

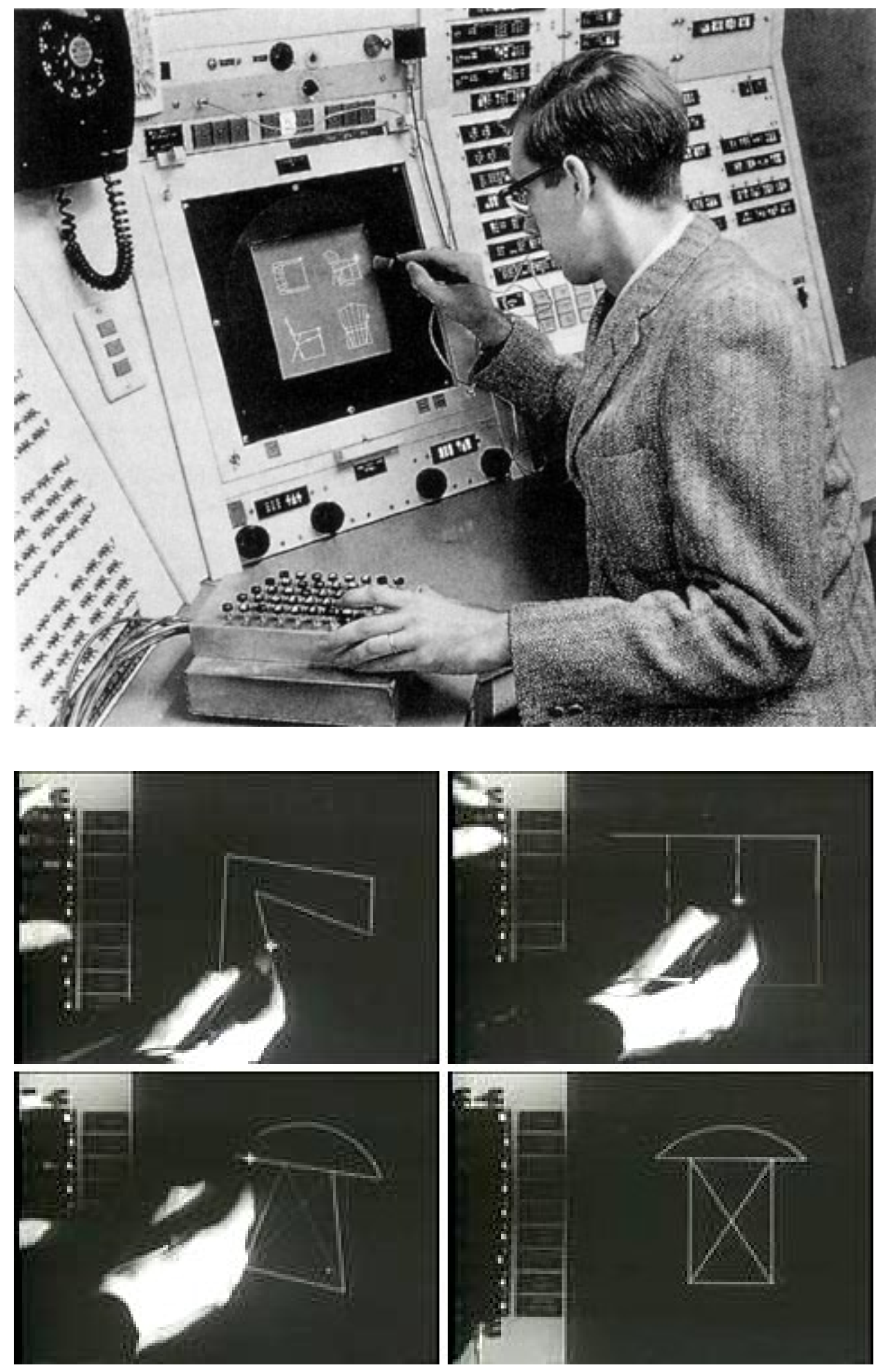

Figure 7: The Sketchpad 

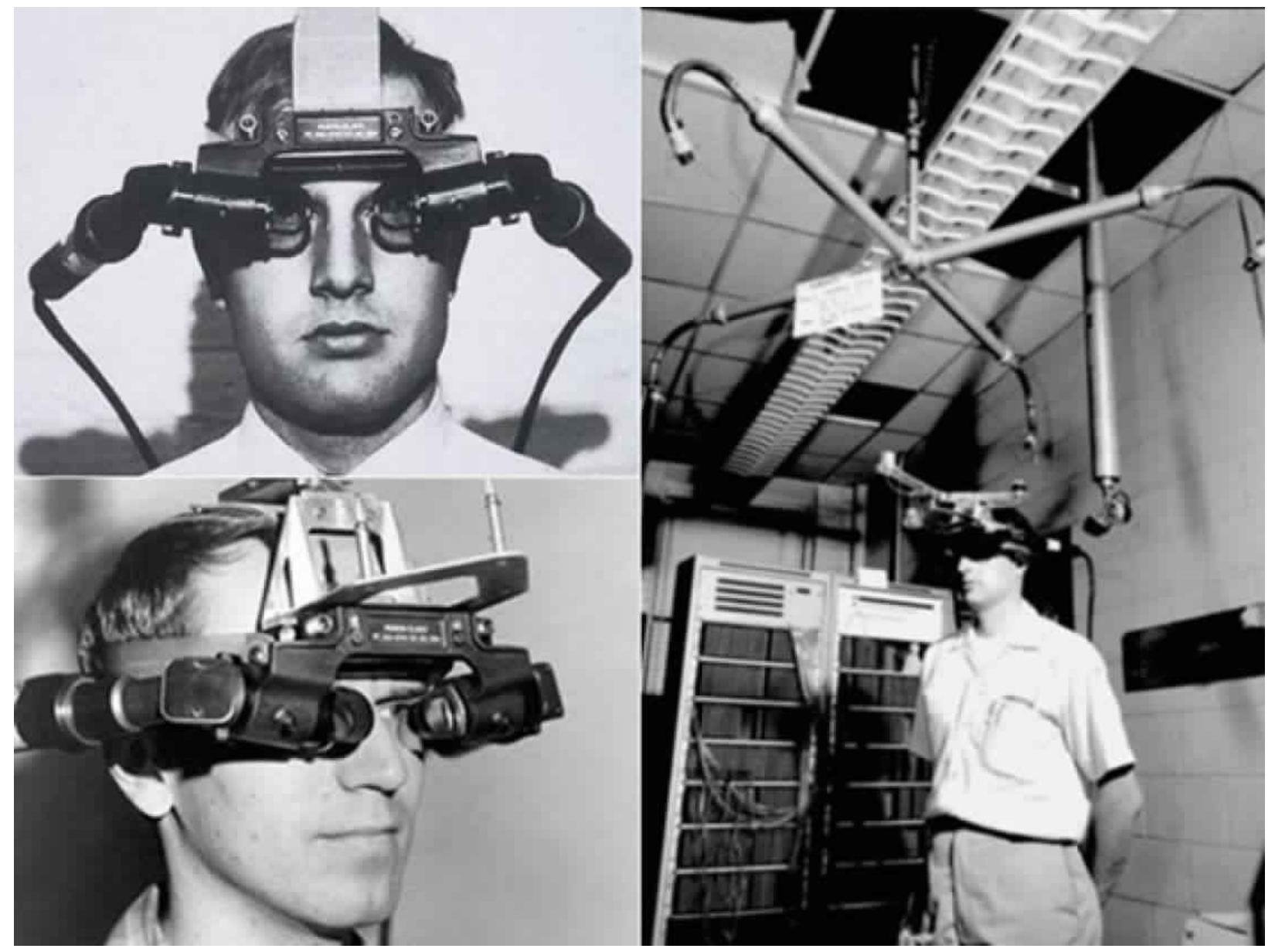

Figure 10: The Sword of Damocles (virtual reality) 


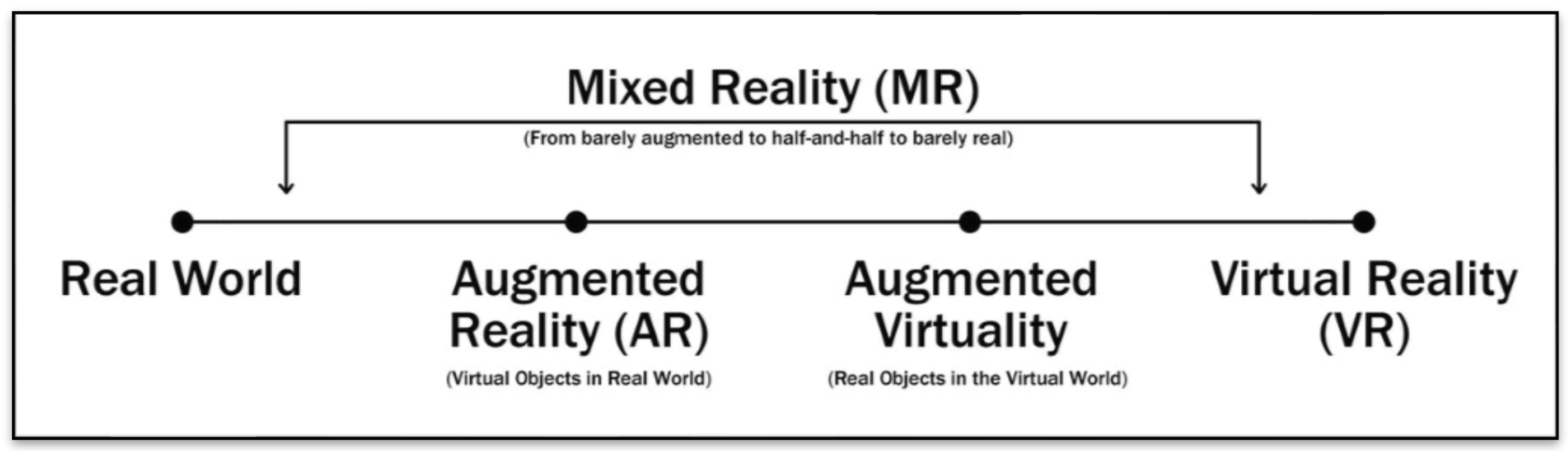

Figure 13: Milgram Mixed Reality Spectrum 


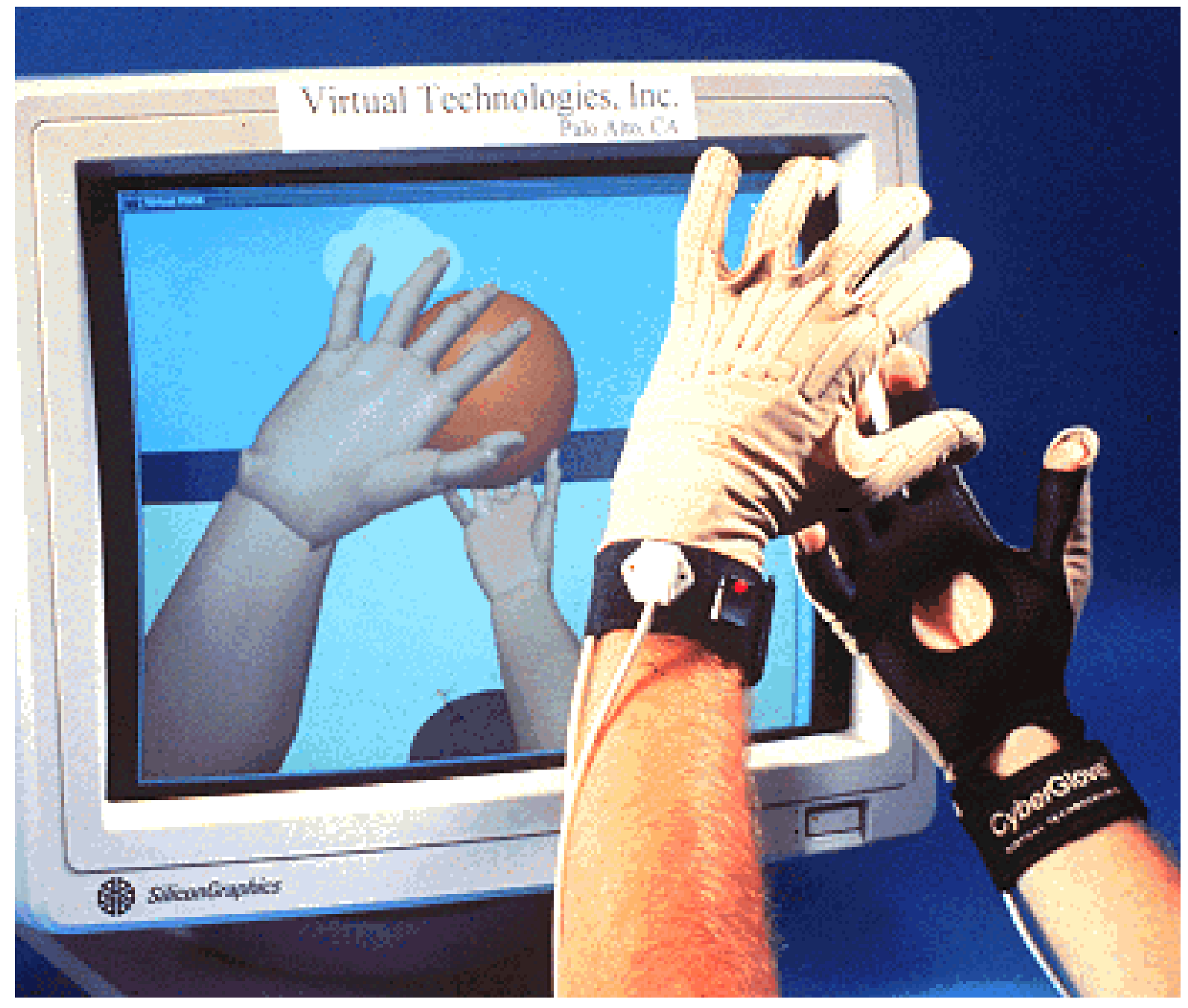

Figure 16: Data Glove 

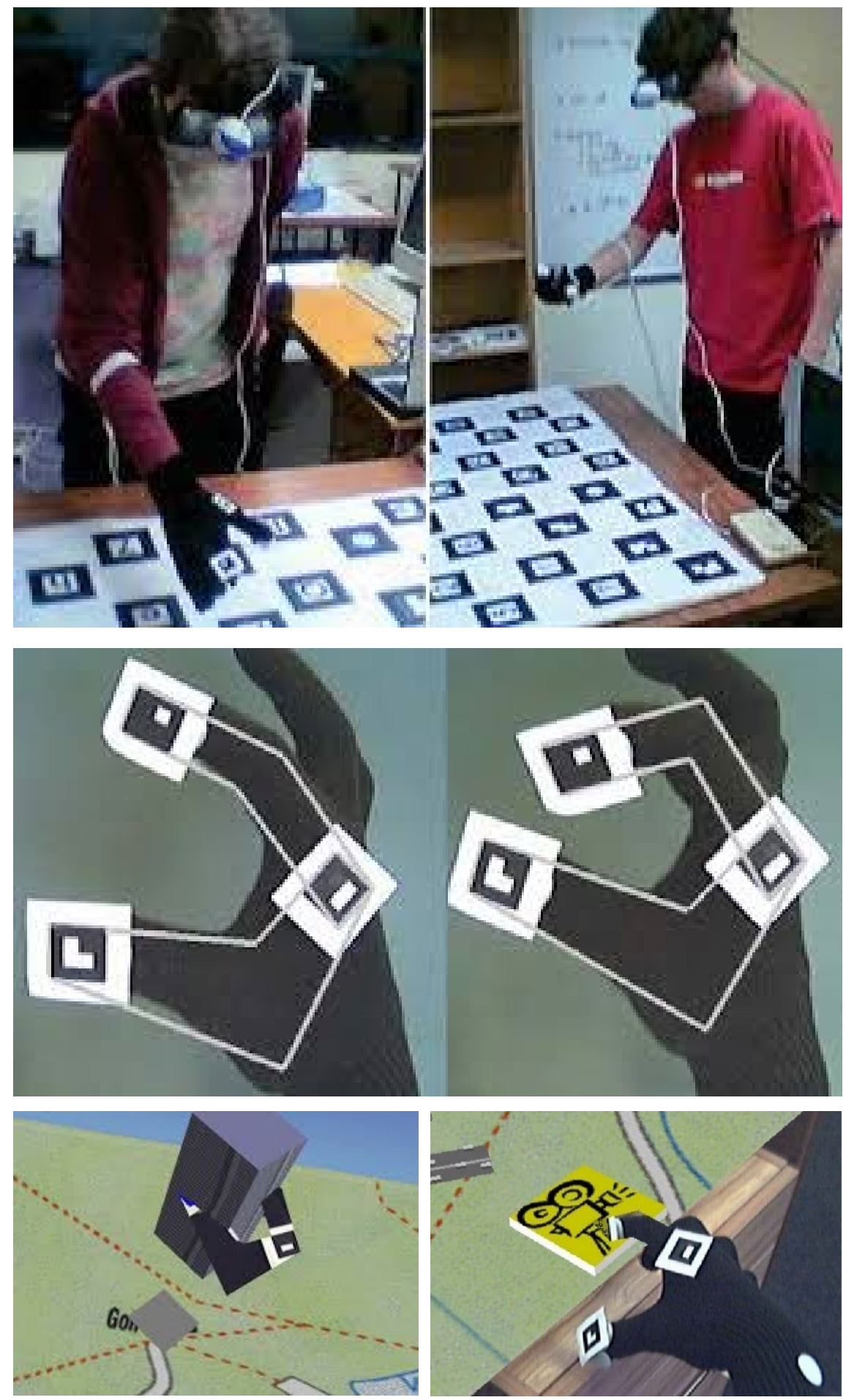

Figure 19: FingARtips 

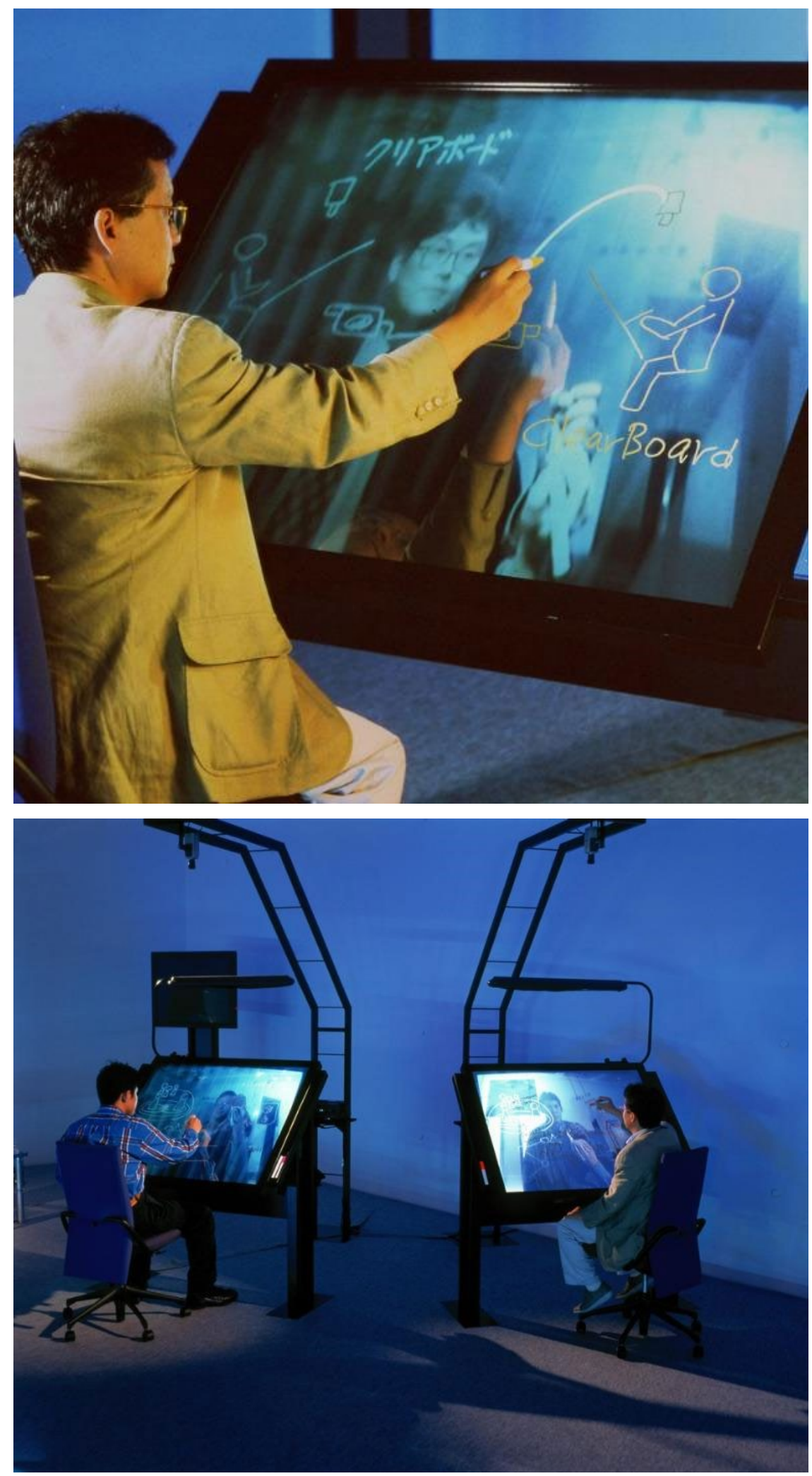

Figure 22: ClearBoard 


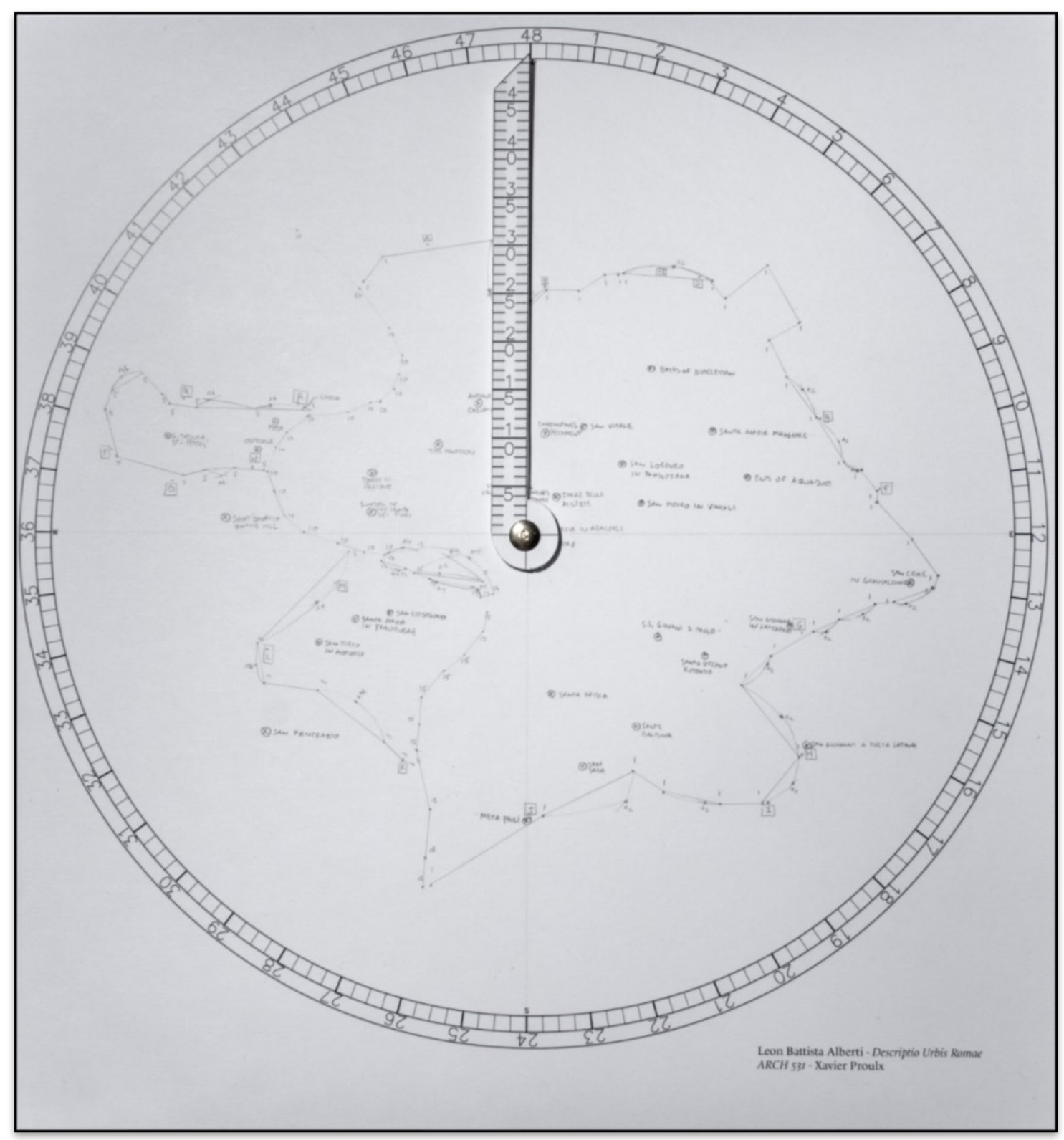

Figure 25: Descriptio Urbis Romae 


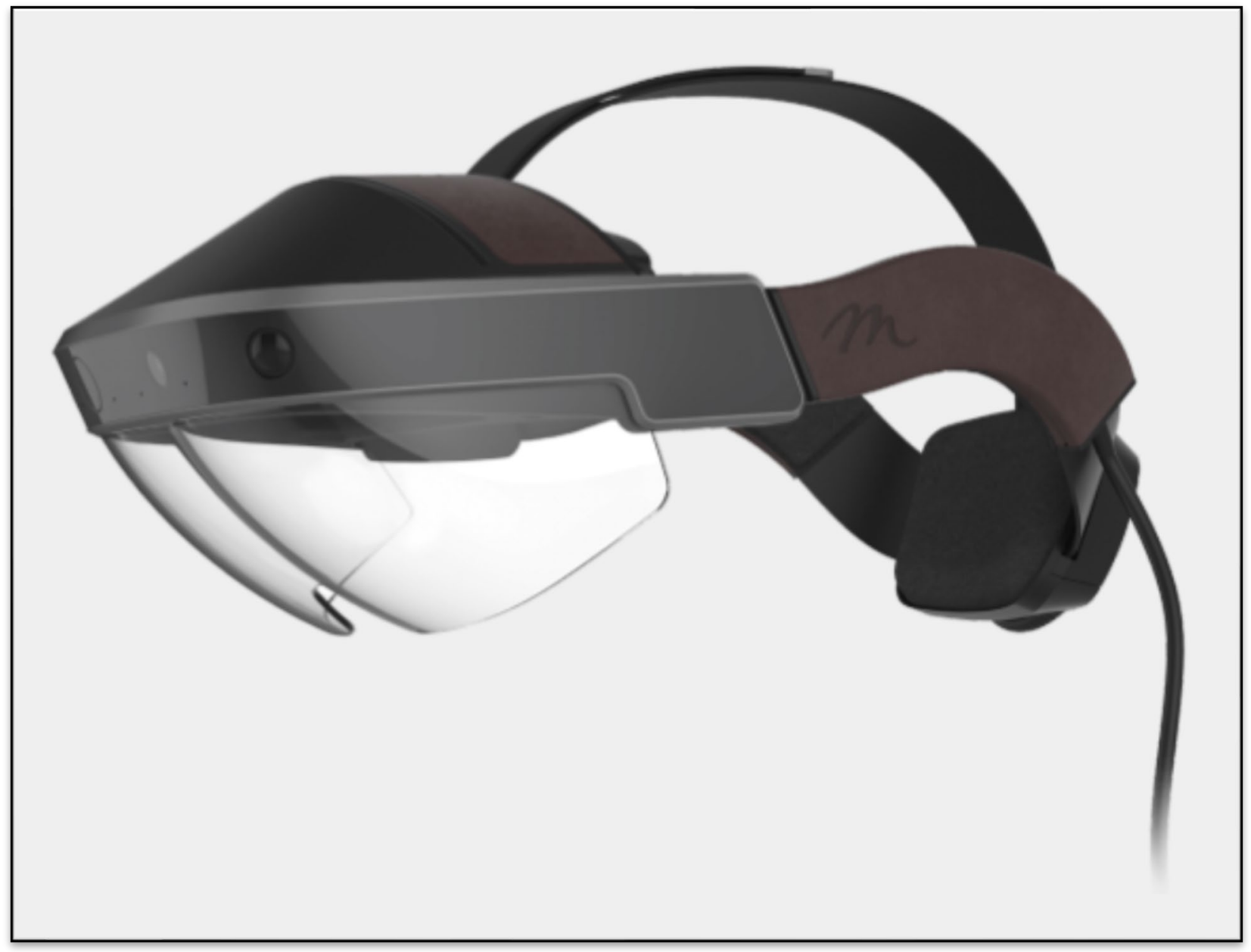

Figure 28: Meta 2 


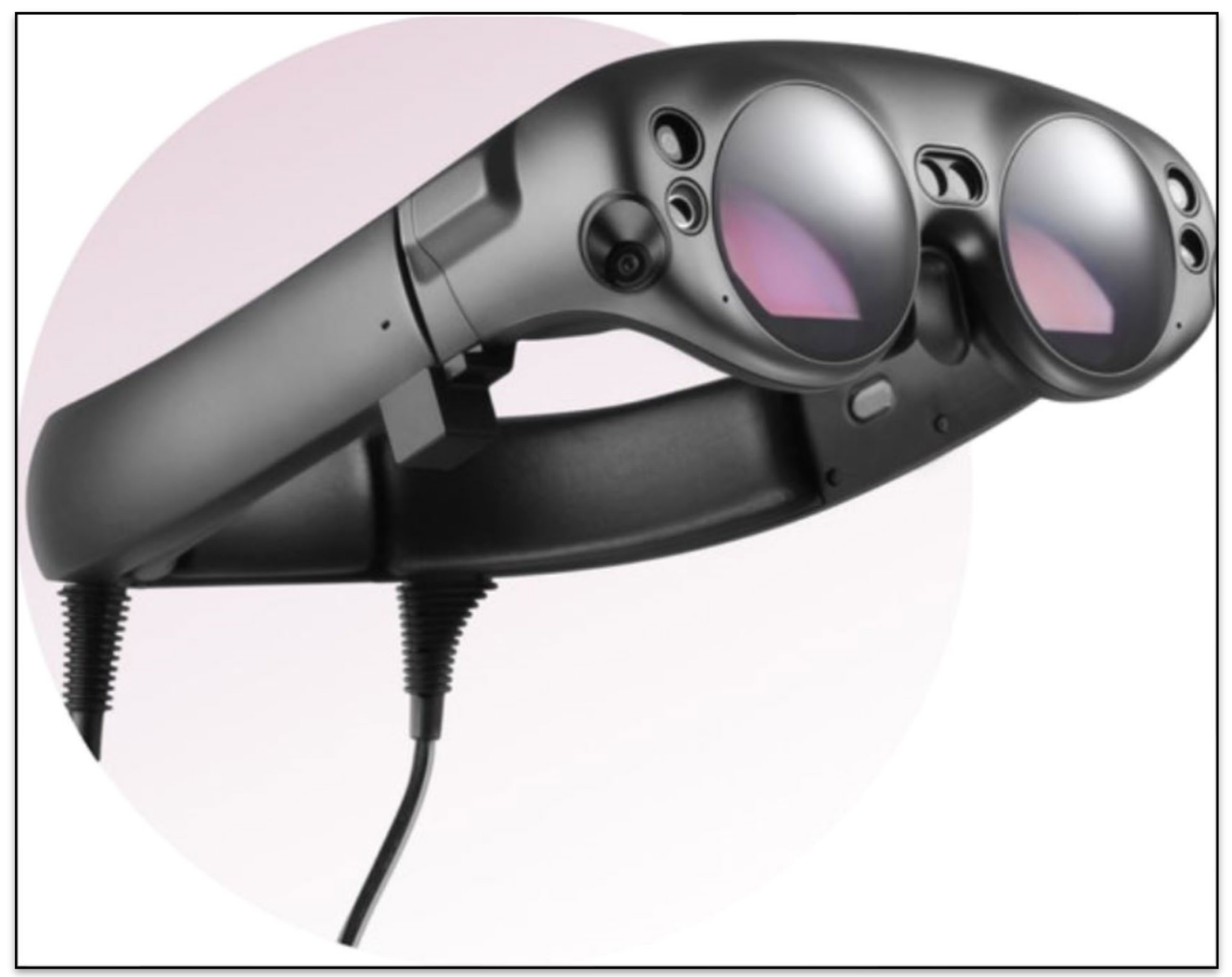

Figure 31: Magic Leap One 


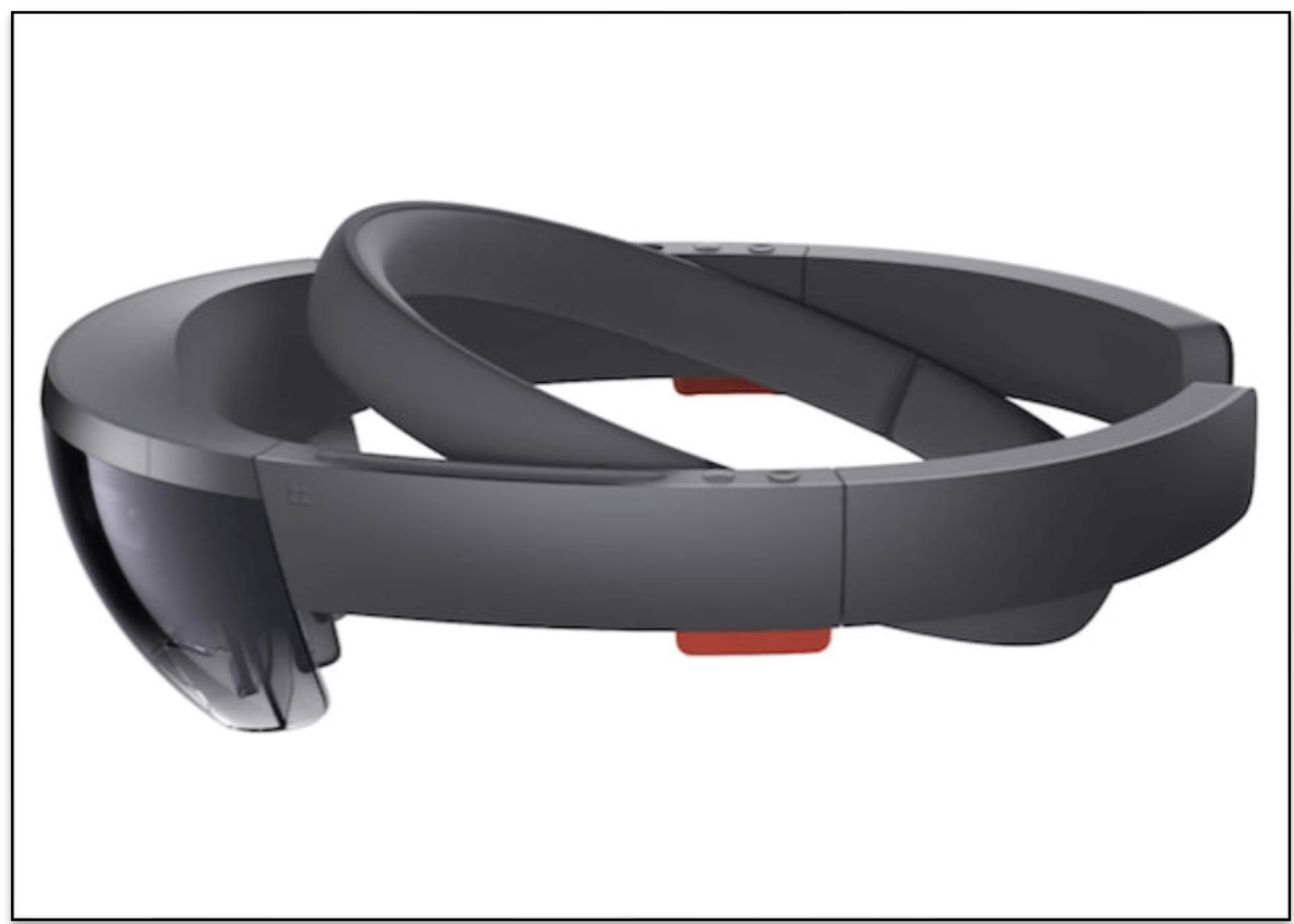

Figure 34: Microsoft HoloLens 1 


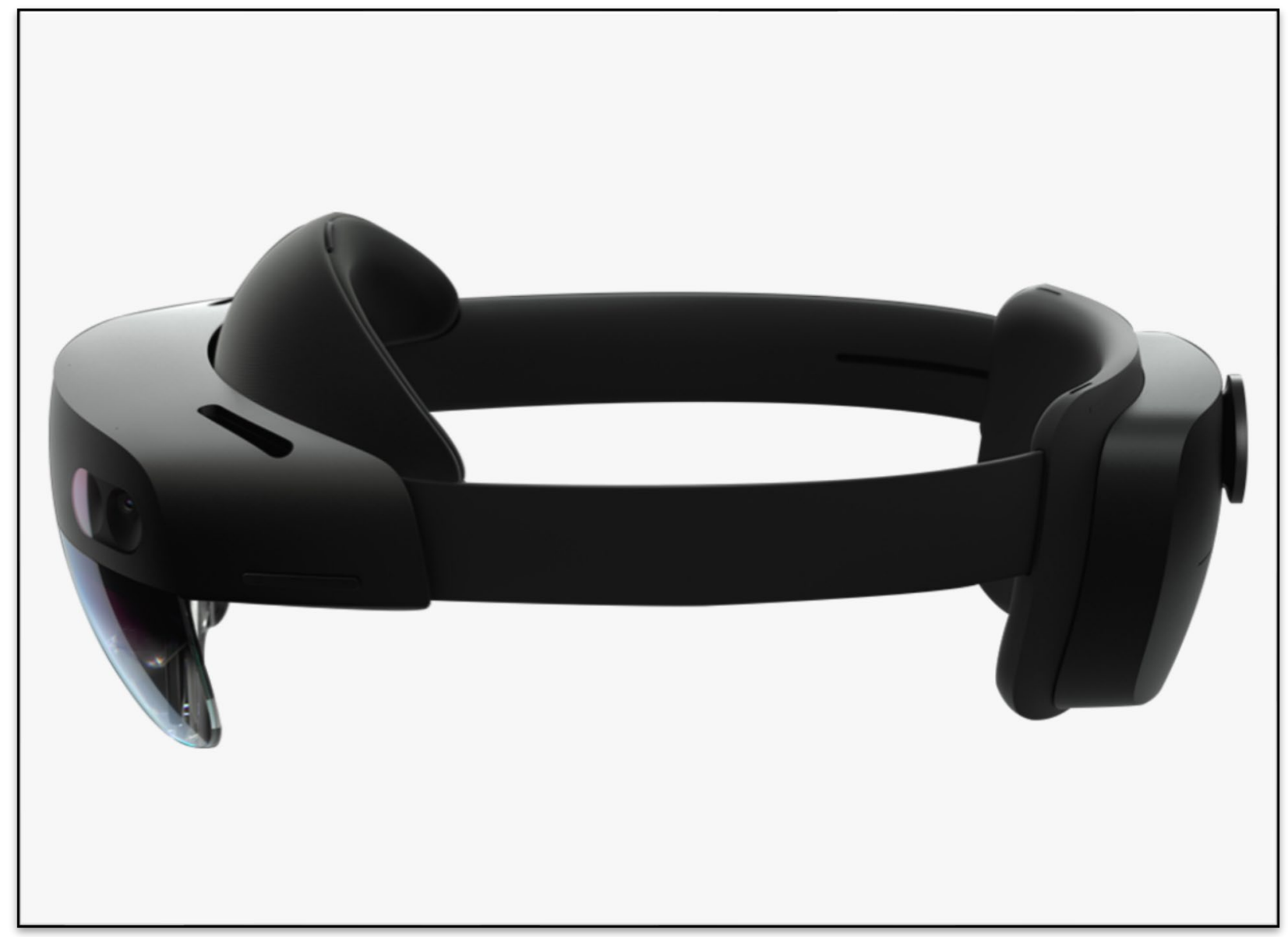

Figure 37: Microsoft HoloLens 2 


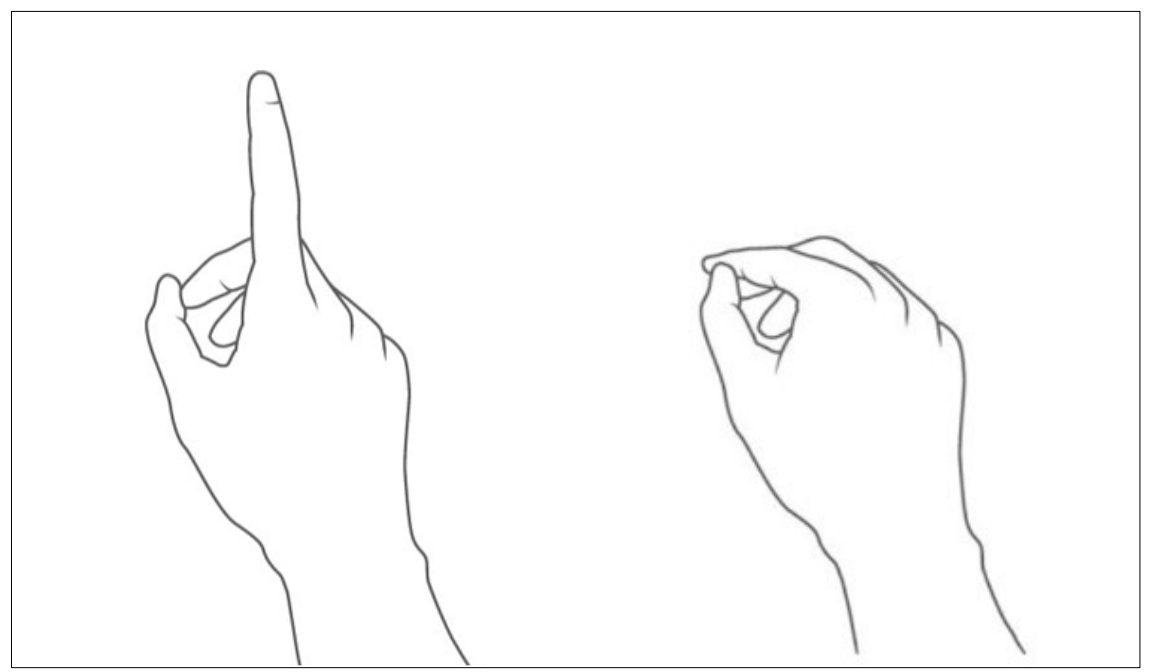

Figure 40: Air Tap Gesture

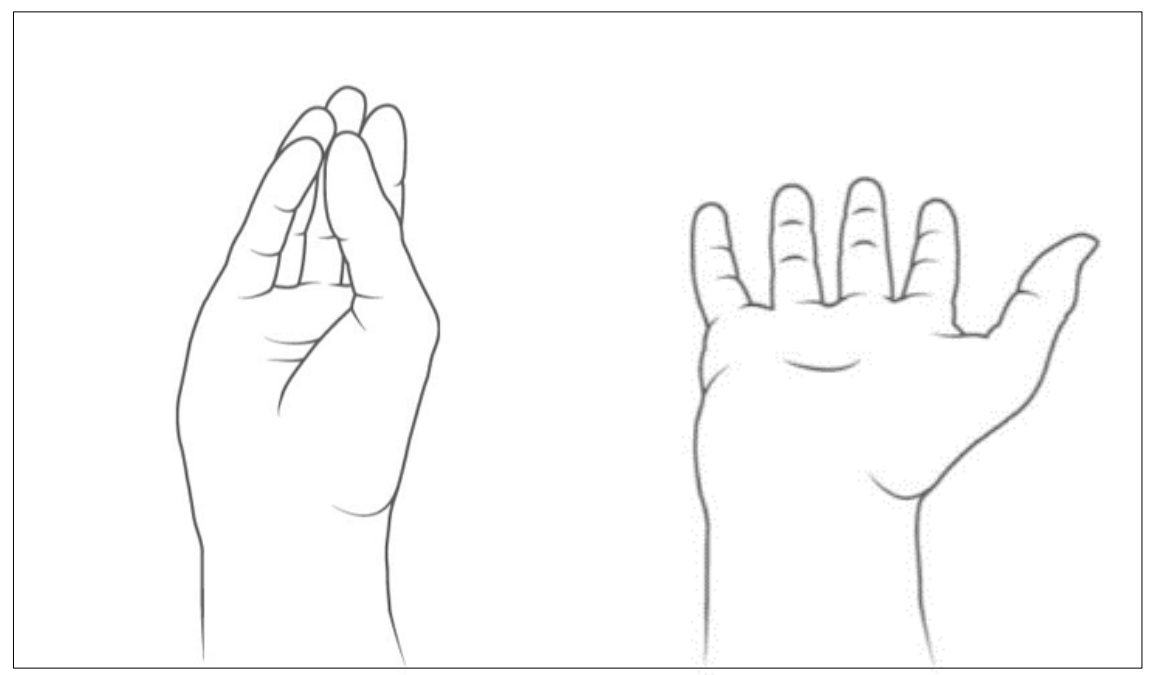

Figure 43: Bloom Gesture 

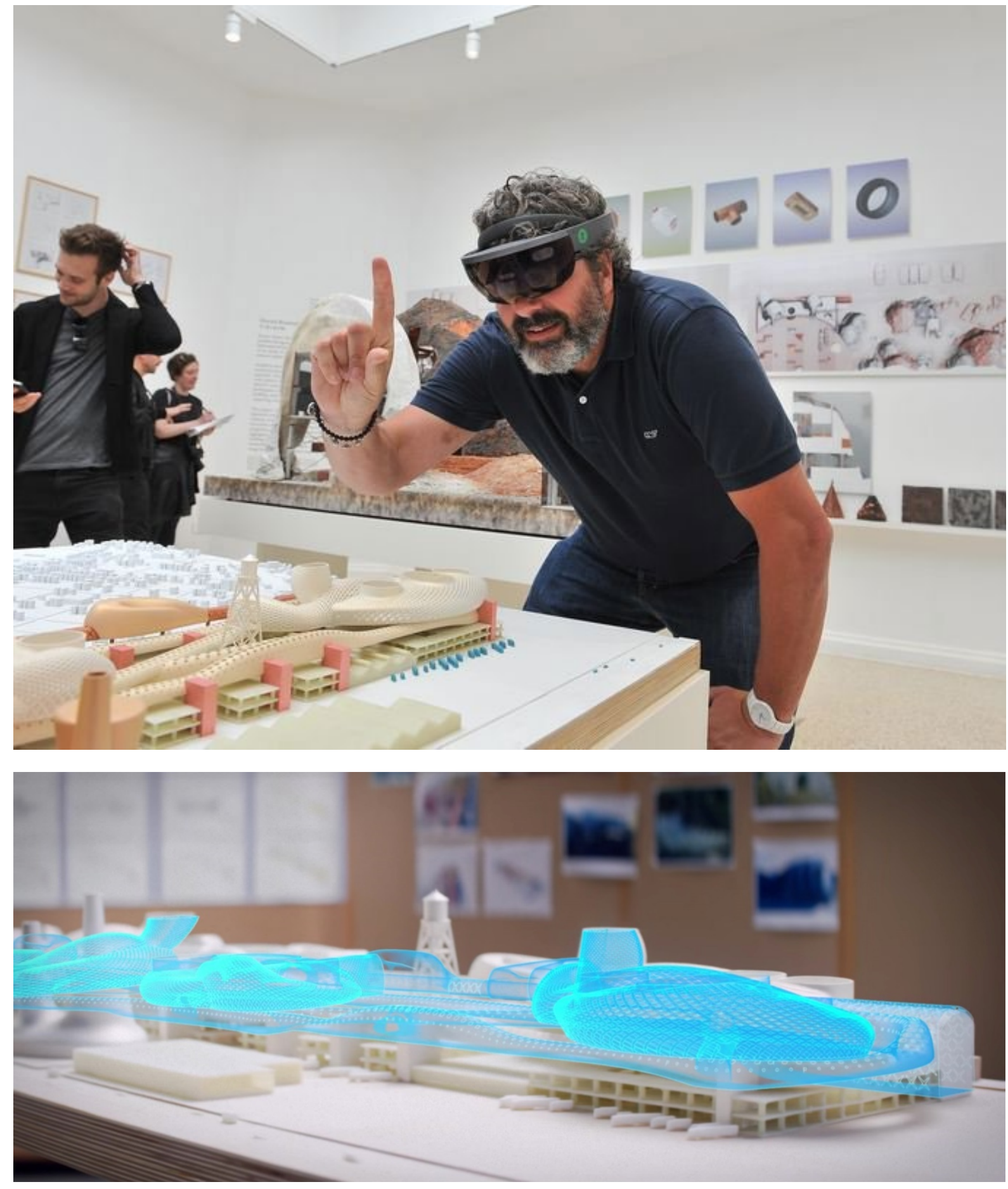

Figure 46: Packard 


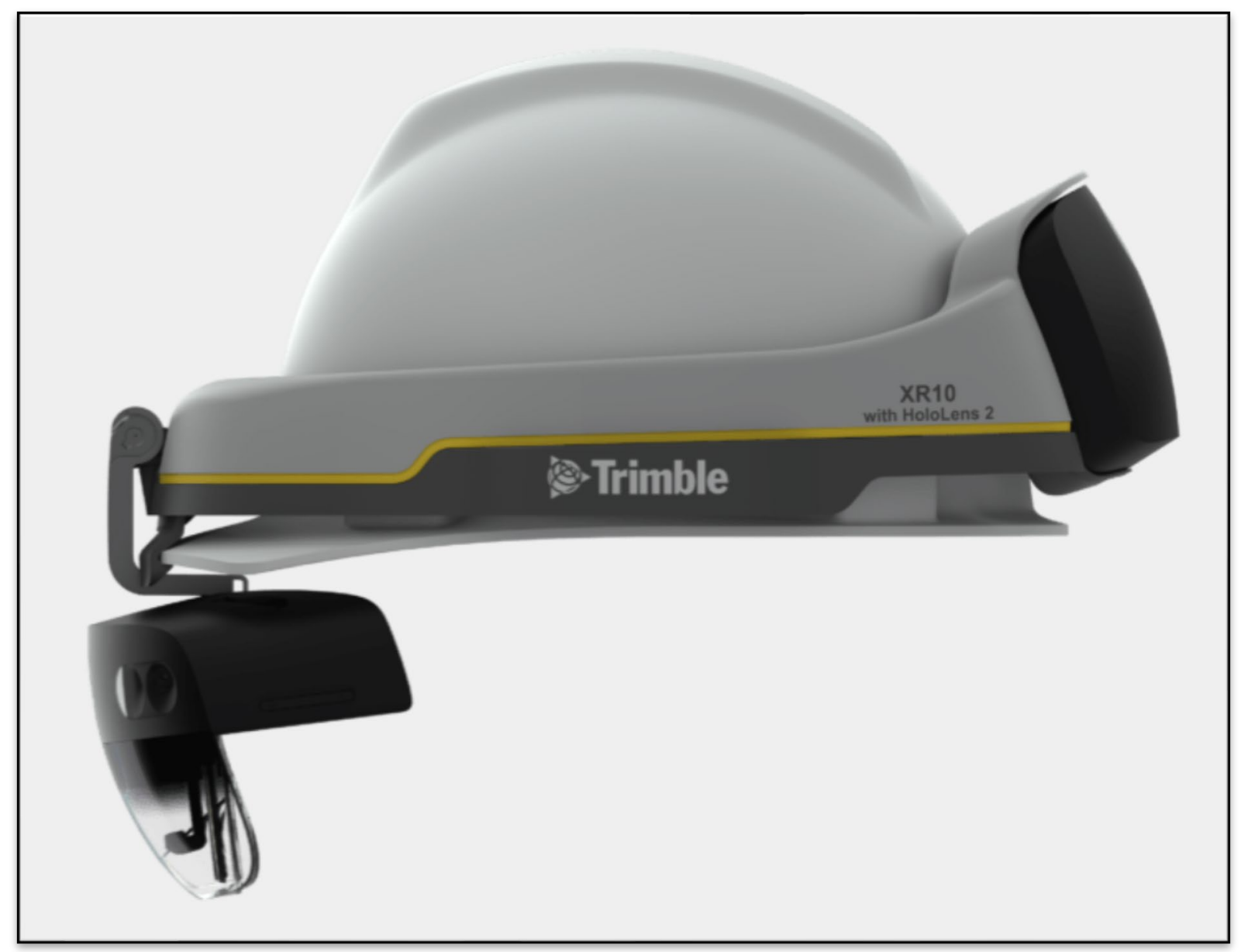

Figure 49: Trimble XR10 with HoloLens 2 

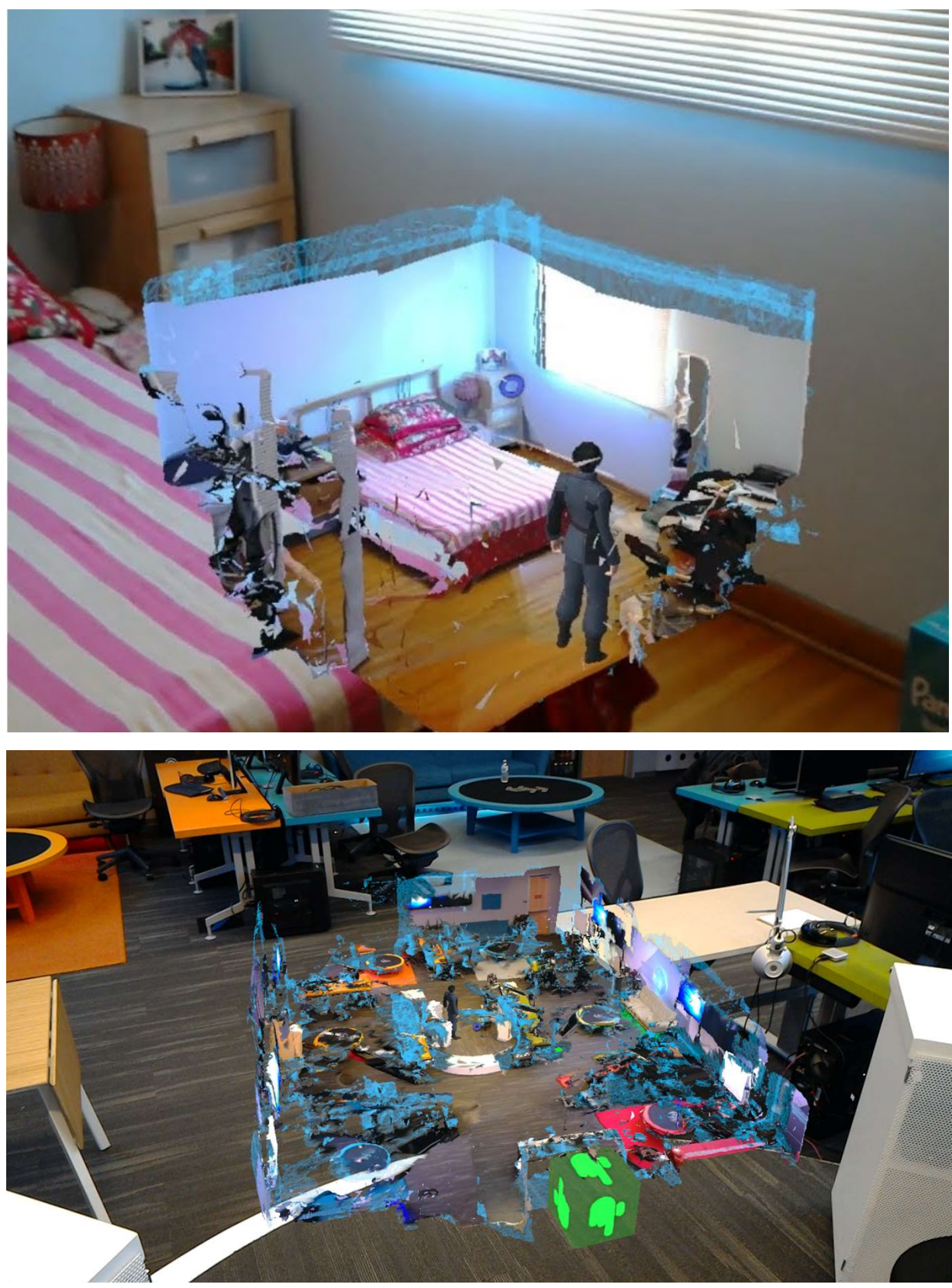

Figure 52: HoloLens RoomScanner 


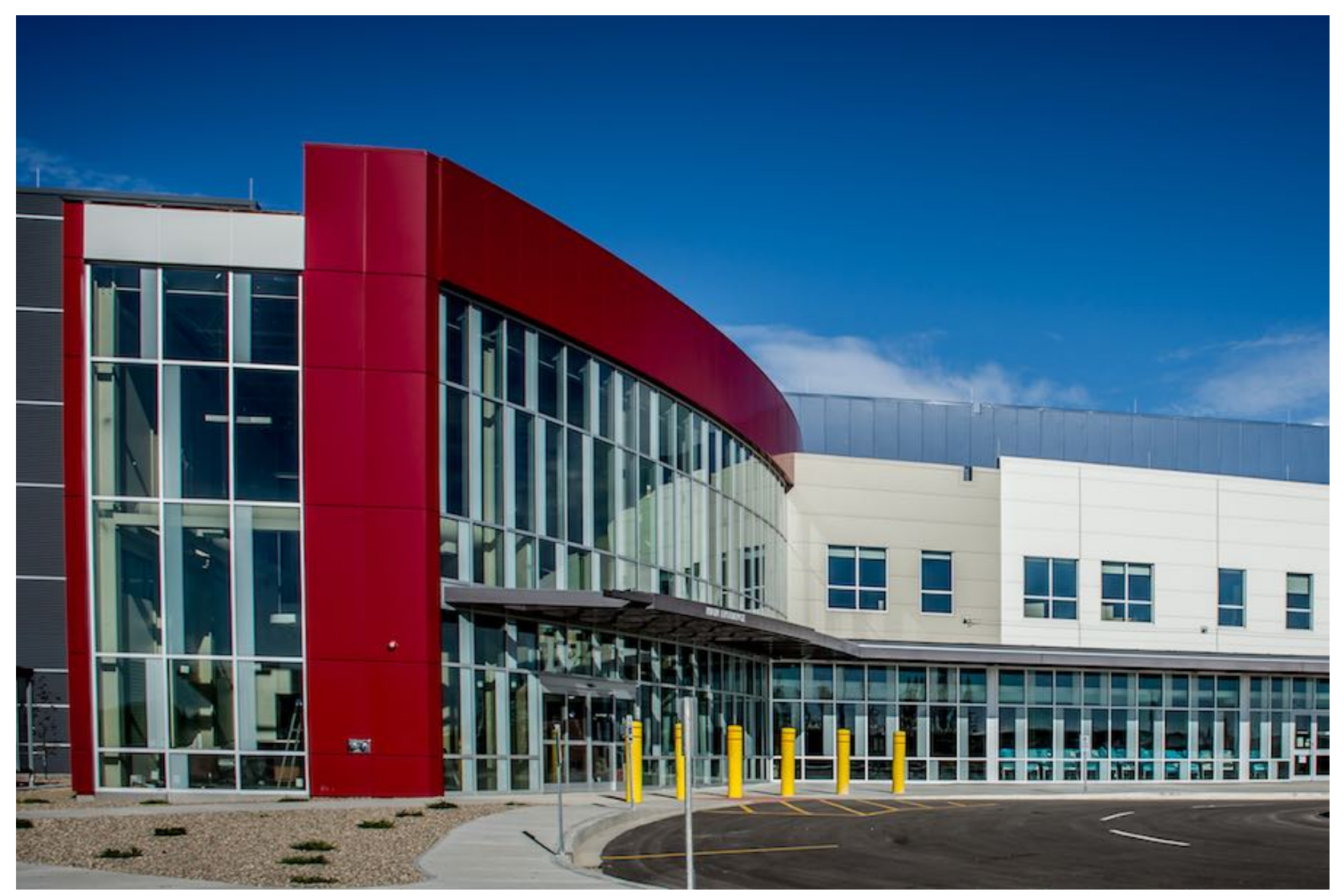

Figure 55: Five Hills Health Regional Hospital 

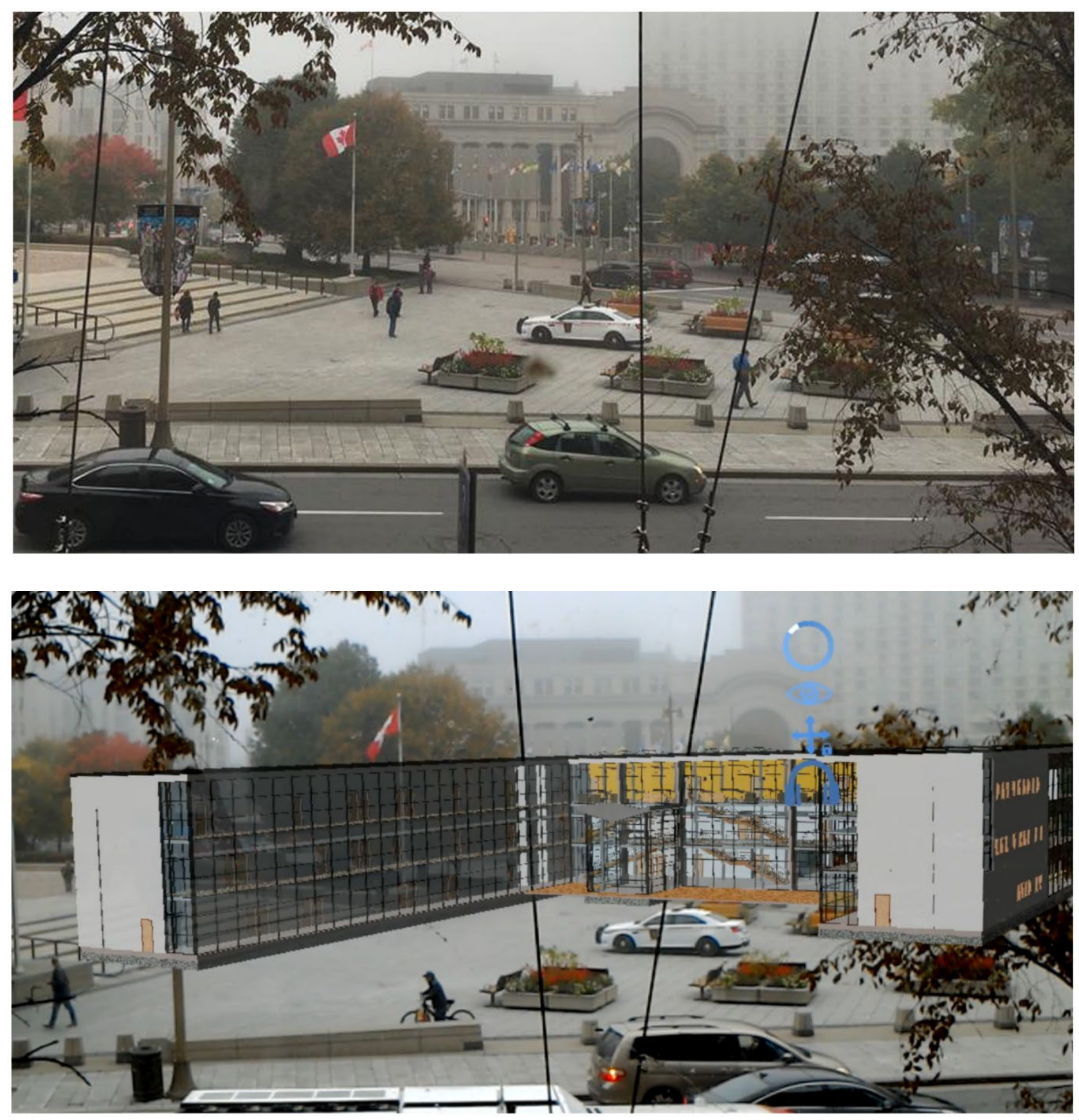

Figure 58: Mixed Reality in Real Estate and Design 

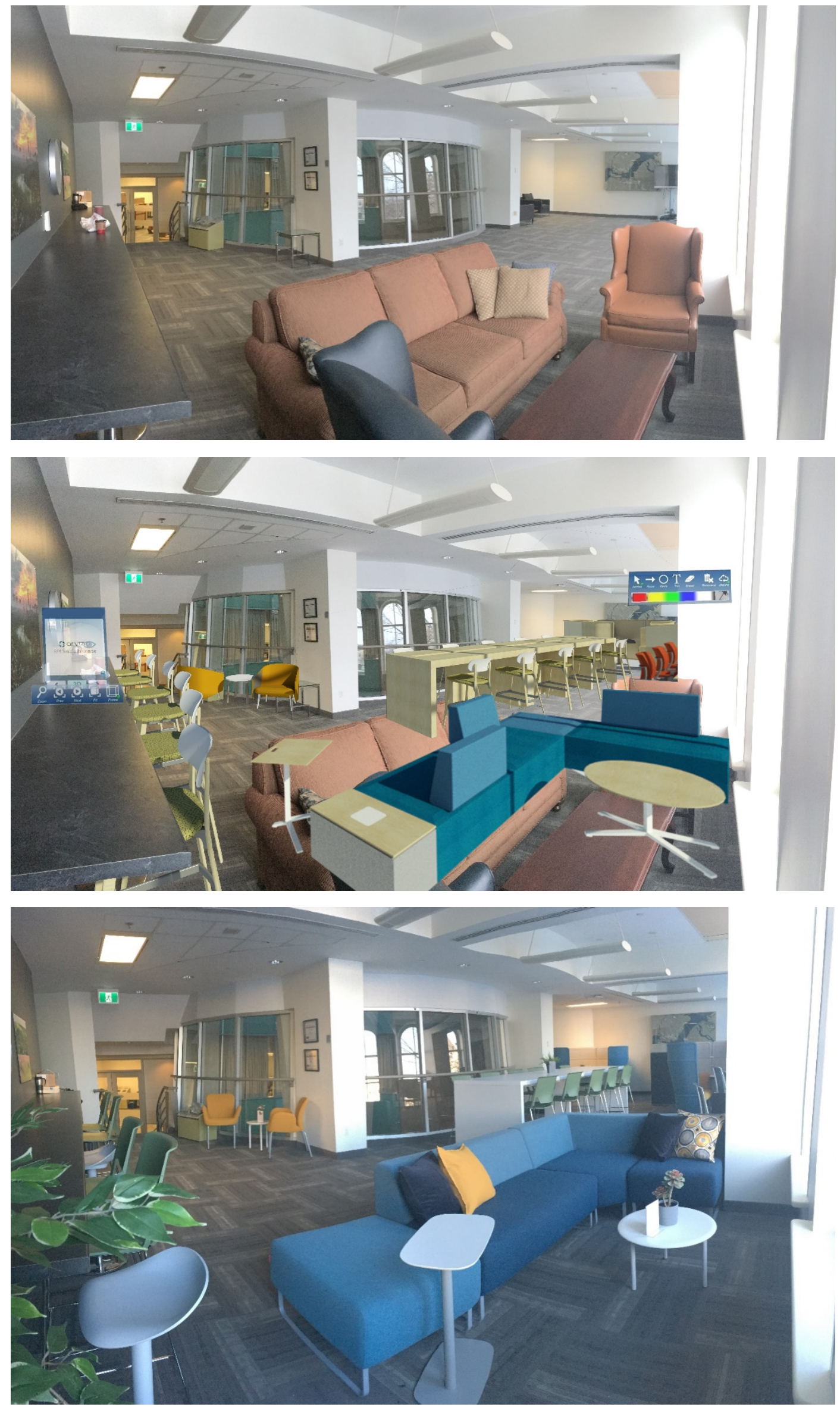

Figure 61: Mixed Reality in Interior Design 

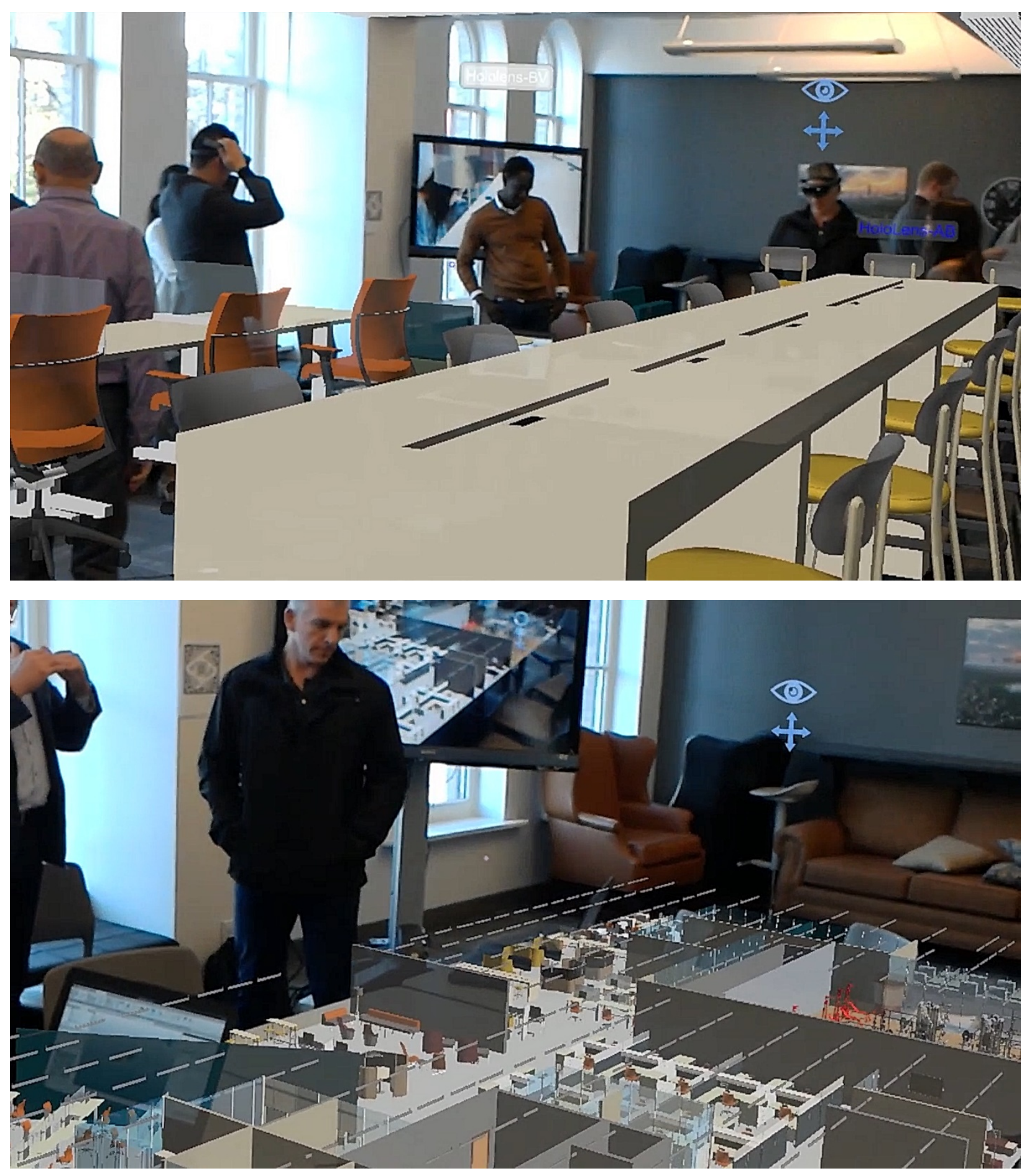

Figure 64a: Mixed Reality in Construction and Management 

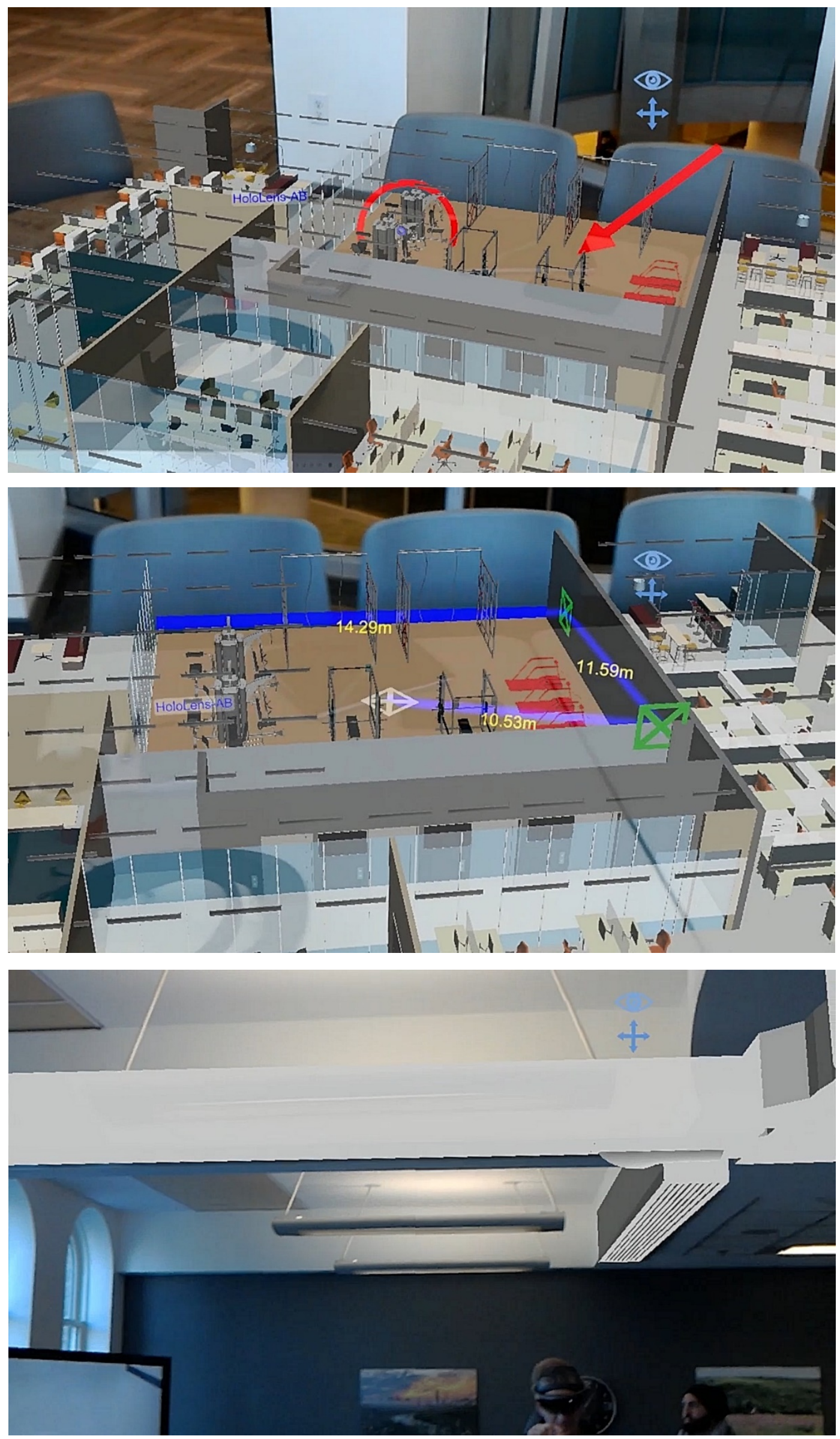

Figure 22b: Mixed Reality in Construction and Management 


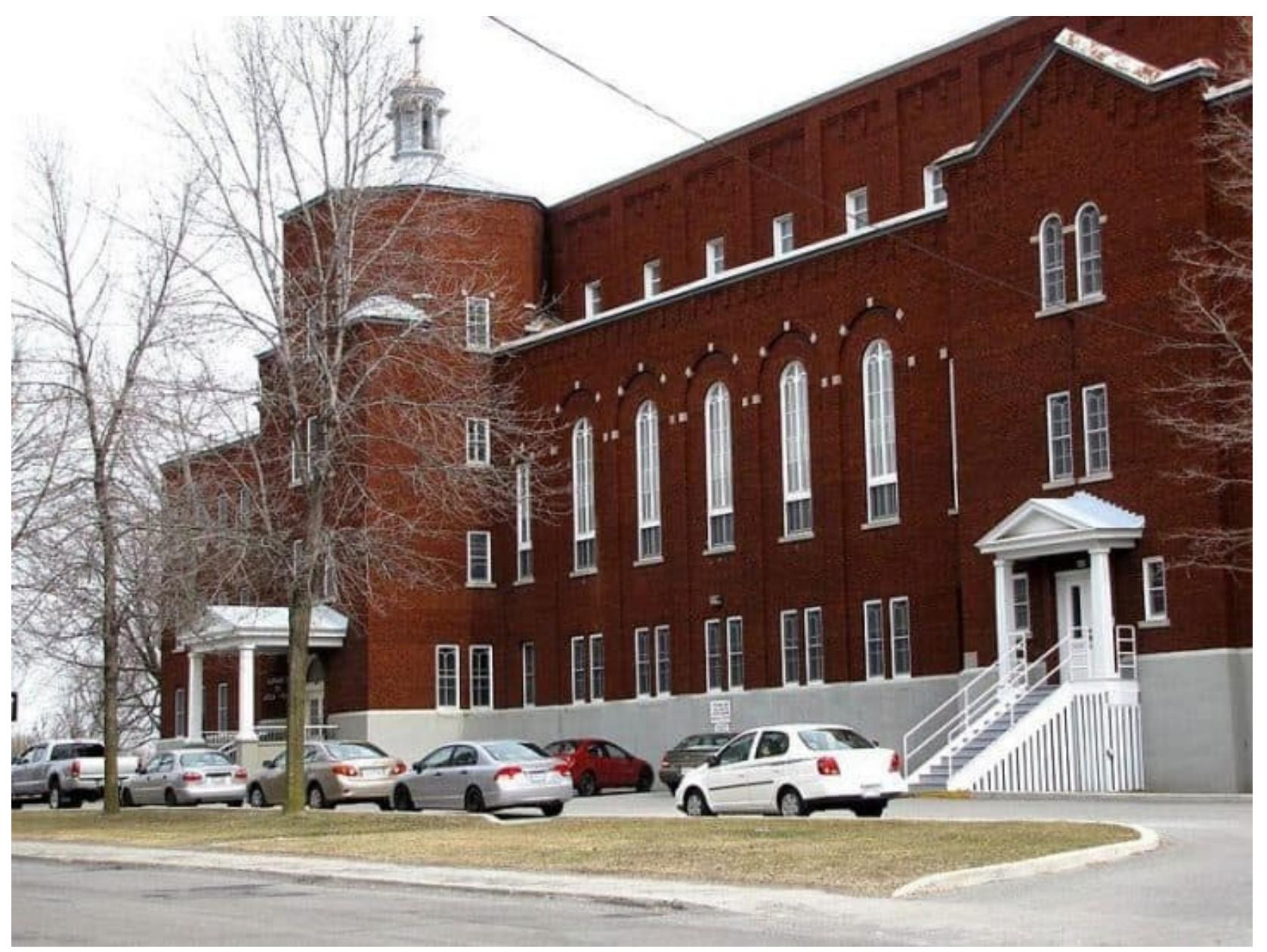

Figure 69: Congregation des Servantes de Jésus-Marie 

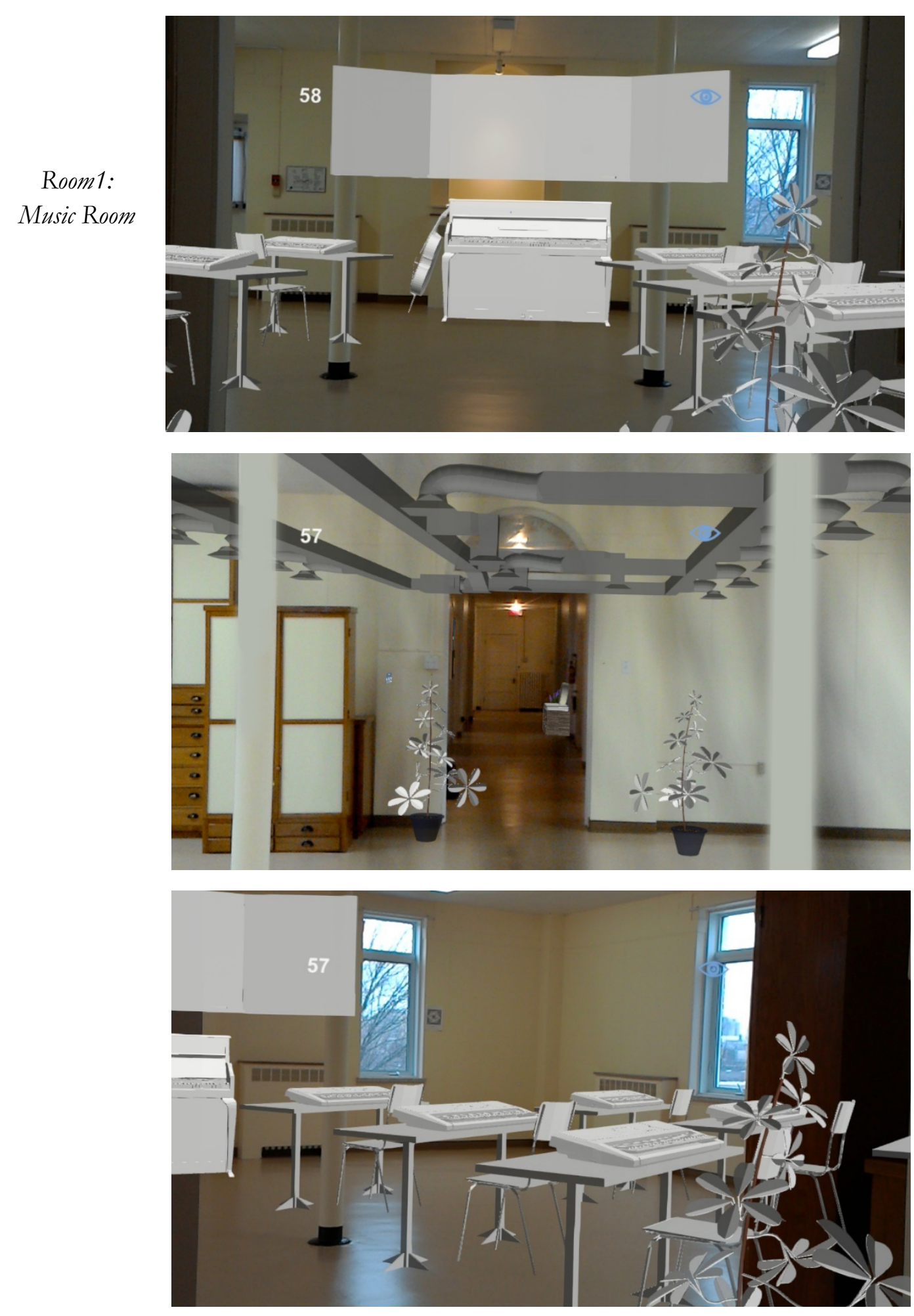

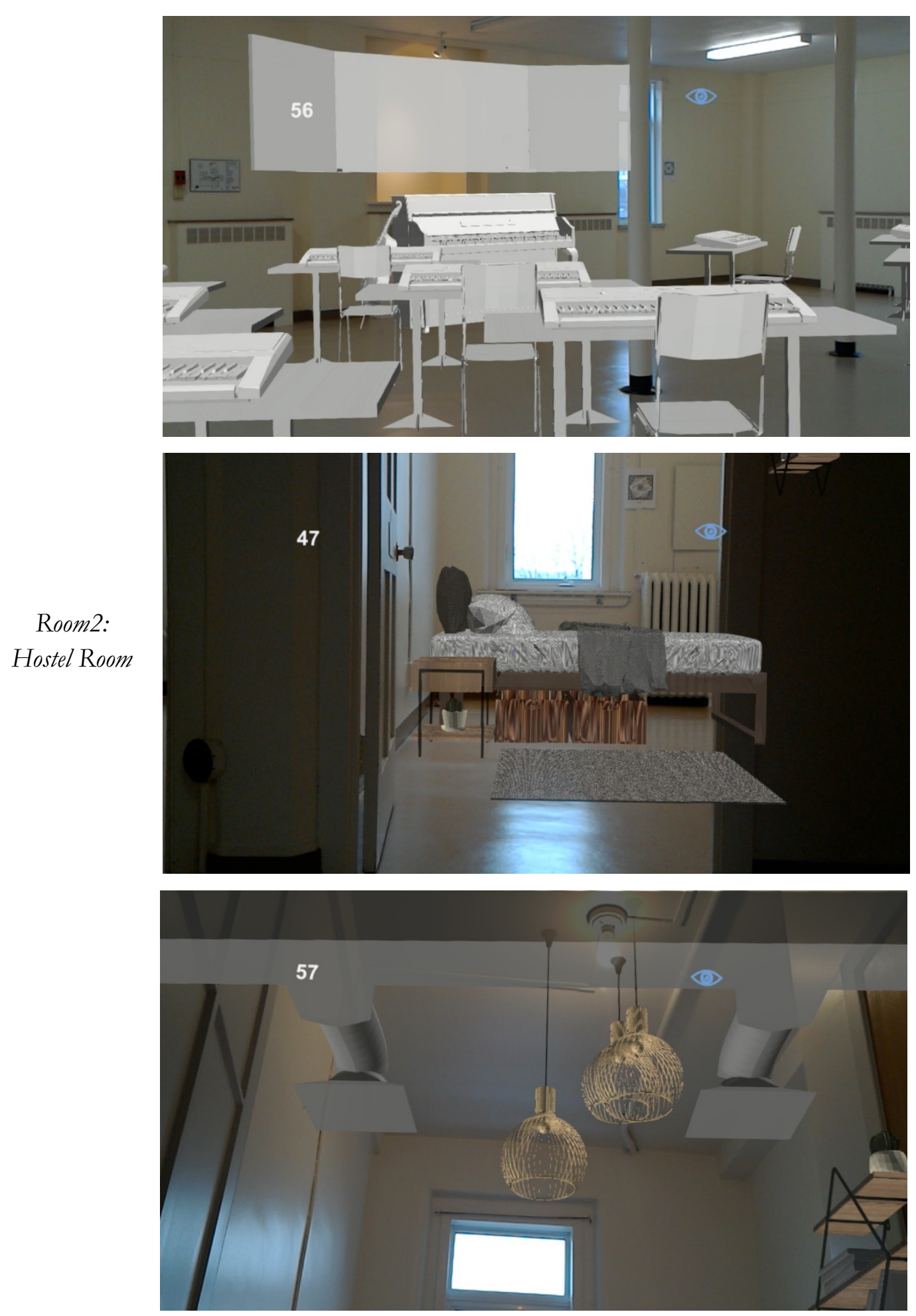

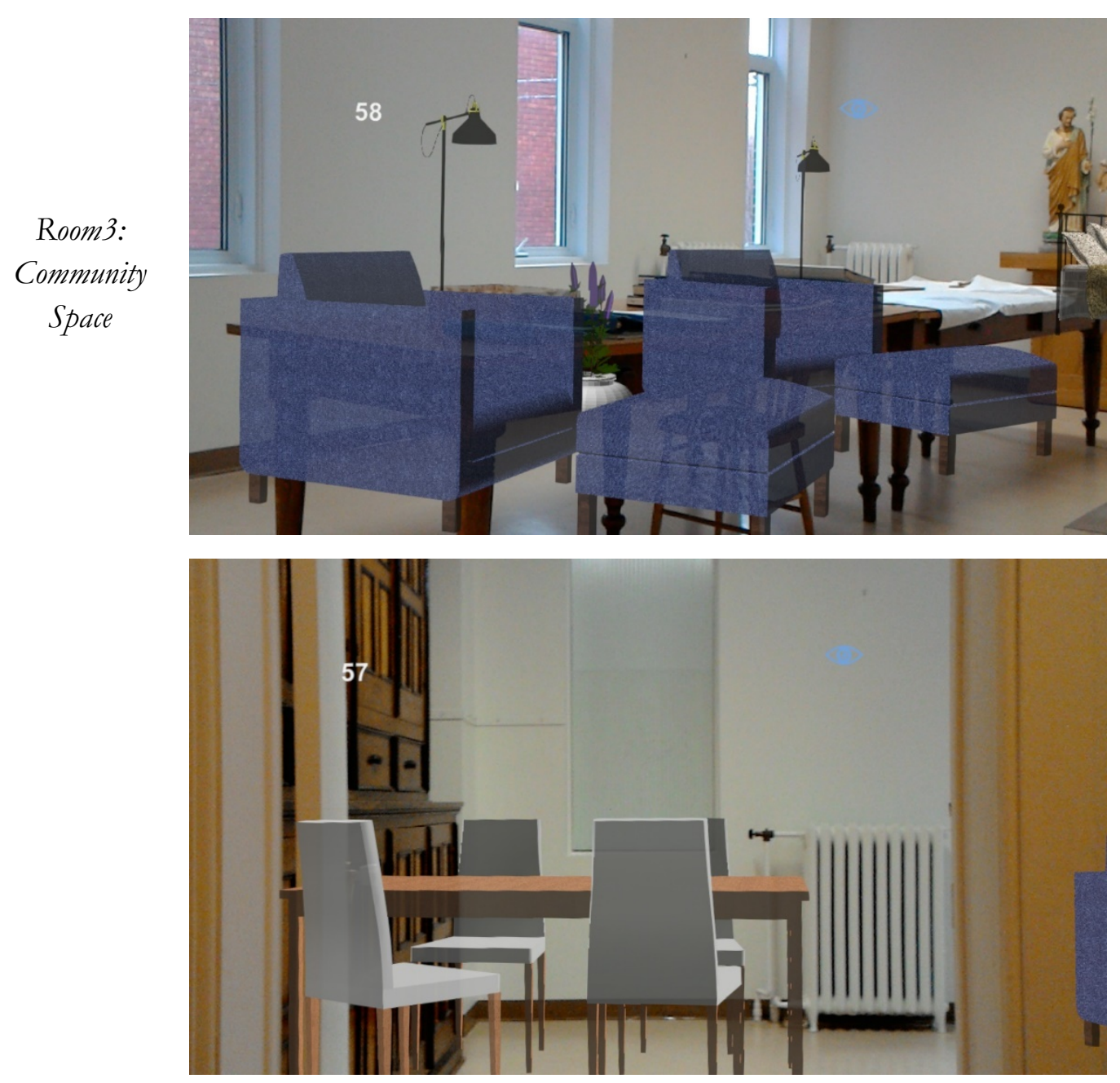

Figure 71: Congregation des Servantes de Jésus-Marie future uses 

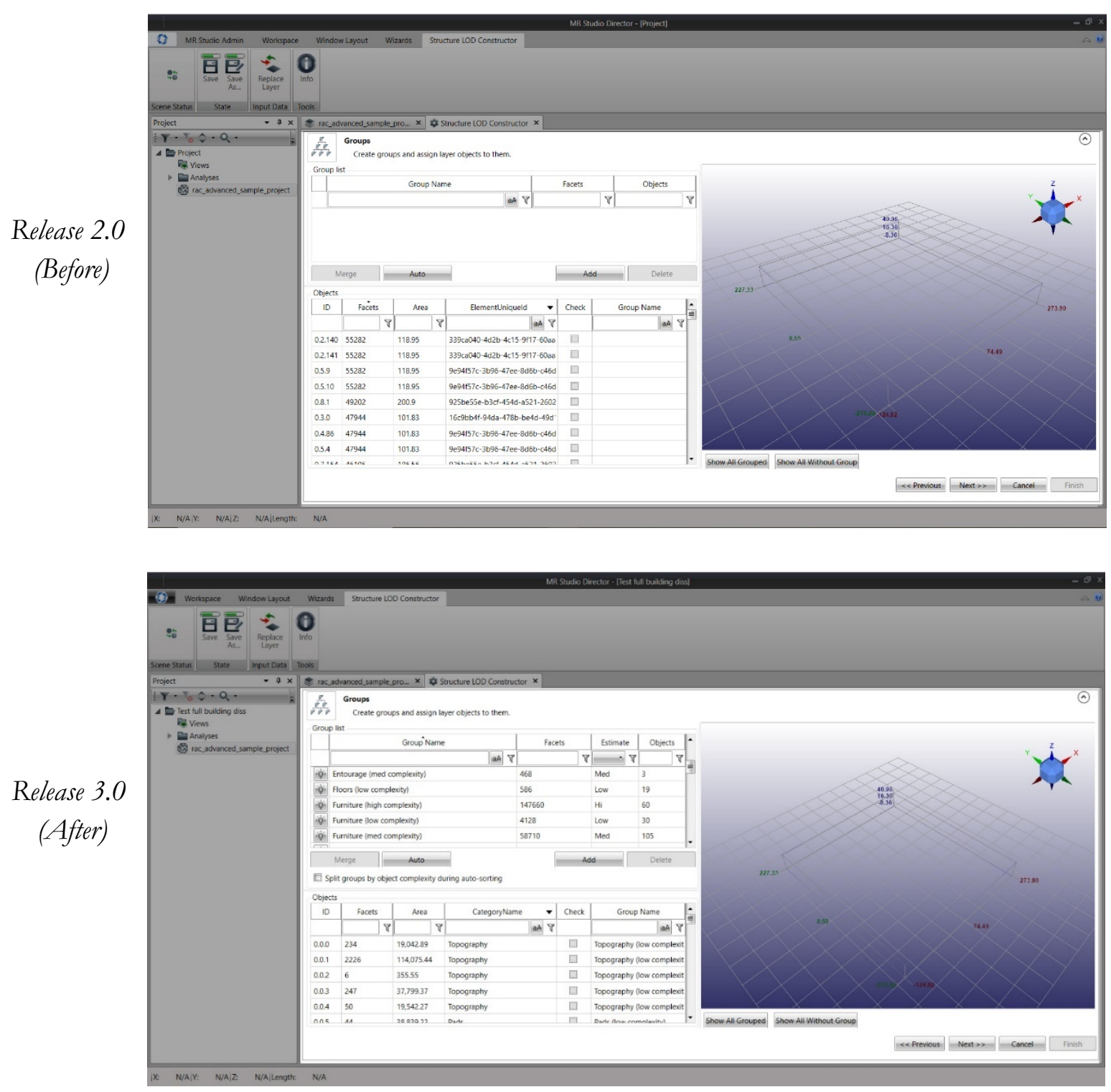

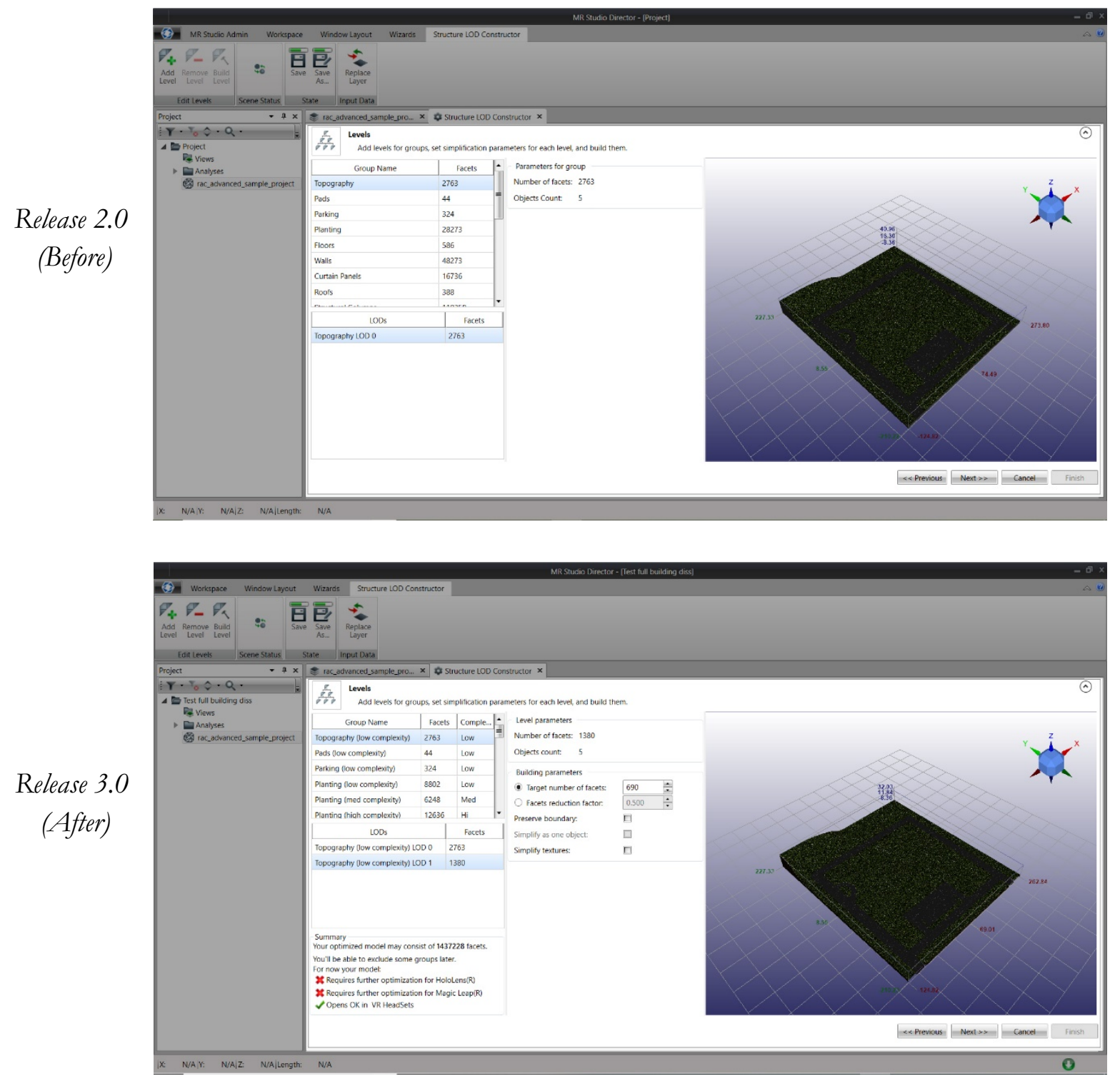

Figure 74: Wizard Constructor Tool 

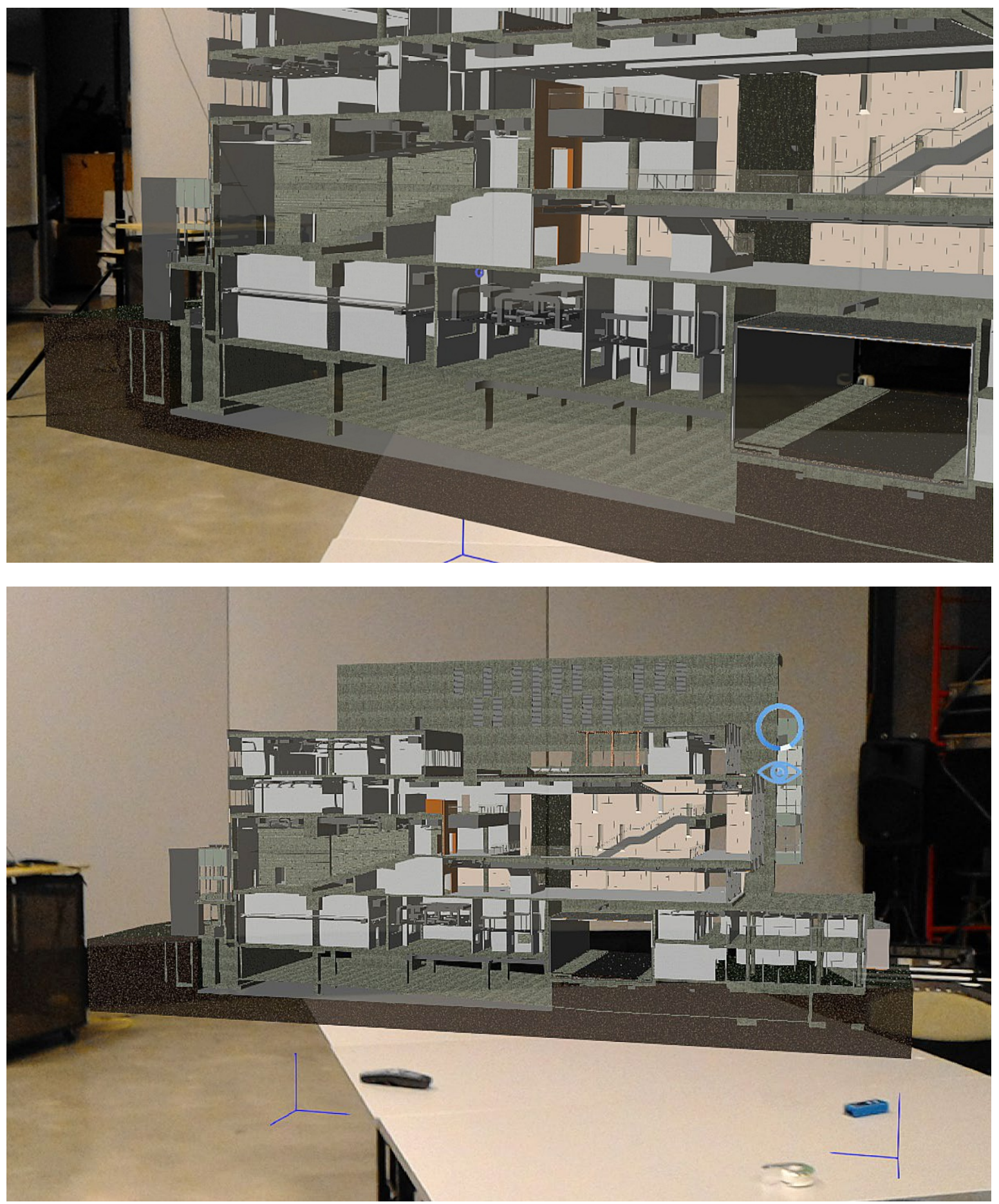

Figure 75: Carleton Richcraft Hall Building 
APPENDIX A

Key Terms 


\section{Virtual Reality}

Merriam Webster defines virtual reality as, "an artificial environment which is experienced through sensory stimuli (such as sights and sounds) provided by a computer and in which one's actions partially determine what happens in the environment." ${ }^{109}$ Virtual reality is widely used in various industries including education, military, medical sector, astronaut training, however, it is most commonly used in gaming and $3 \mathrm{D}$ cinema. The user gets immersed into the virtual world using a special head mounted device (HMD).

\section{Augmented Reality}

In 2015, a report in Huffington Post in 2015 suggests that augmented reality "provides an interactive experience of a real-world environment, but the objects in the real-world are "augmented" or increased through computergenerated perceptual information." ${ }^{\prime 10}$ Unlike virtual reality, augmented reality brings components of the digital world into a person's perception of the real world by overlaying digital data and objects on real environment.

\section{Haptic Feedback}

It is the simulation of the sense of touch. A familiar example is the vibration in a mobile phone or the rumble in a game controller. Many new technologies aim to improve haptic feedback to increase the user's engagement with the device. In addition, haptic feedback is essential for higher quality experiences especially in virtual reality or augmented reality.

\footnotetext{
${ }^{109}$ Merriam Webster, s.v. "virtual reality," accessed February 16 , 2019.

110 "Infographic: The History of Augmented Reality," Huff Post, October 25, 2016, , https://www.augment.com/infographic-lengthy-history-augmented-reality/.
} 


\section{Architectural Representations}

\section{Hologram}

Merriam Webster defines it as a "three-dimensional image reproduced from a pattern of interference produced by a split coherent beam of radiation such as a laser." 111 An introduction to the Microsoft HoloLens serves as the first untethered holographic computer.

\section{Cloud Computing}

The practice of storing, managing, and processing data over the Internet rather than a local server or a personal computer. Today, many applications and programs demand high engine speed. Instead of investing in upgrading computing devices, cloud-based services can be used to enhance performance speed.

3. Interpretation of the Nature of Mixed Reality

\section{Lightpack}

It is a small wearable computer device that is tethered to Magic Leap headsets. This portable device process has the necessary power to process high quality graphics required for the augmented reality experience. According to Magic Leap, "inside this engine is an integrated GPU and CPU that generates highfidelity, gaming-quality graphics to create next-level experiences." 112

\section{Facets}

In Geometry, facets are the number of planar surfaces that forms part of the boundary of a solid object.

${ }^{111}$ Merriam Webster, s.v. "hologram," accessed February 16, 2019.

112 "Magic Leap One: Creator Edition | Magic Leap," https://www.magicleap.com/magic-leap-one. 
The complexity of a shape results in high number of facets.

\section{Point cloud}

It is a collection of points that represent a 3D representation of a shape. Each point has its own set of $\mathrm{X}, \mathrm{Y}$ and $\mathrm{Z}$ coordinates. Using a 3Dd scanner, site's shapes are captured and turned into a cloud of data points- point cloud. In construction, point clouds offer the ability to align digital models with physical space in exacting detail.

\section{Towards a Harmonious Collaboration}

\section{Blobitecture Movement}

Also known as 'blobism', is a term given to a post-modern architectural style characterised by curved and rounded building shapes, or 'blob architecture'. ${ }^{113}$ Blobitecture buildings have organic form without traditional edges or symmetrical form. This type of architecture made possible by CAD software and was coined by Greg Lynn in 1995.

\section{Big Room}

The "Big Room" in construction refers to a large facility where all members of the project meet to address critical problems, therefore increases trust and collaboration among participants. However, one of the most demanding aspects of this concept is the physical presence of all team members. Today "Virtual Big Room" concept deploys workers through virtual technologies. In particular, Microsoft HoloLens supports remote collaboration feature that allows participants to virtually meet and discuss a construction project from the comfort of their office.

${ }^{113}$ John K. Waters, Blobitecture: Waveform Architecture and Digital Design (Gloucester, MA: Rockport, 2003). 
APPENDIX B

List of Microsoft HoloLens 1 Application 


\section{Formula One racing}

Guests are able to get additional information when they look at the car in the garage or during a race.

Instant remote collaboration in design reviews when experts are in two factories or in different countries.

2. The French National Center for Scientific Research (CNRS) and HoloForge Interactive

They created a color restoration experiment around the bust of the Pharaoh Akhenaton that allows the observer to examine it from every angle.

\section{Mixed River and NFL}

Help Baltimore Ravens better prepare for football games by developing a pre-game preparation platform that uses Microsoft HoloLens to give players holographic versions of practice.

\section{Airbus}

Passenger jet maker Airbus has created a Microsoft HoloLens app for its A350 XWB, to train engineers and cabin crews.

\section{Dance With fl $A R$ mingos}

An entertainment project that engages the audience in an animated line dance, "turning" humans into flamingos.

\section{Prism by Object Theory}

Application that allow participants anywhere in the world to have a shared experience to discuss 3-dimensional objects and environments in true 3D.

\section{Typography Insight application}

A HoloLens application that allows user to experiment and play with types in threedimensional mixed reality space.

Contains a spatial type layout and reference tools to learn and experiment.

\section{News Space}

It's a spatial news headline visualizer which fills up a physical space with he latest news headlines.

9. Department of Dance at Case Western Reserve University in Cleveland.

Audience see holograms on stage during the performance of an original piece titled Imagined Odyssey through HoloLens headsets.

\section{BMW's New X2}

Promotional experience that allows users to interact with a holographic model of the car, pain tit, or take a selfie with it.

\section{Tetra Pak}

Service engineers at this Swedish packaging firm use HoloLens to rapidly diagnose and fix machine issues even for remote locations.

\section{Dokodemo Anywhere Door}

A real-life teleportation door inspired by the Japanese cartoon Doraemon.

\section{Macllan party in New York City}

Gallery guests pun on HoloLens and walked around a custom-made art installation that brought to life different stages of the whisky making process.

\section{Holo-Cow}

A holographic, interactive cow brought into the classroom at Harper Adams to boost learning by embracing latest technologies.

\section{Black Marble and tuServ}

TuServ's Scene of Crime application has been developed with operational police 
officers using HoloLens to help officers in the field place virtual markers, trace 3dimensional objects, and gather multi-media evidence eliminating the risk of disturbing the physical evidence at a scene.

\section{CyberSnake}

A game of mixed reality environment game played in first person and inspired by the 2dimensional snake arcade.

\section{MyLab}

An application that connects between chemistry textbook concepts and the observational experiments by offering an interactive periodic table which also visualizes the hidden structures of the elements.

\section{Halo Recruit}

A mixed reality first-person project that allows gamers to see and play around in the sci-fi universe.

\section{Thyssenkrupp Elevators}

An instant generation of a 3-dimensional holographic lift shown instantly to the customer. The engineer adjusts the model as needed and gets a final approval on the spot. This process has already been applied in over 100 homes during a pilot project in Holland, Spain, and Germany.

20. Teleport to Arctic Alaska.

Exhibition of holograms that takes the user to a faraway Arctic marsh.

\section{Tom River Municipal Utilities Authority (TRMUA)}

First mixed reality utility that guides fieldworkers in locating underground utilities.

\section{Cappasity}

In-store browsing experience to online retail.

\section{MSPoweruser}

face recognition application that uses Microsoft's cloud-based cognitive toolkit to identify and annotate people in their environment.

\section{Volumetric Capture}

A technique used to film footage in three dimensions for viewing in a virtual or mixed relaity headsets

\section{Myxd3D}

The world's first holographic chat application for HoloLens.

\section{HoloLens RoomScan}

Application that captures a full-color 3dimensional model of any room and shares it with others for interactive conversations.

\section{HoloFlight}

An application that provides flight tracking data of every plane in the sky. It takes flight data and renders it on a holographic globe. User can zoom in and out to look at specific areas and watch planes travel from one location to another.

\section{White Cane}

An application that spatially maps a room and determines the distance of any objects through sound.

\section{International Space Station}

Part of NASA's Sidekick project to provide assistance to station crews when and where they need it. According to NASA, this new capability reduces crew training requirements and increases the efficiency at which astronauts can work in space.

\section{0. apoQlar VSI}

it is a Virtual Surgery Instructor (VSI) designed to help real surgeons navigate better during surgeries. The HoloLens recognizes 
anatomical structures and, through anatomical landmarks recognition, simultaneously graphically displays the details of the performed operation itself.

\section{Hologarage}

A car maintenance demo of a professional mechanic performing on a BMW MINI R56 at Y's Garage in Japan.

\section{Ford Modern Workplace}

Ford designers blend 3D holograms digitally with both clay models and physical production vehicles which allowed them to experiment much faster without having to physically build every design prototype.

\section{Surgical Assistance}

An application developed by three Biomedical Engineering students from Xidian University in China. They worked with children suffering from congenital heart disease to develop a medical imaging processing platform that allows for both $2 \mathrm{D}$ and $3 \mathrm{D}$ visualization.

\section{Holo-Grid: Monster Battle}

A holographic chess-style game using animated monsters and other iconic creations from the film Star Wars.

\section{Palmer High School}

uses mixed reality technology in classrooms for collaboration and hands-on experience in animation, programming, and 3D modeling and design.

\section{Yu-Gi-Oh}

A game that uses use holographic projections of trading cards.

\section{HoloMind}

3-dimensional mind mapping that allows users to break down large problems into components to visualize them in different ways.

\section{CWRU and Boulevard Arts}

A museum application with HoloLens that allows user to see holograms of paintings and historic objects ad other people whether in the same physical space or connected virtually.

\section{Reggie Watts Holograms}

A mixed reality music video that featured holograms of Reggie Wats.

\section{Sketch AR}

Similar to the iPhone app under the same name, this MR application allows the user to bring up various drawings and project them into the real world to be traced.

\section{Legion}

An experience using the HoloLens to put viewers into the eyes of lead character David Haller, a diagnosed schizophrenic who discovers he is a super powerful mutant instead.

\section{Super Mario Bros}

A recreation of Mario Kart game completed with real-life go karts and virtual coins and bombs.

\section{TRACE}

An investigation tool developed by students from the University of Washington Interactive Design Program to scan and preserve crime scenes in $3 \mathrm{D}$, annotate important exhibits, process clues, enable walkthroughs and visualization, and allow collaborative investigations.

\section{Echelon}

A multiplayer mixed reality boardgame created by Helios Interactive as proof of concept.

\section{The Transformation Mask}


Heiltsuk artist Shawn Hunt collaborated with a group of developers at The Garage to create an experiential sculpture that transforms a person into a raven.

\section{Sturmtiger $A$}

demonstration of a WWII tank showcased at TankFest 2017 by Wargaming.

\section{Holograms from Syria}

An art project that integrates holographic images from the war in Syria into the viewer's physical space.

\section{Toy Soldier and Rabbid Rockets}

Games prototypes by Ubisoft.

\section{Canberra Grammar School in Australia}

Chemistry students interact in 3D with the atomic structure of elements in the periodic table.

\section{Lifeliqe}

Free educational application designed to tech $\mathrm{K}-12$ sciences.

\section{London Fashion Week}

World's first holographic dressing room designed by the designer Sabina Rachimova.

\section{Touch Surgery}

Innovative platform, which helps surgeons learn and practice an operation without the need for an actual patient.

\section{Asobo}

A holographic crane simulator for construction training.

\section{CapitolaVR}

It employs a rapid prototyping strategy that allow teams to quickly develop and test ideas, and to customize and control Mini cars.

\section{Scope AR}

A WorkLink platform that enables users to help remote workers learn to repair or assemble complex machinery.

\section{Rooted in Exception}

An experience for Remy Martin's drinkers to educate them on the refined production process. The brand teamed up with Kazendi to create a unique, interactive presentation that traces how the beverage is made.

\section{Portal}

It is a famous video game that was brought to HoloLens by Toronto developer Kenny Wang.

\section{HoloTower}

A new HoloLens Software from 360 World used to free up space with customizable holographic 3D virtual panels.

\section{Concrete Storm}

An installation created with Microsoft in collaboration with Artsy. While wearing the HoloLens, viewers enter a mixed reality, enlivened by responsive holograms that augment physical environment of the installation.

\section{Netflix}

Netflix has plans to support HoloLens. Their objective is to provide a great experience to all Windows app users in a variety of devices including "HoloLens and VR devices.

\section{X-ray vision}

Cambridge Consultants announced the development of an AR surgical System that allows doctors to see inside their patients 
while operating (in real time) through minimally invasive openings.

\section{Charite Medical University in Berlin}

The HoloLens is used during a resection of the liver. The 3D model of the organ is generated before the operation and placed above the patient. Whenever the main surgeon has a question regarding blood vessel, the assistant wearing the headset consults the model and has a precise answer within seconds.

\section{University of Houston Mechanical Engineering}

A software that is used to aid engineers in visualizing and interacting with their ideas by creating a holographic topographical map of the Gulf of Mexico to visualize where the oil pockets are.

\section{Boeing and Wildfires}

The HoloLens is used to convert INEXA Control's 2D maps into an accurate 3D map of hazardous areas like the location of wildfires. Fire chief has is able to make decisions while keeping humans on site safe. multiple HoloLens users can access the map at the same time and coordinate with one another.

\section{State-of-the-Future}

An anatomy laboratory created in Case Western Reserve and Cleveland Clinic where medical students use the HoloLens to see body's organs and systems, and to collaborate with their long-distance professor.

\section{Cirque du Soleil}

A method for the acrobatic entertainment company to test out stage setups and choreography in augmented reality using HoloLens.
Gensler, the largest design and architecture firm in the world, used SketchUp viewer of HoloLens to virtually experience and inhabit holographic designs.

\section{Air New Zealand}

The airline has partnered with Dimension Data to develop custom HoloLens software that supports cabin crew by overlaying data onto flight attendants. Th data consists of the customer's preferred mean, drinks choice, onward travel, loyalty membership, and can detect their emotion based on their visual and audio cues.

\section{Virtual Geology}

Washington University's Department of Earth and Planetary Sciences is transforming education with the opening of the Virtual Geology Lab. This allows students and scientists to examine exquisite minerals and geological wonders.

\section{Cortana Intelligence}

Envisioned by Lowe's and Microsoft, an application that shows how to use telemetry emitted by HoloLens to understand the [virtual] places that customers are gazing at, as they experience an immersive home remodeling experience in $3 \mathrm{D}$, using the augmented reality capabilities of HoloLens.

\section{SketchUp Viewer}


APPENDIX C

MR Studio Director: Revit User Guide Release 3.0 


\section{Open 3D View of your Revit model:}

- View > 3D View

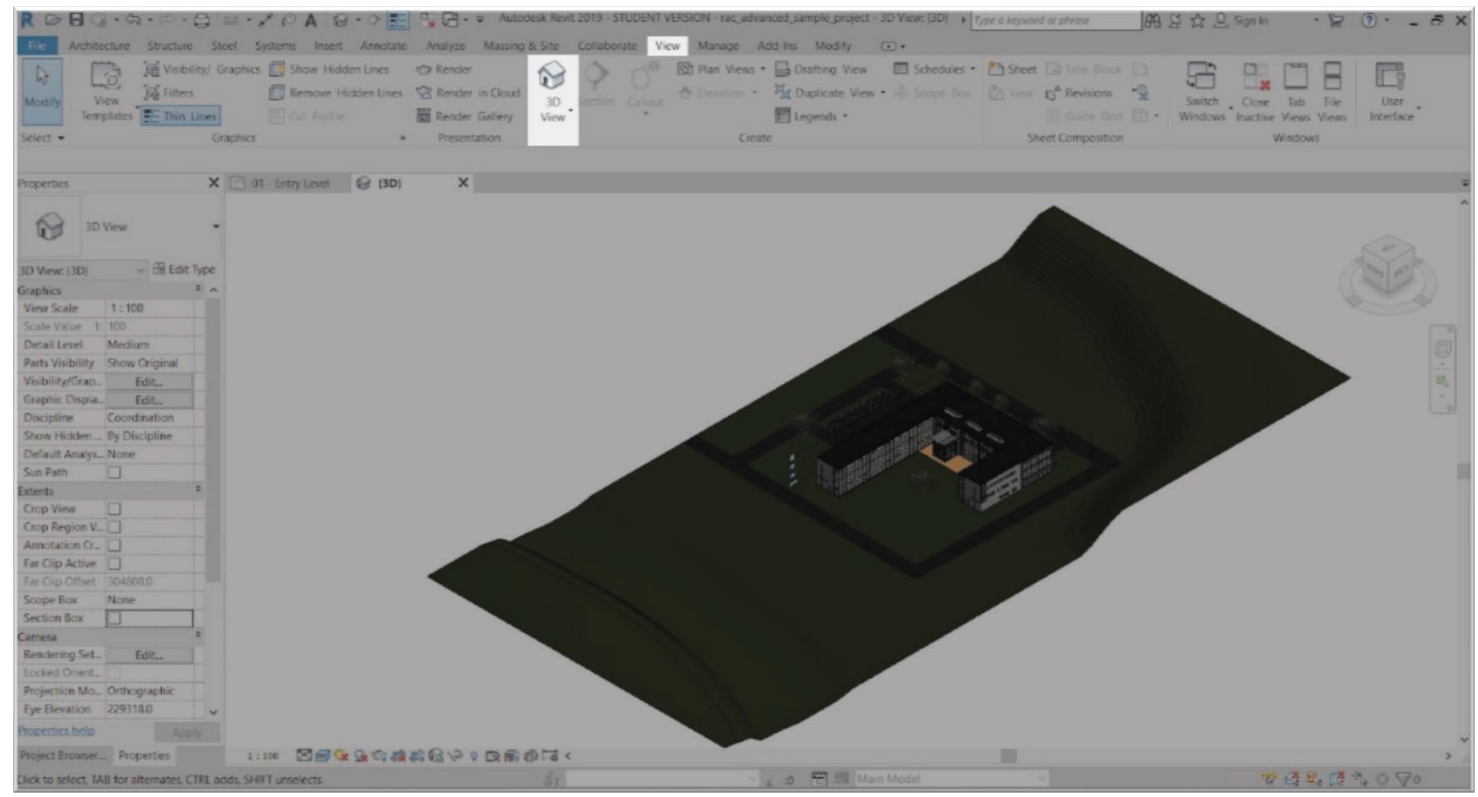

2. Crop view

- Use "Section Box" to crop the model and reduce the number of elements that will be exported.

- Properties palette* $>$ Extents $>$ Section Box $>$ Apply

- Select the "Section Box" and use the drag controls to modify the extents, as necessary

*If "Properties" palette is hidden, click Modify > Properties

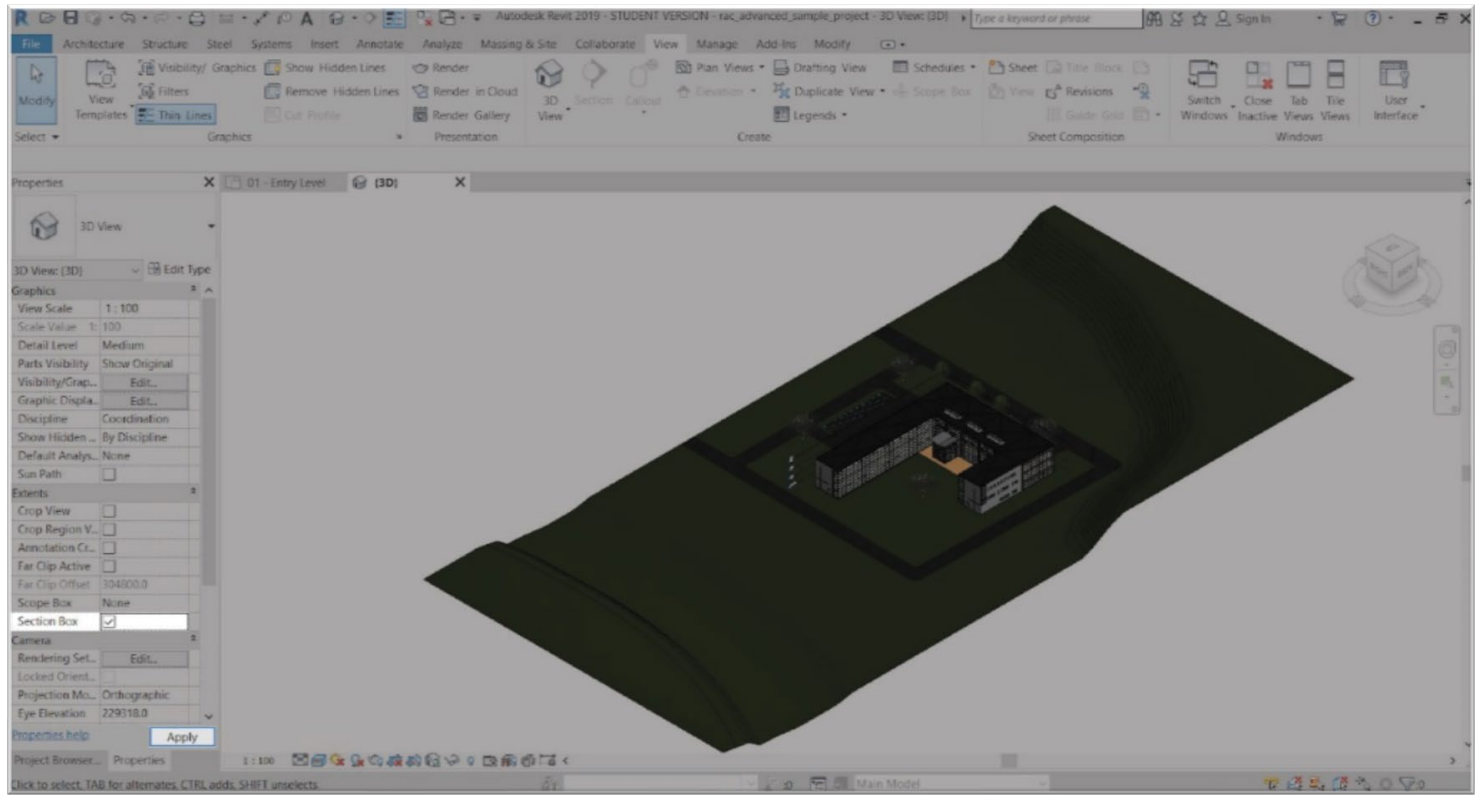



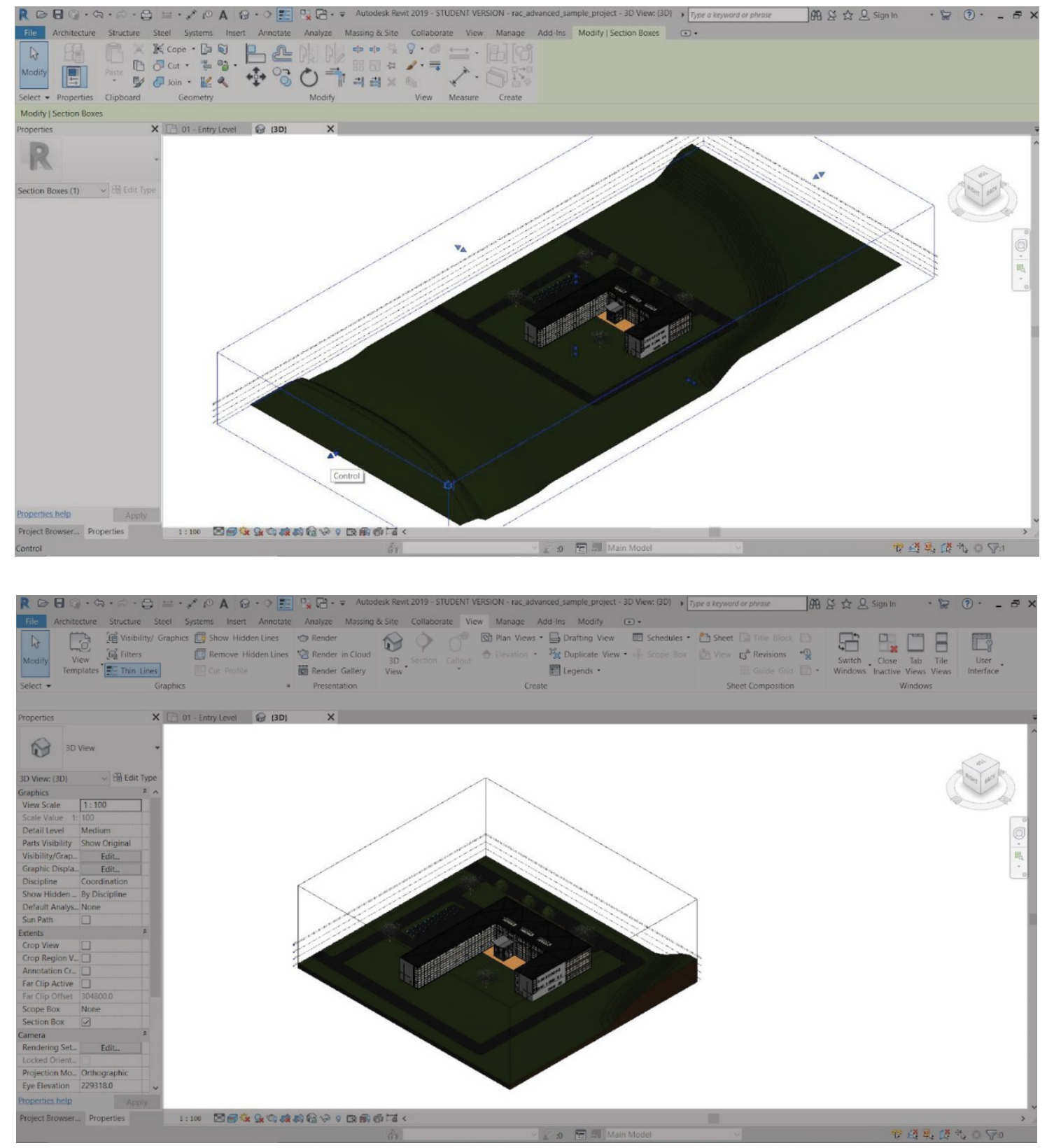
- If section box is not visible even if it was enabled. Check "Reveal Hidden Elements" to reveal it. - Reveal Hidden Elements> select the hidden element "section box" > right click > "Unhide in View" > "Elements" > select "Reveal Hidden Elements" to exit hidden mode.
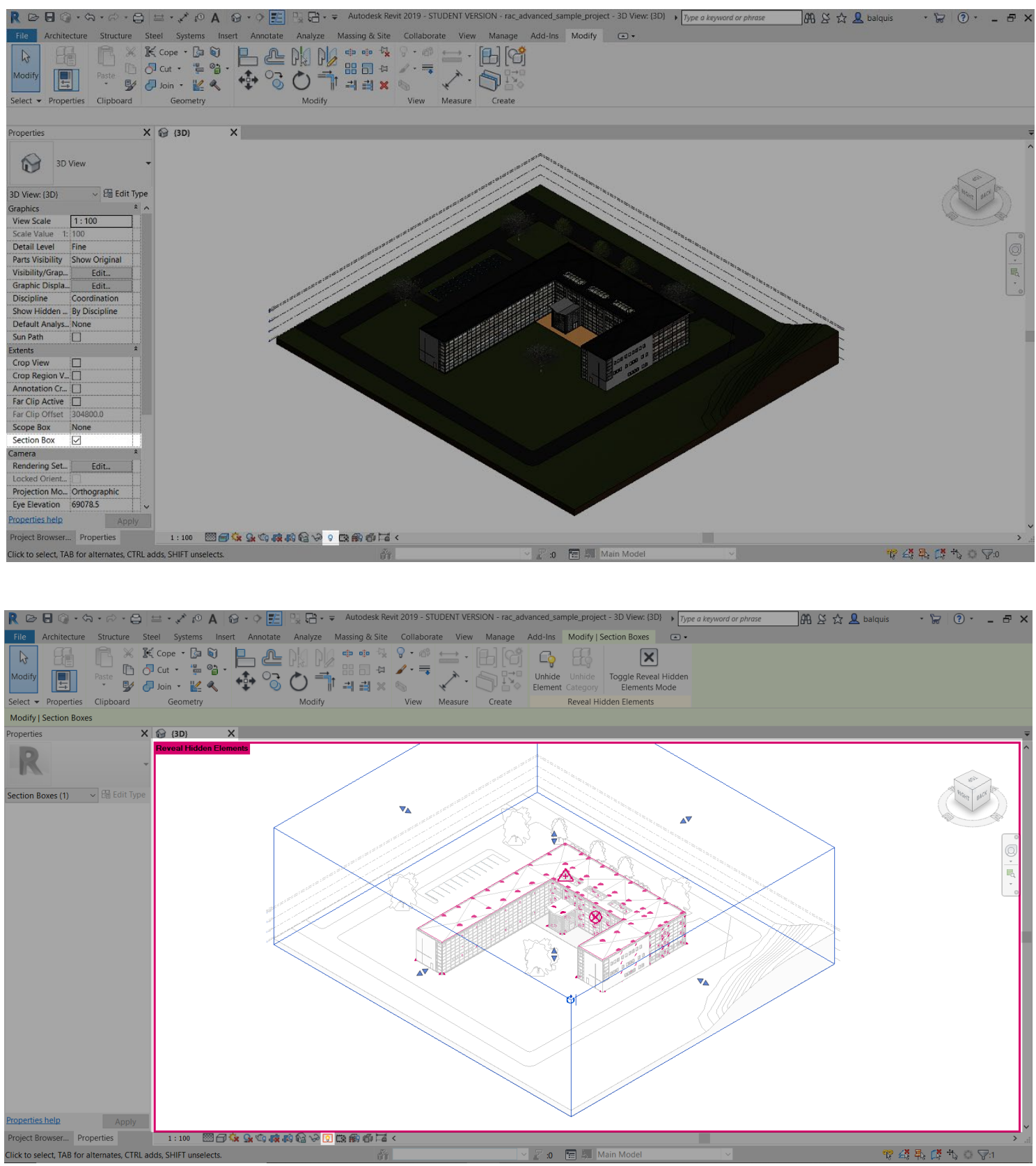

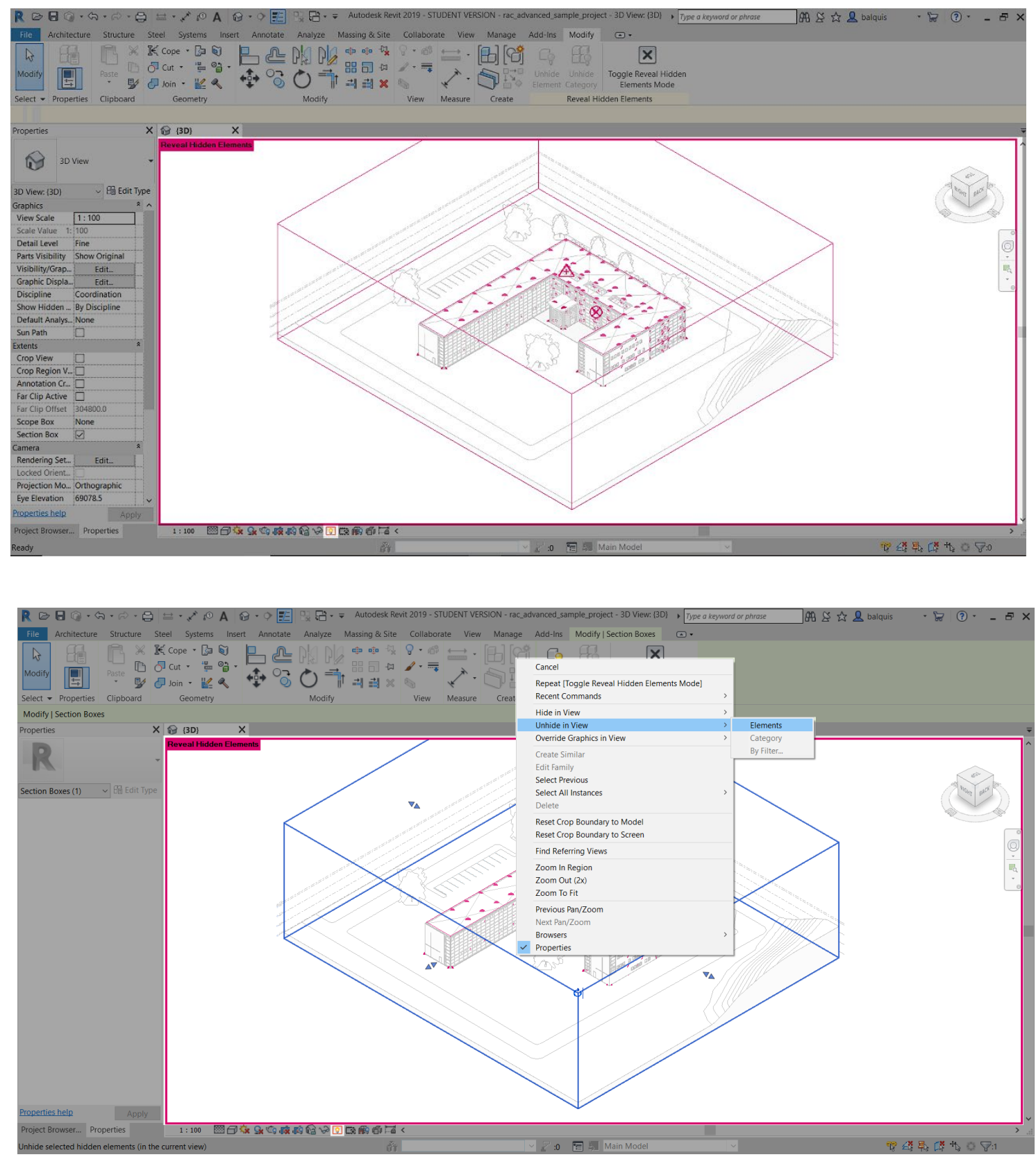

\section{Hide Category}

- Railing, furniture, generic models, structural columns, electrical and lighting fixtures tend to be the most complex objects. If they are not a necessity, hide them before exporting. If they are a necessity to your immersive experience, a further model optimization may be required through MR Studio Director (see Wizard Guide).

- Turn off/ hide categories that you do not need to export.

- If there is a category you wish to hide:

View $>$ Visibility and Graphics $>$ Model Categories $>$ Visibility

- Navigate through categories and uncheck the box next to the one you wish to hide. 

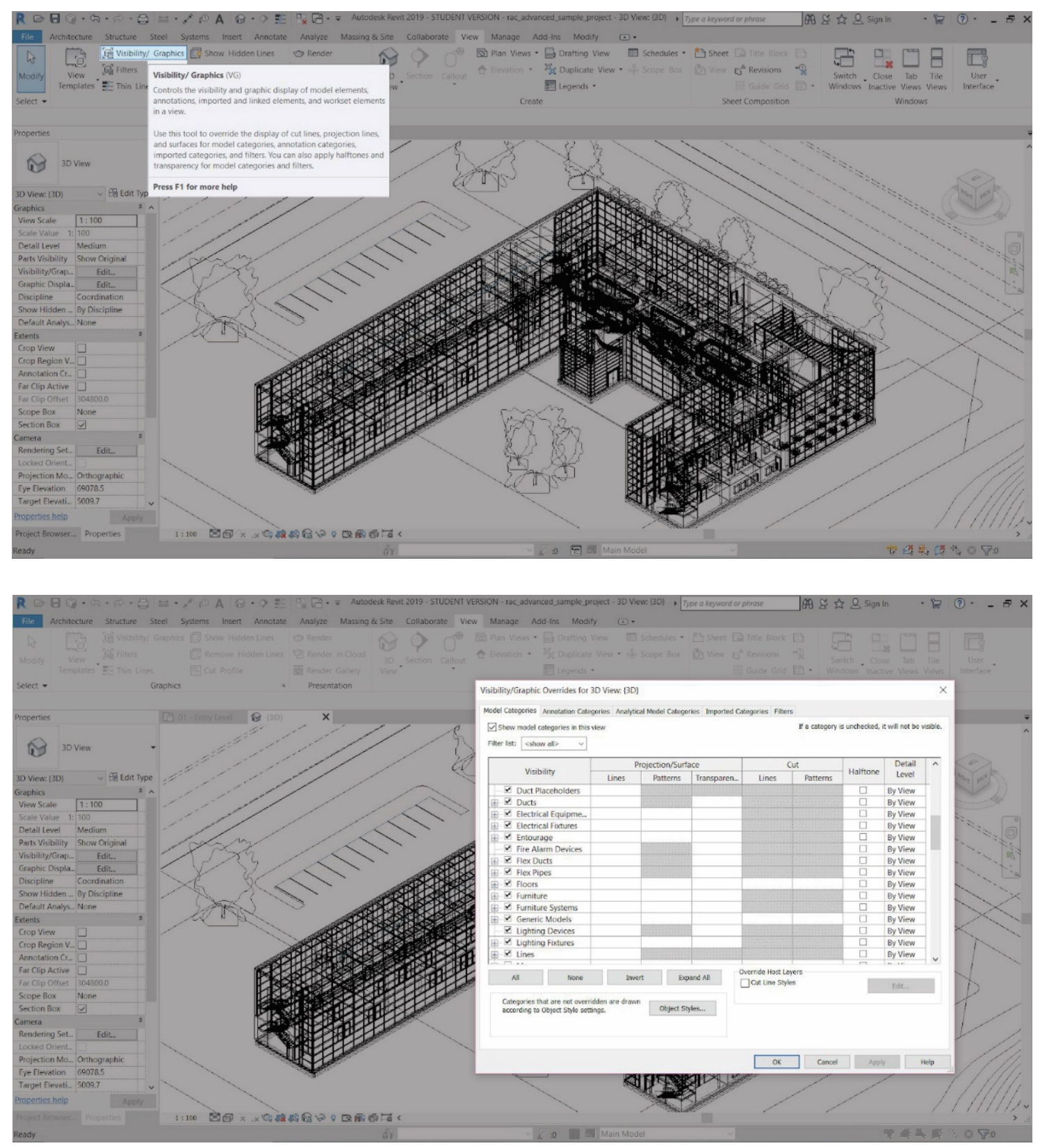


\section{Hide Elements}

- Instead of hiding an entire category, you can hide specific elements that you do not need to see in your MR experience.

- If there is a specific element you wish to hide: select element > Temporary Hide/Isolate View
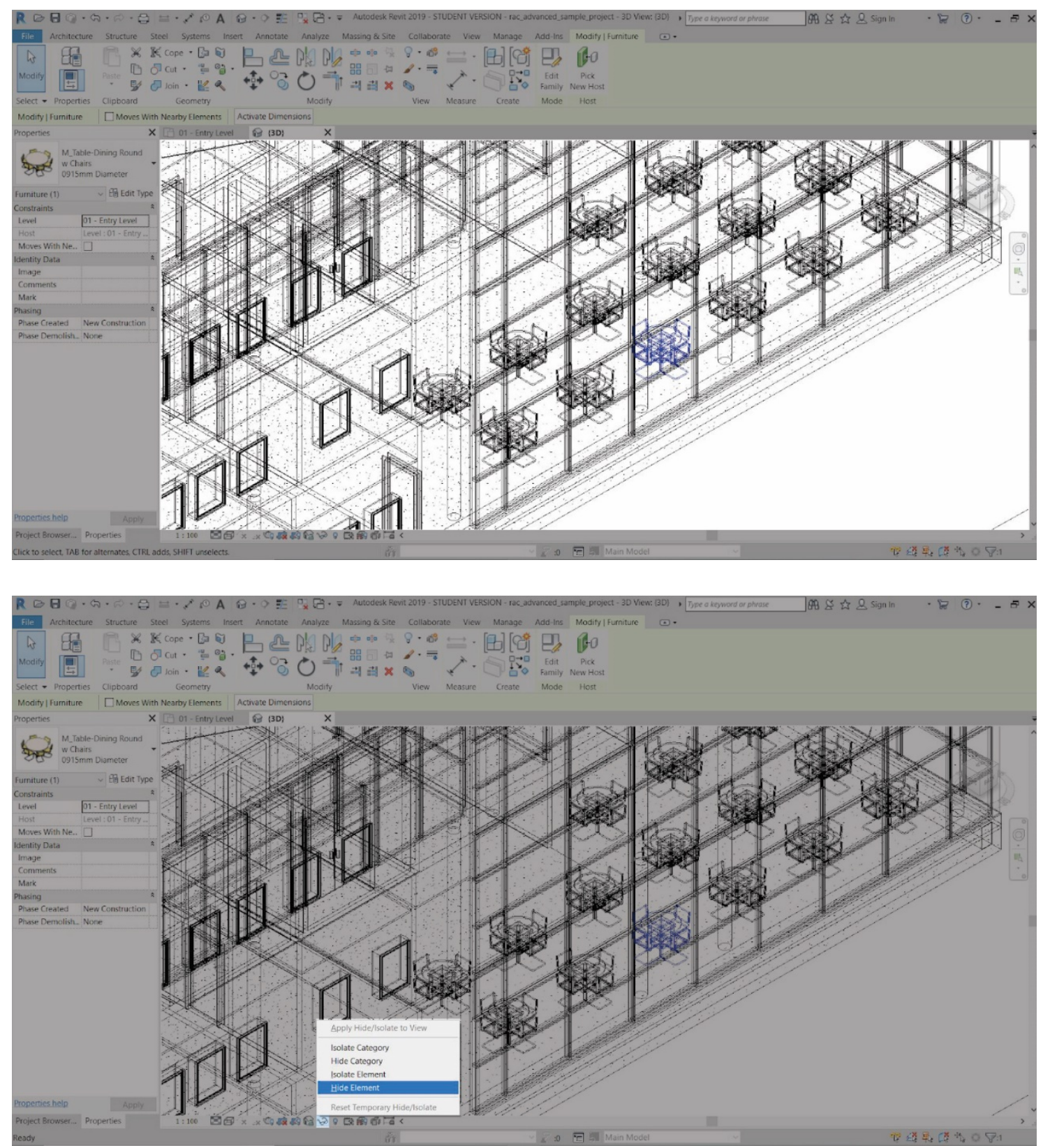
-As shown above, elements were selected while the model was on "wireframe mode". This mode helps to navigate through the model faster.

-To enter wireframe mode: Visual Style > Wireframe
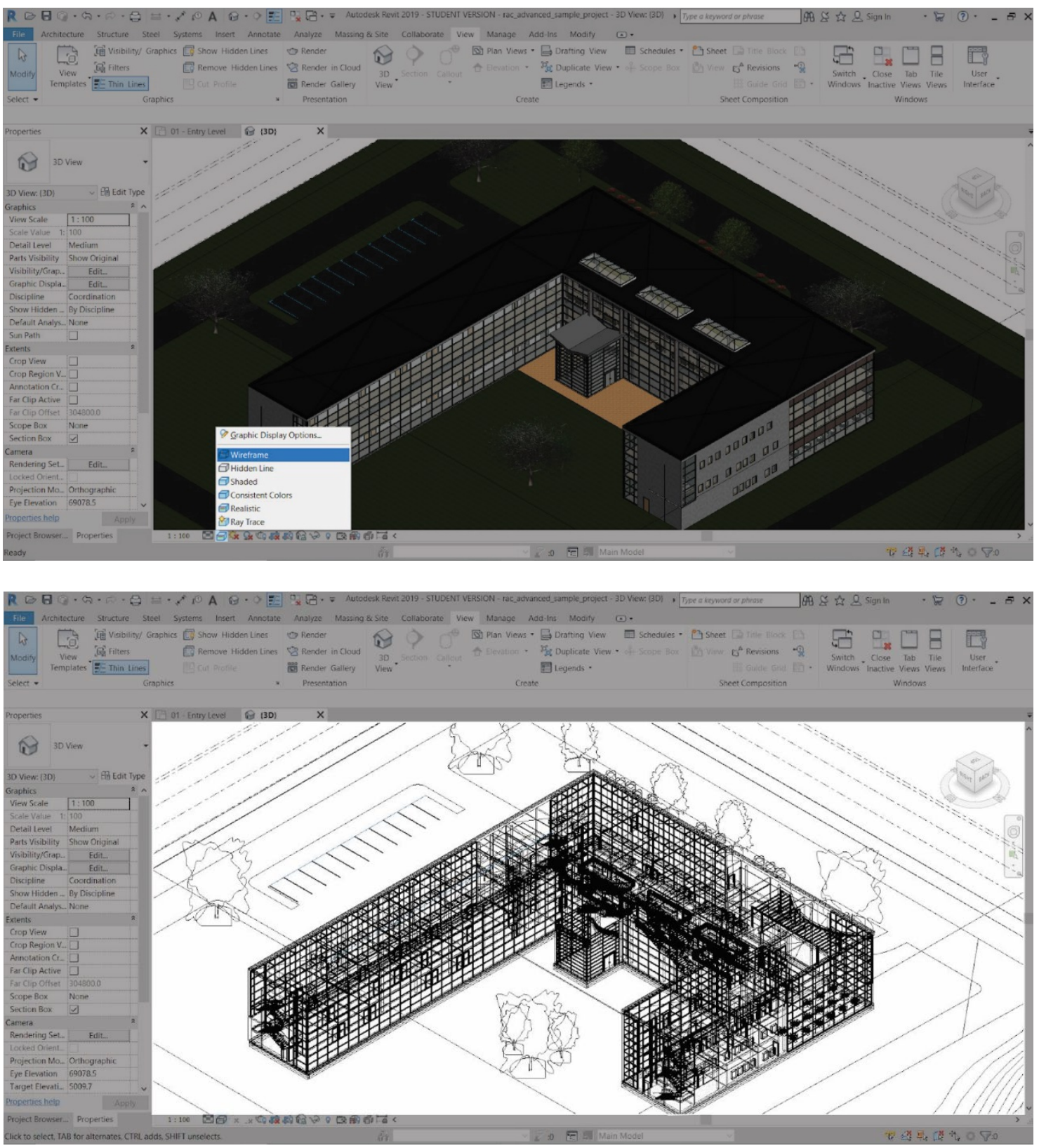


\section{Export}

- The model is ready to be exported through Arvizio's Revit plugin.

- Add-Ins > XSF Exporter for Revit > Save

- Exported model will always be in "Realistic" mode regardless of the "Visual Style" it was exported at.

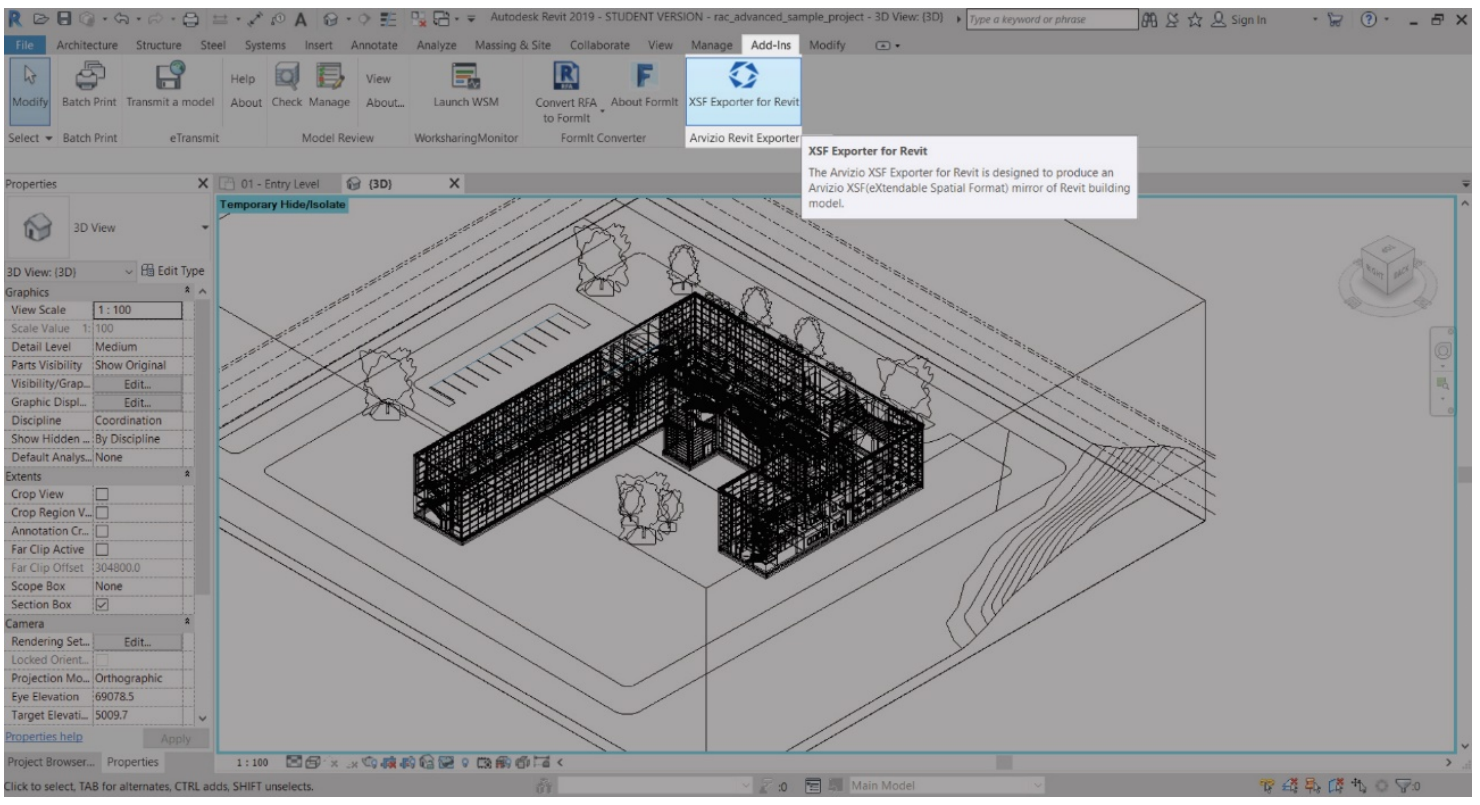

\section{Revit to MR Studio Director}

\section{Import model to MR Studio Director}

- New Project $>$ select Name and Path $>$ right click in "Project Panel" $>$ Import $>$ locate the model.

\section{Check number of facets}

- Different Mixed Reality and Virtual Reality headsets allow a limit to the number of facets (geometry) to achieve the finest virtual experience.

- Project Panel > right click on the model > Properties > Number of Facets 

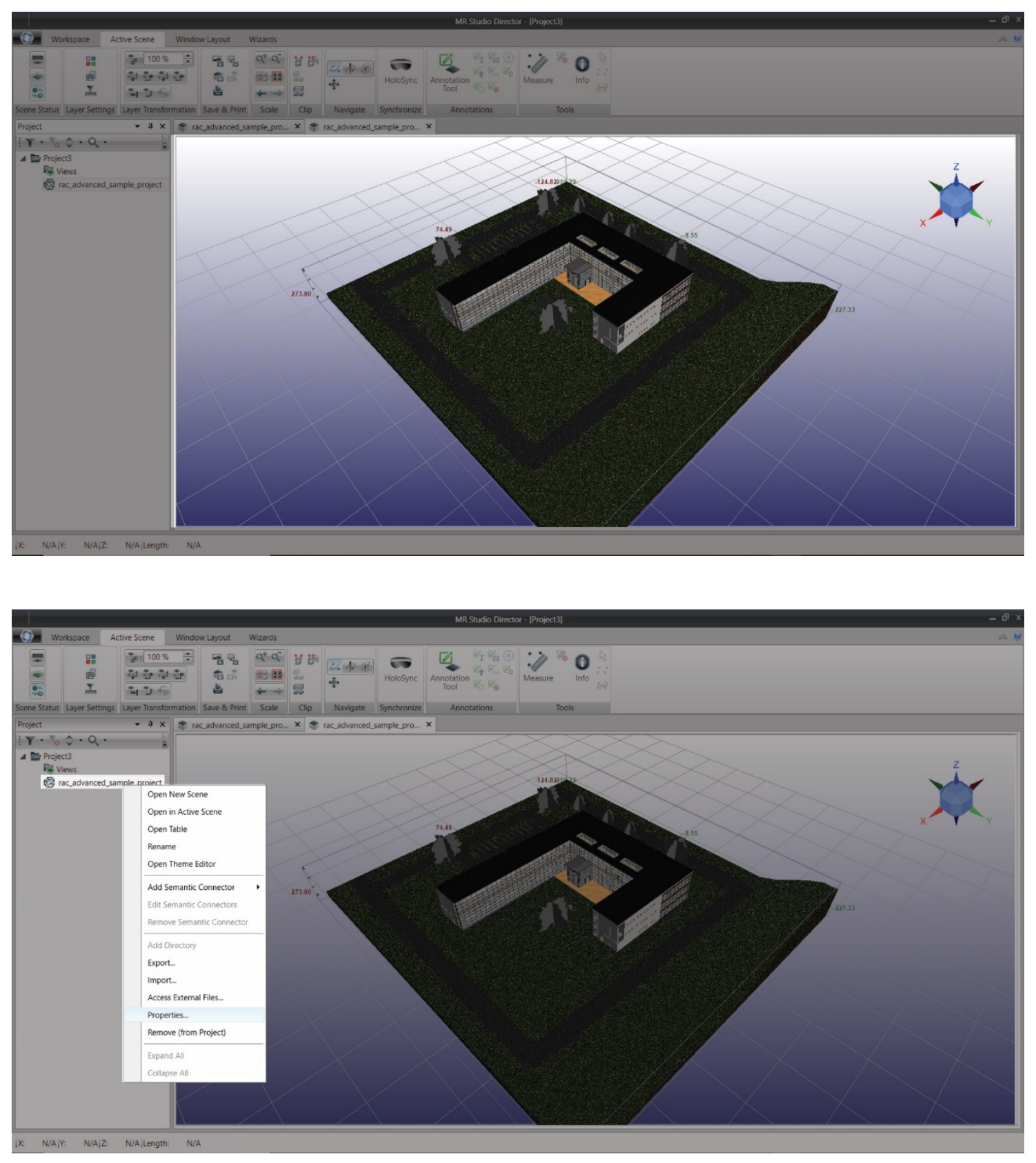


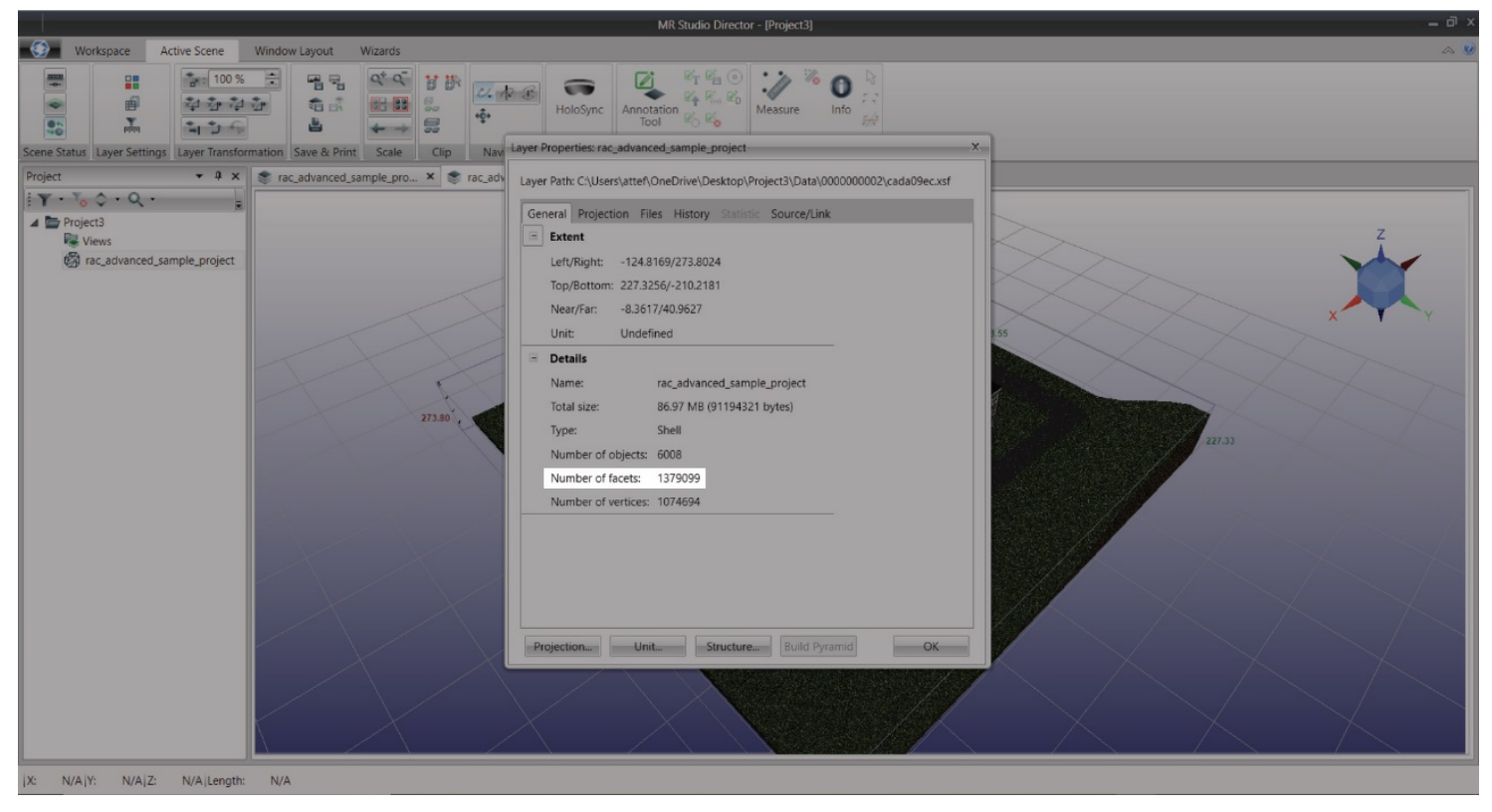

- If the number of facets exceeds your head device allowance, further optimization is required through MR Studio Director (see Wizard Guide). 
MR Studio Director: Wizard Guide Release 3.0 


\section{Wizards: MR Studio Platform Optimization Tool}

1. Launch Wizard optimization

- wizards > Structure LOD Constructor

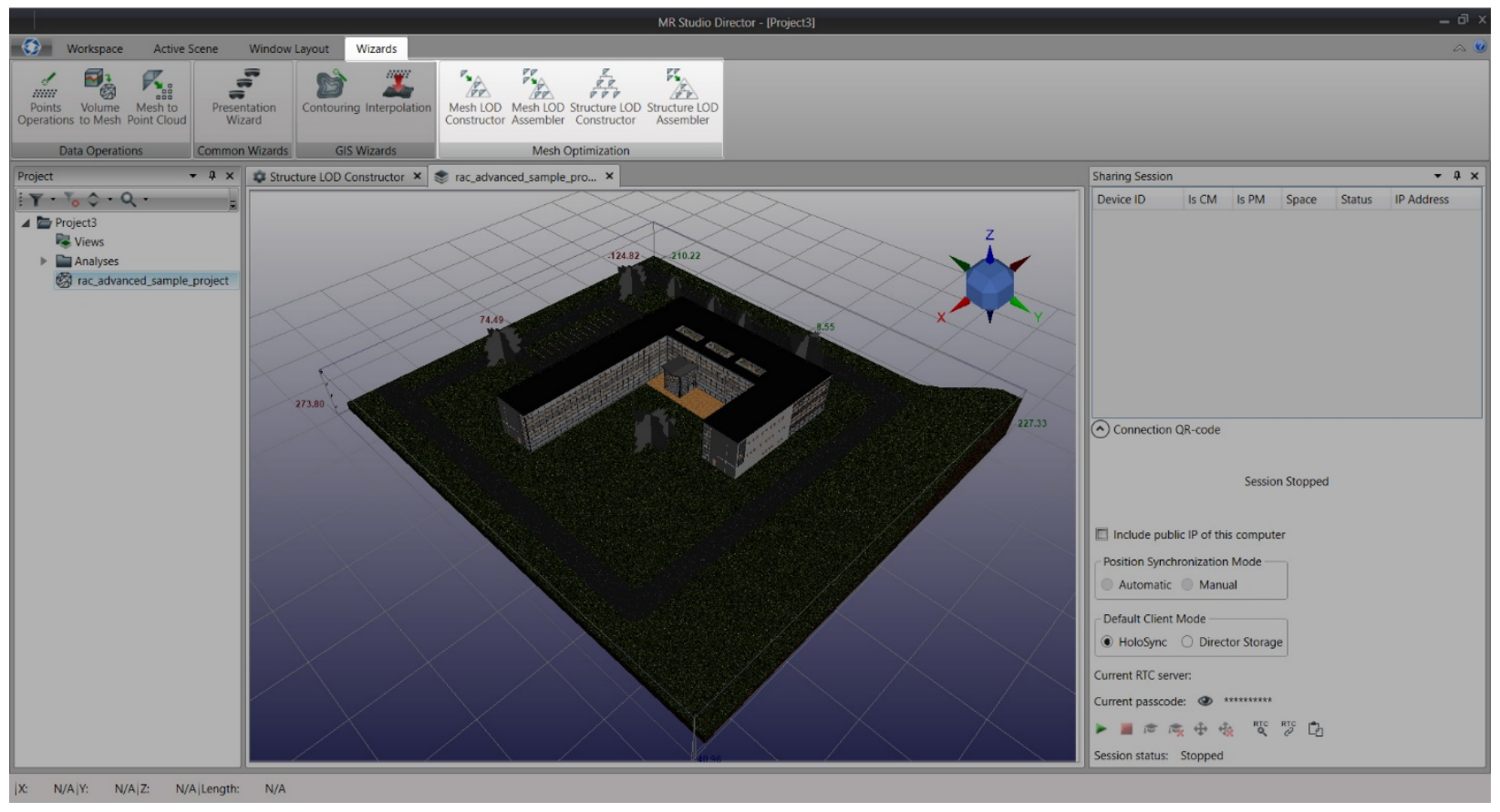

2. Select output folder $>$ Next

- MR Studio Director generates a new output folder whenever "Structure LOD Constructor" is launched.

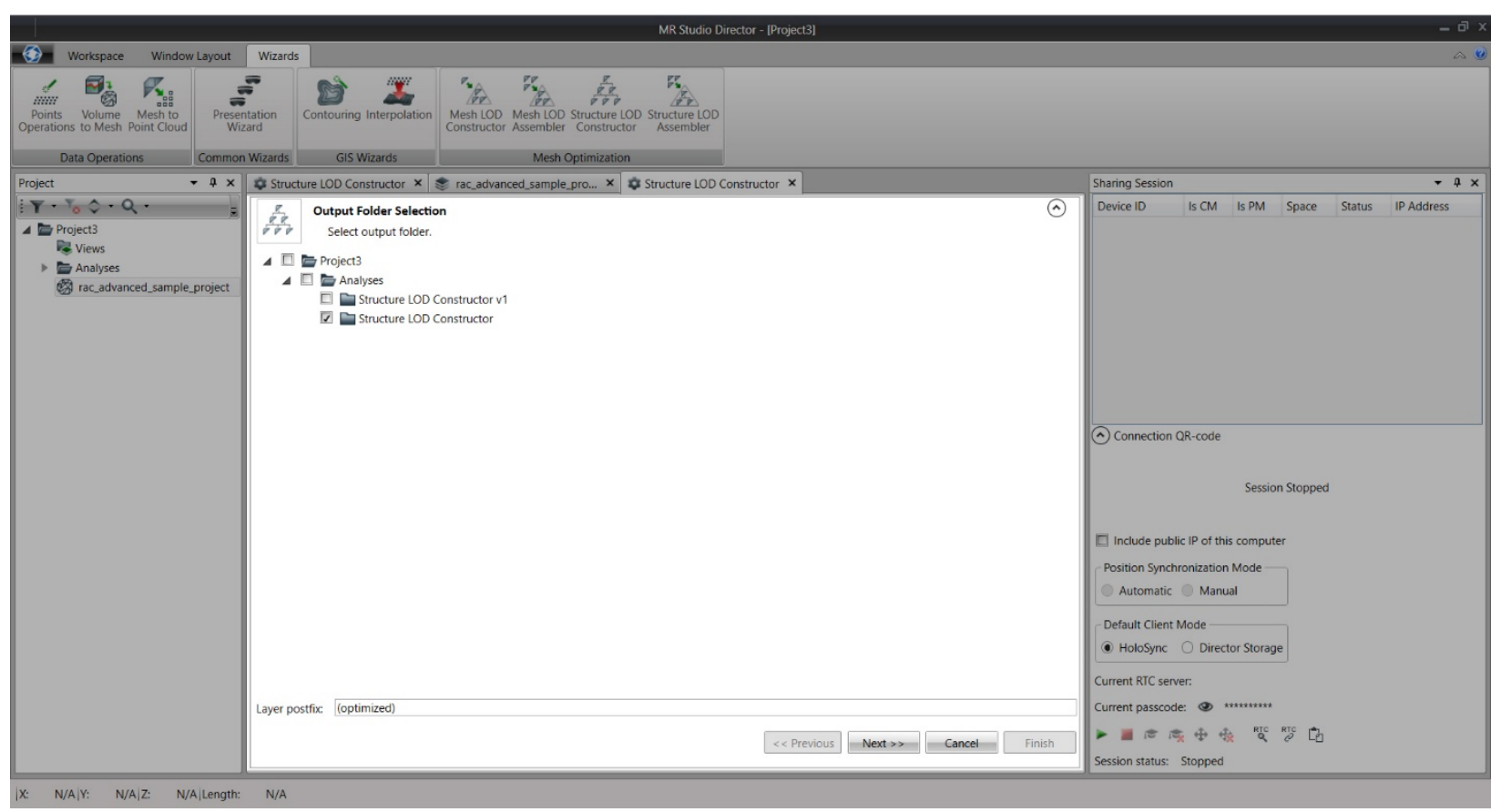




\section{Select input data $>$ Next}

- select the project you wish to optimize.

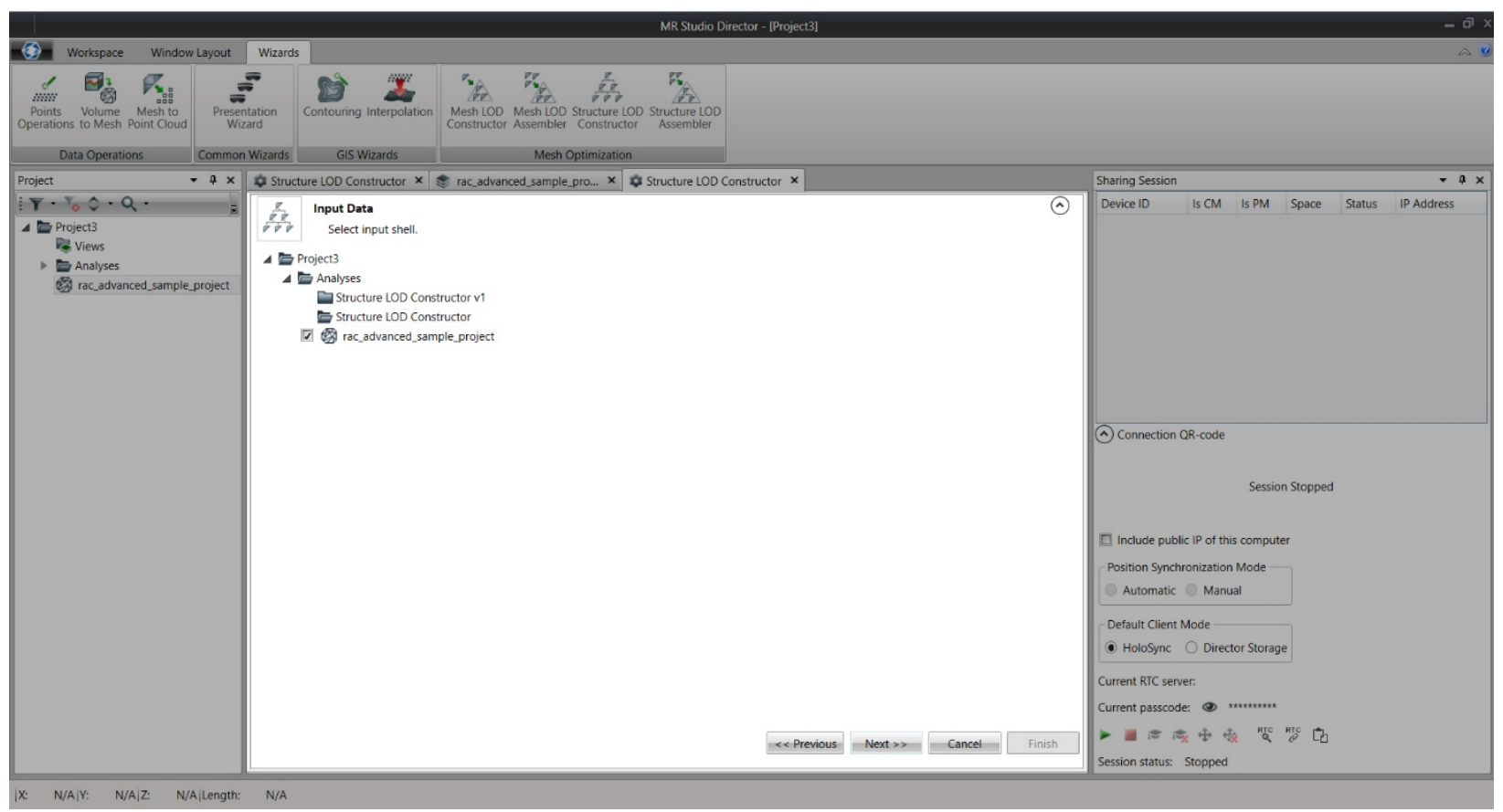

\section{Automated message}

- follow the automated messages instructing you through the auto-grouping feature.

- "Wizard" groups Revit model based on their Revit Category name. This is useful to then decide what group needs more optimization than others based on their facets density and relevance to the Virtual experience.

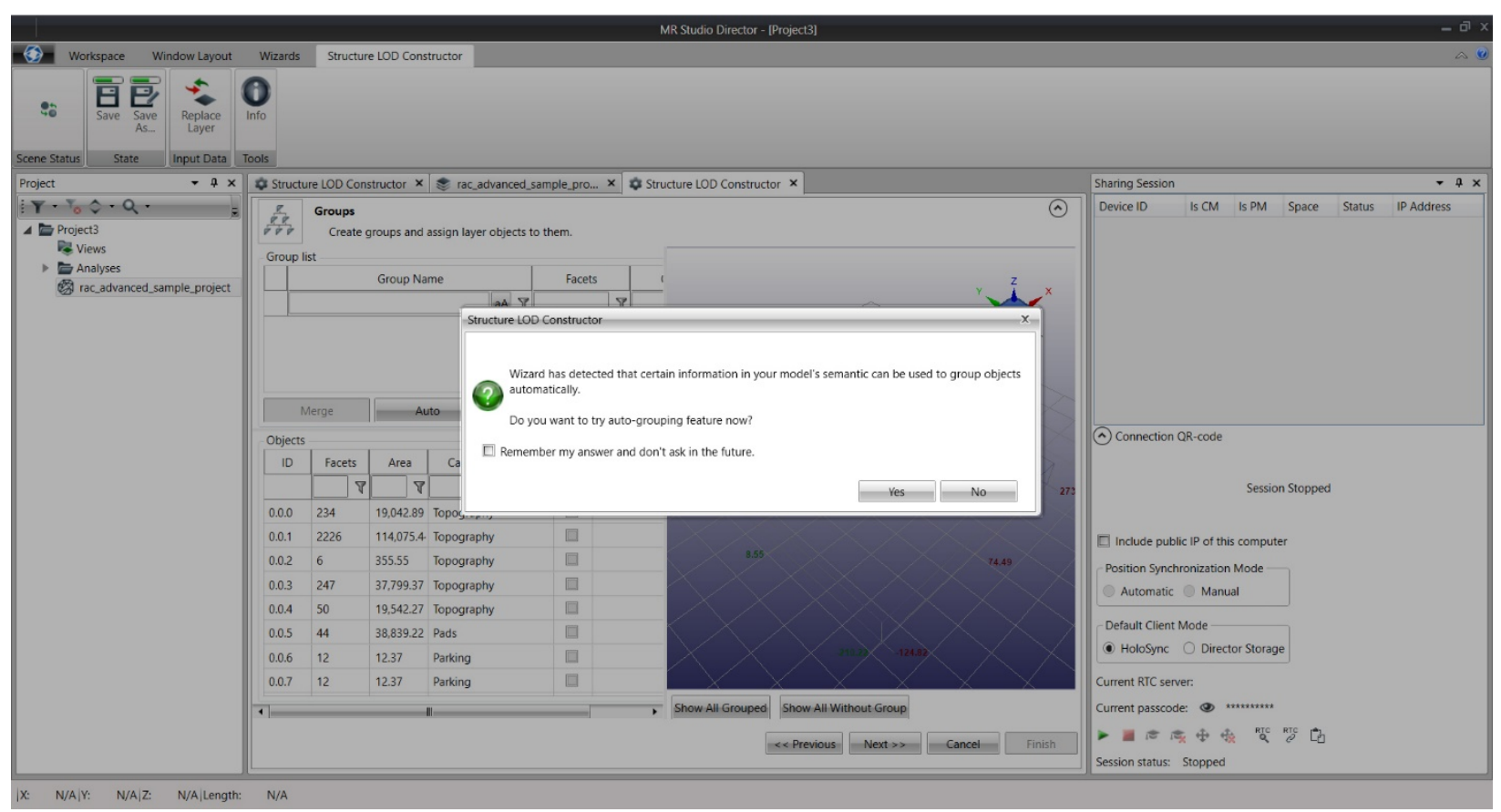



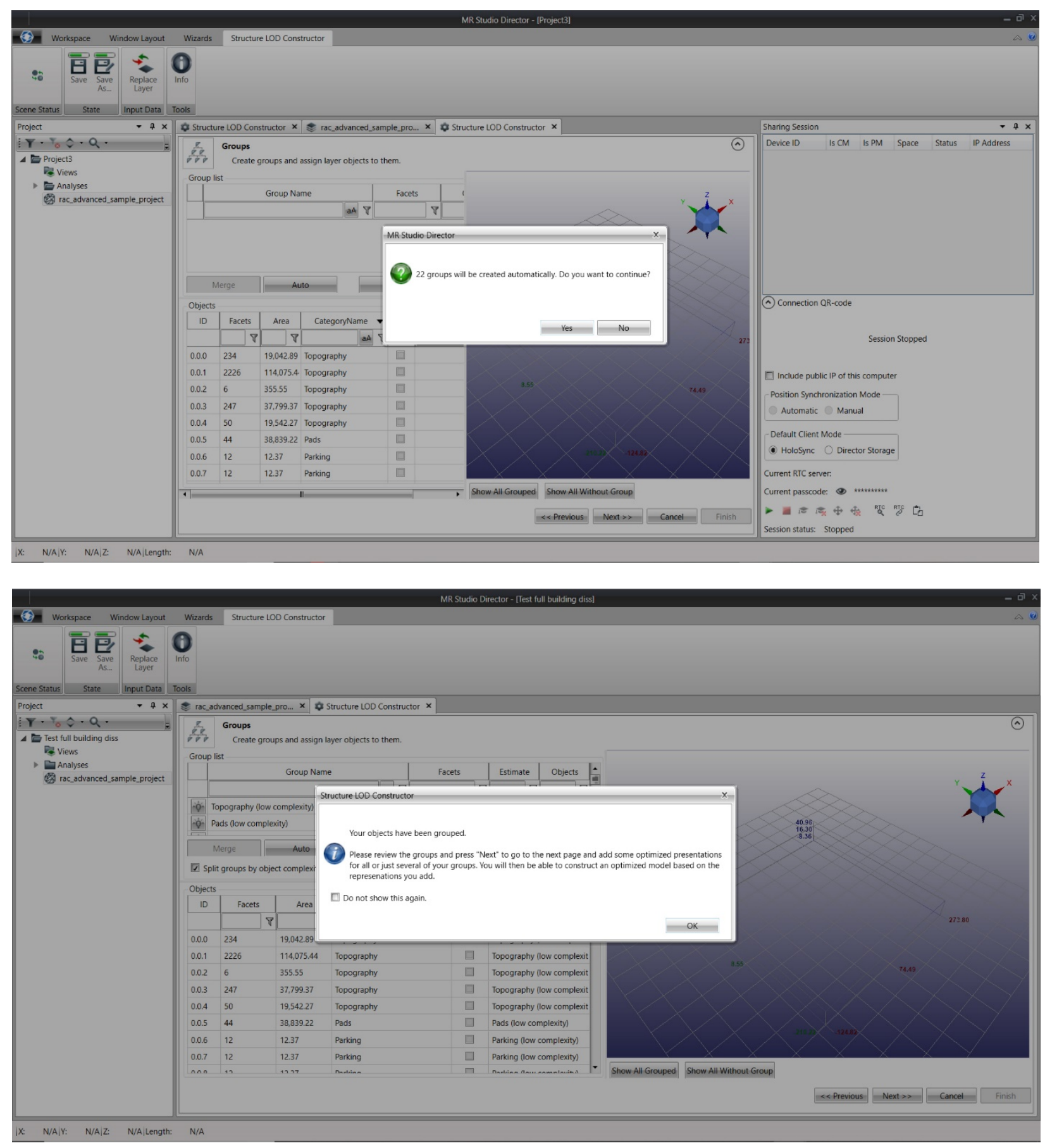

\section{Groups}

- This page consists of three sections:

1. Group List: lists all the created automated-groups. This list can be assorted by clicking on the head of the column "e.g. Group Name". Note that the list also assorts groups by complexity level (high, medium, low). 
2. Objects: lists all imported objects. This list can be assorted by clicking on the head of the column.

3. Viewer: whenever an object or a group is selected, the "Viewer Screen" will visualize it.

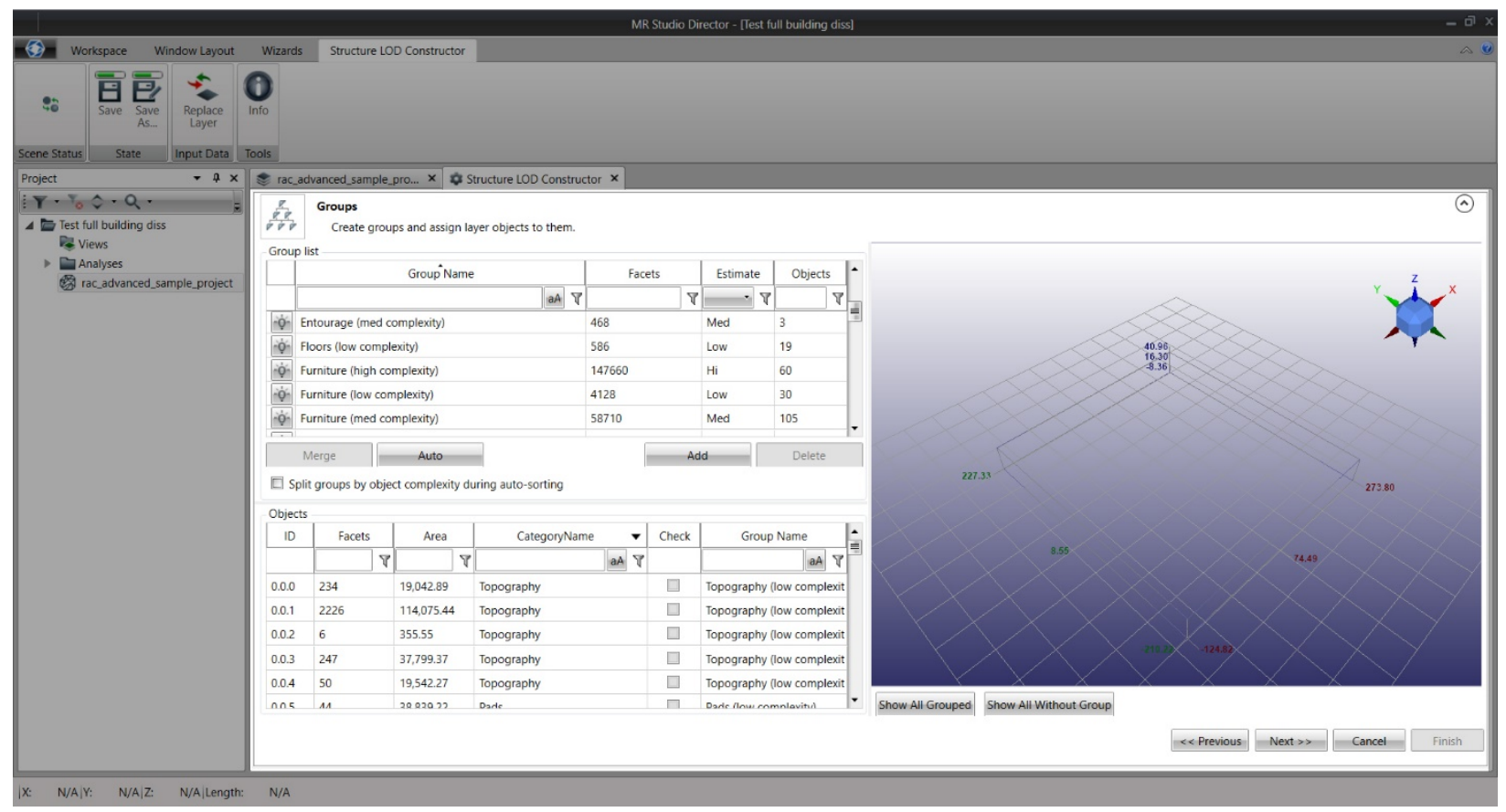

- In the "Group" list, you can:

- "Merge" multiple groups if you wish to optimize multiple groups as one.

- $\quad$ Select the groups > Merge

- "Delete" a group if you wish to eliminate some or all its auto-grouped objects.

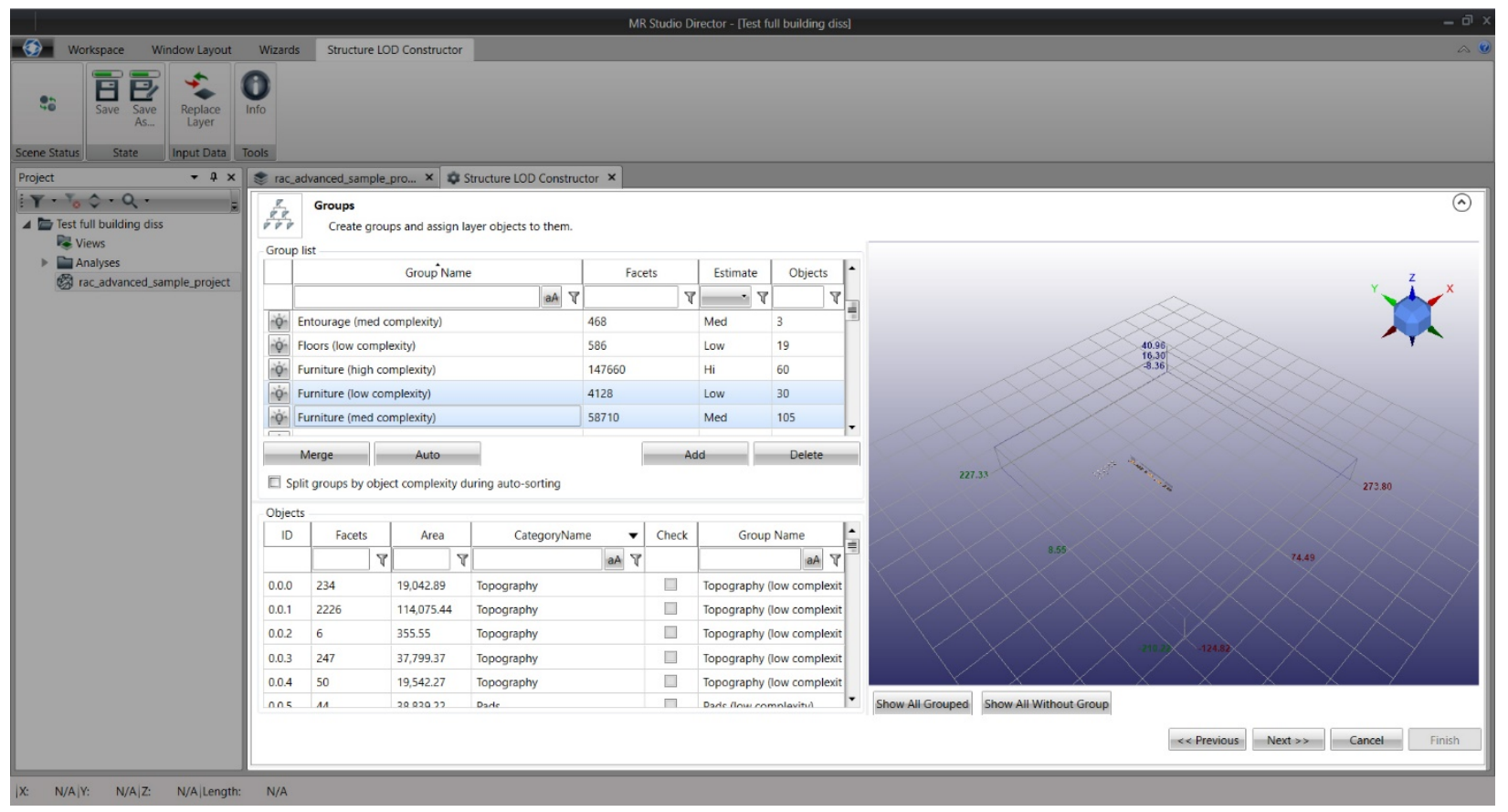


- Objects will NOT be deleted from the project, instead, they will be found in the "Object" section and categorized as an unidentified "Group Name".

- You can select them again either by locating them in the "Object" section or by clicking on "Show All Without Group" in the "Viewer" section.

- "Add" a new group to the list: Add > Rename > find objects from "Object" section > check the box next to the object.

- Note that if the object you select for the new group is already in another group, then Wizard will automatically replace it to the new group.

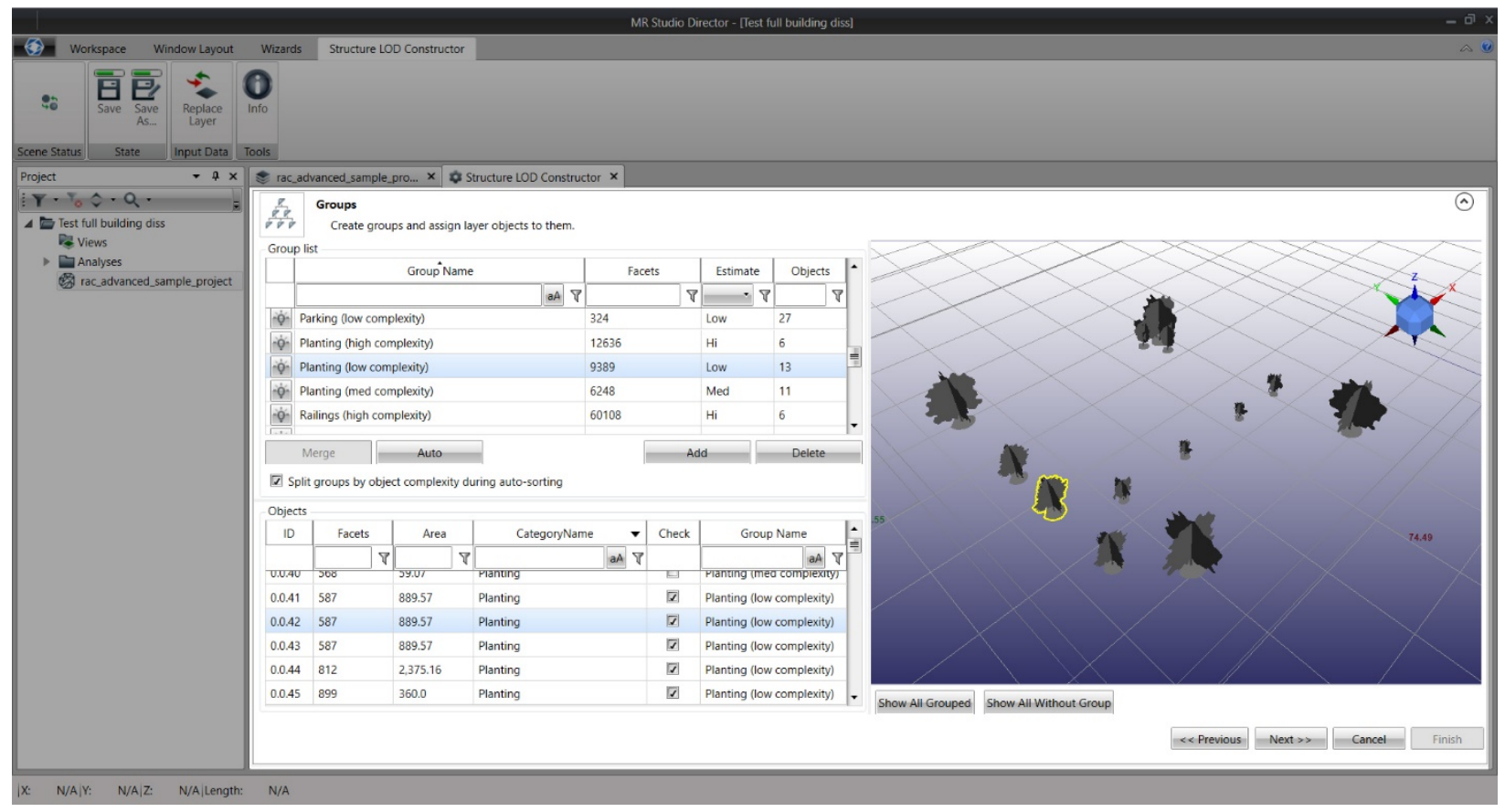

Note: the planting group is selected and represented in the "Viewer" screen. Then, when a specific object is selected, it was highlighted in "Viewer", then disappeared when its box unchecked in the "object" section.

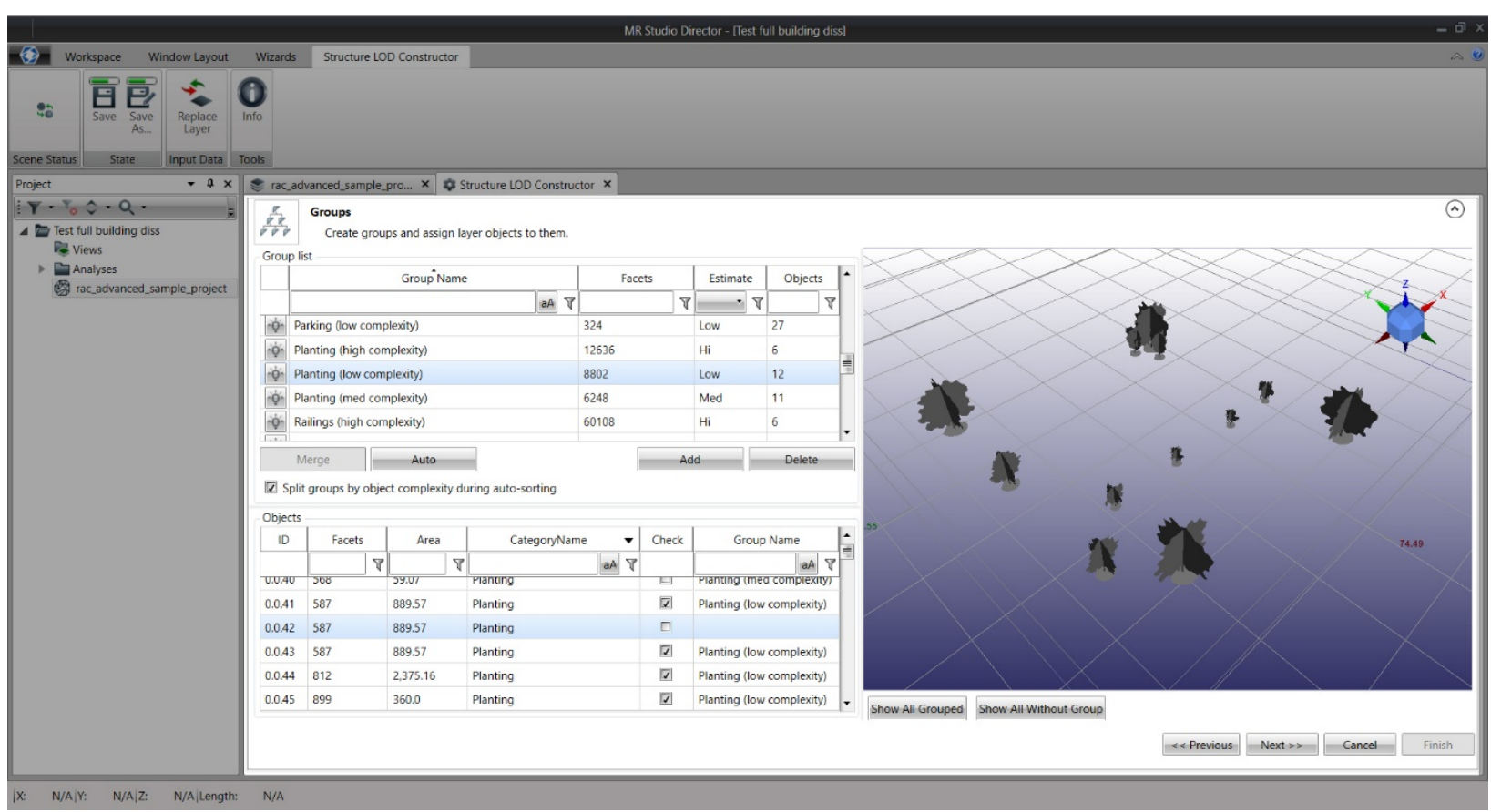


Note: when "Show All Without Group" is selected; the missing object will reappear.

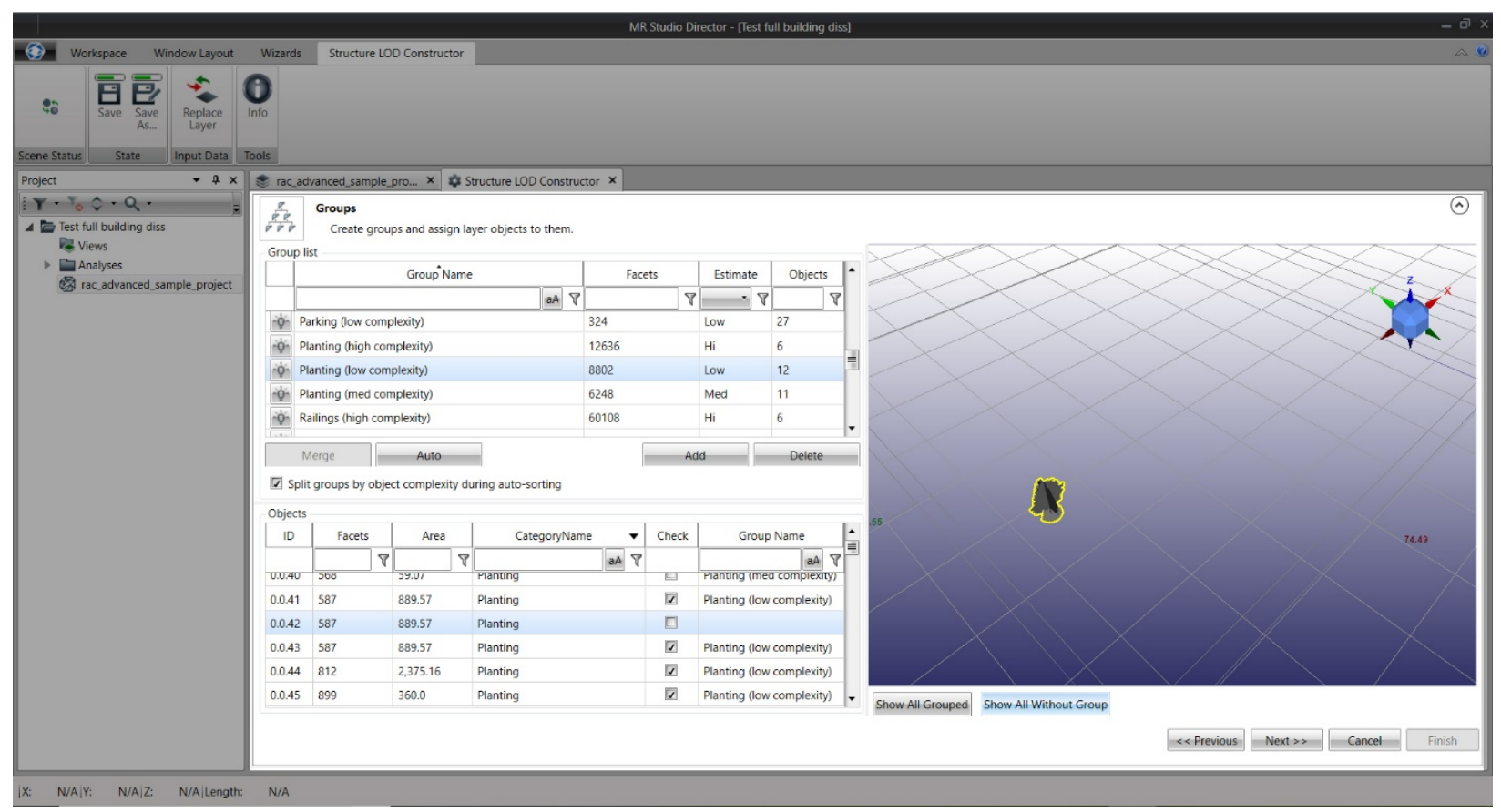

Note: if you leave the object without an assigned group "unidentified", an alert message will pop when pressing "Next".

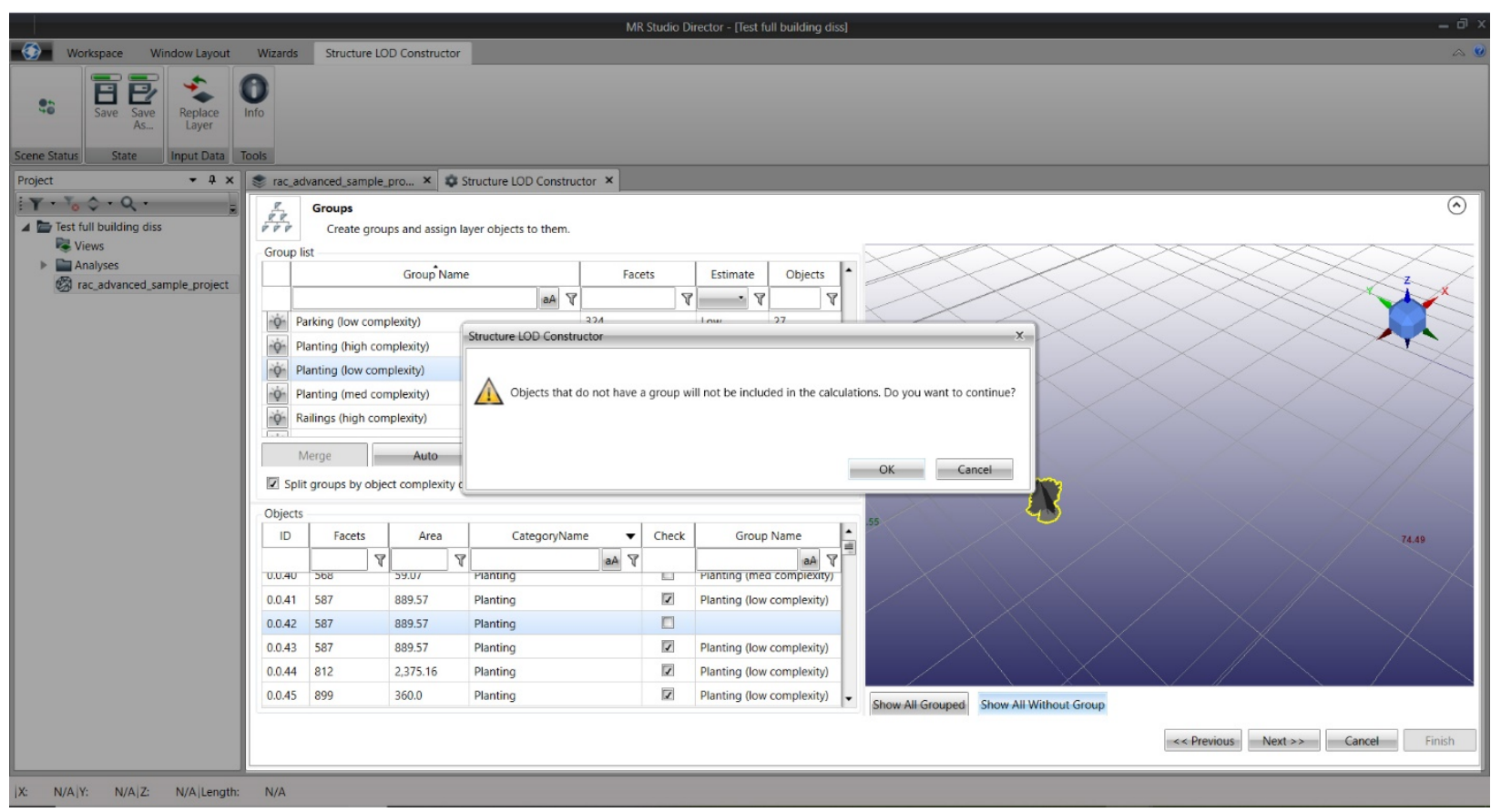




\section{Levels}

- This page allows you to take each group produced in the previous page and create multiple Level of Detail “LOD” to it.

- An indicator is placed at the bottom left corner of the page showing the total number of facets achieved and the type of Virtual device it can handle.

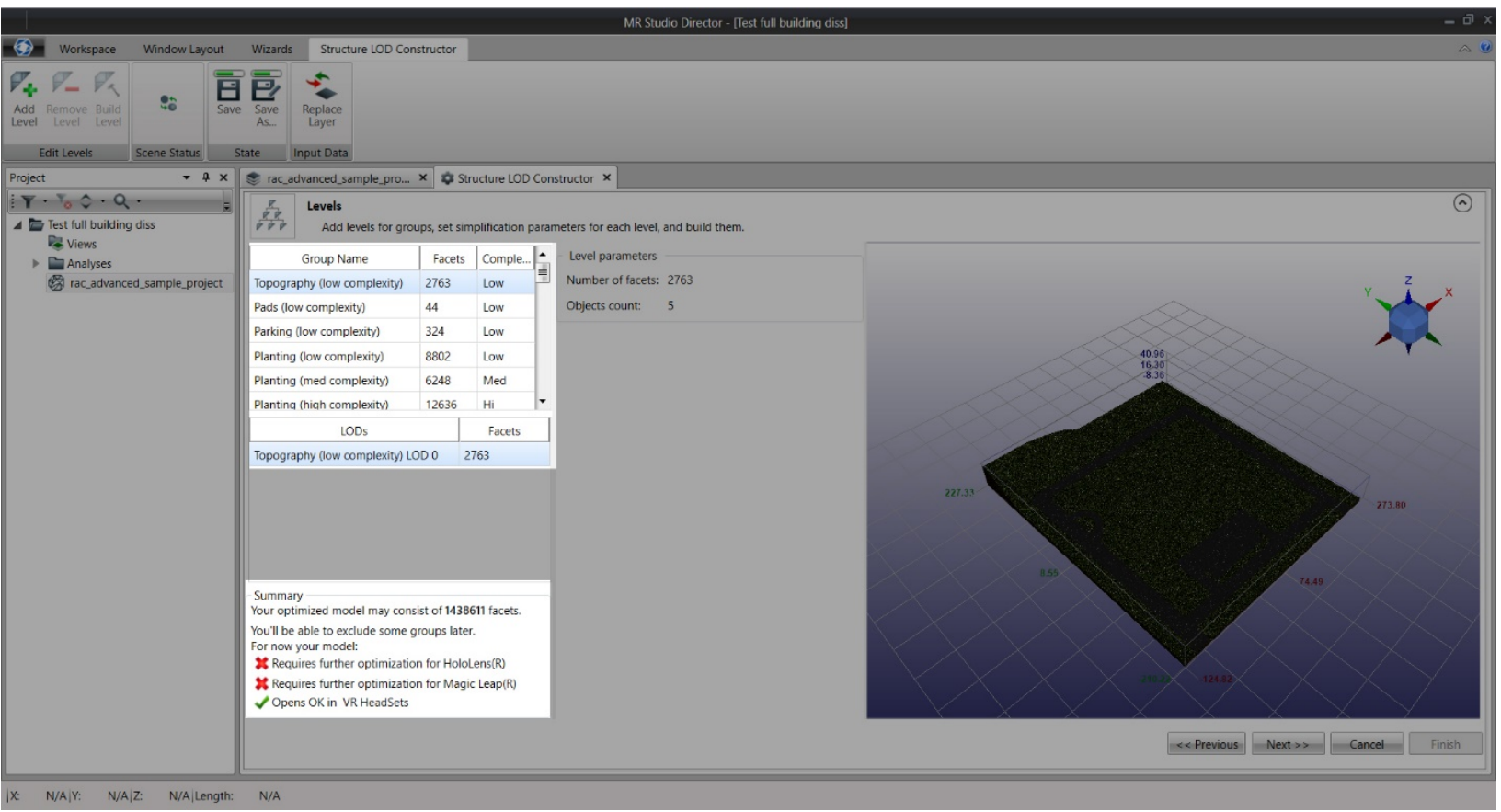

- To add "LOD": select group > Add Level > Building Parameters

- Number of facets is reduced by targeting a final number of facets or by providing a reduction factor.

- 0.3 reduction factor produces a lower number of facets that 0.7

- Upon completion, press "Build Level" under Edit Levels.

- Note that groups with (high complexity) can be optimized more than (low complexity) groups.

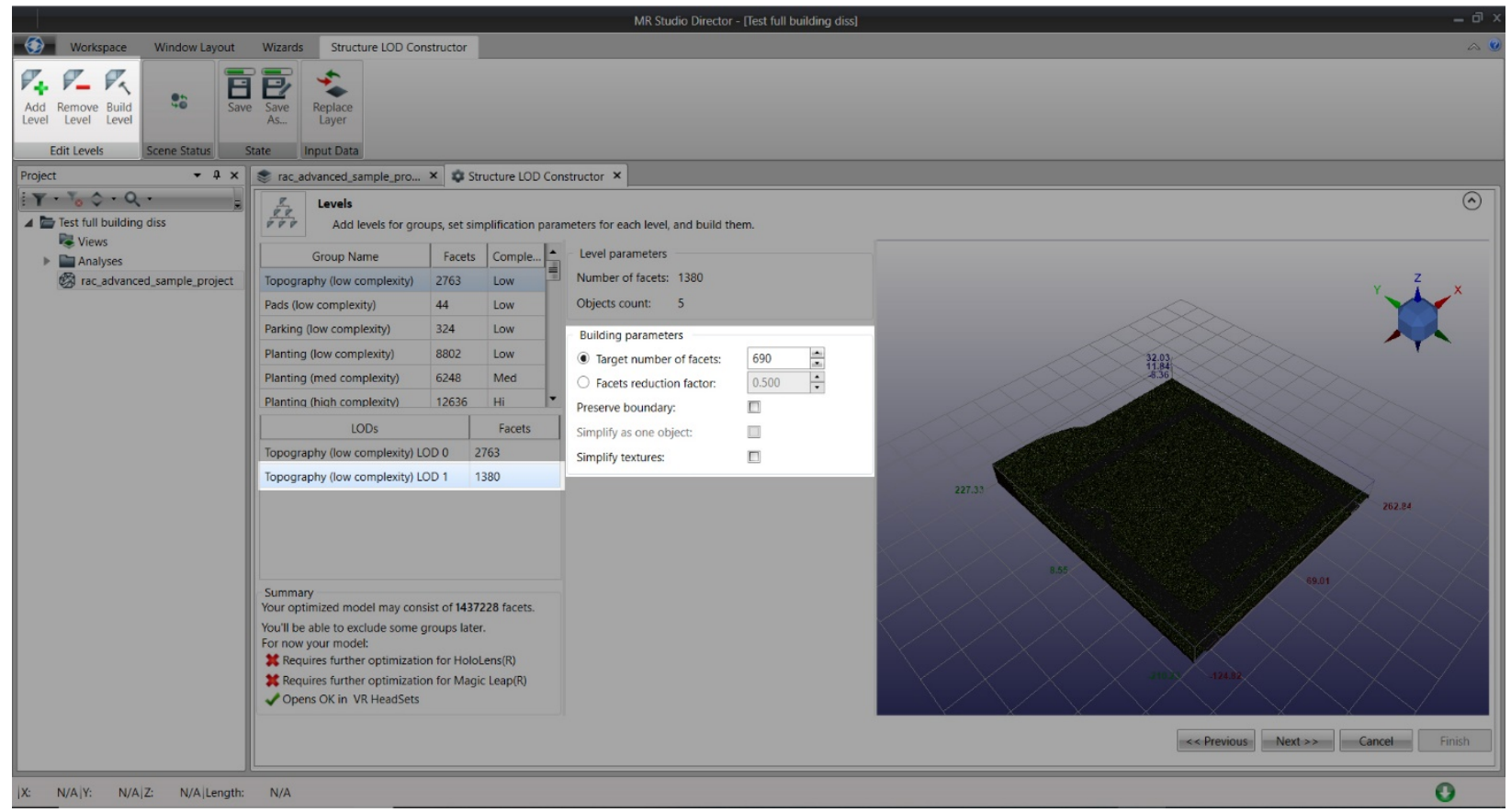


Note: information in the indication box has changed.

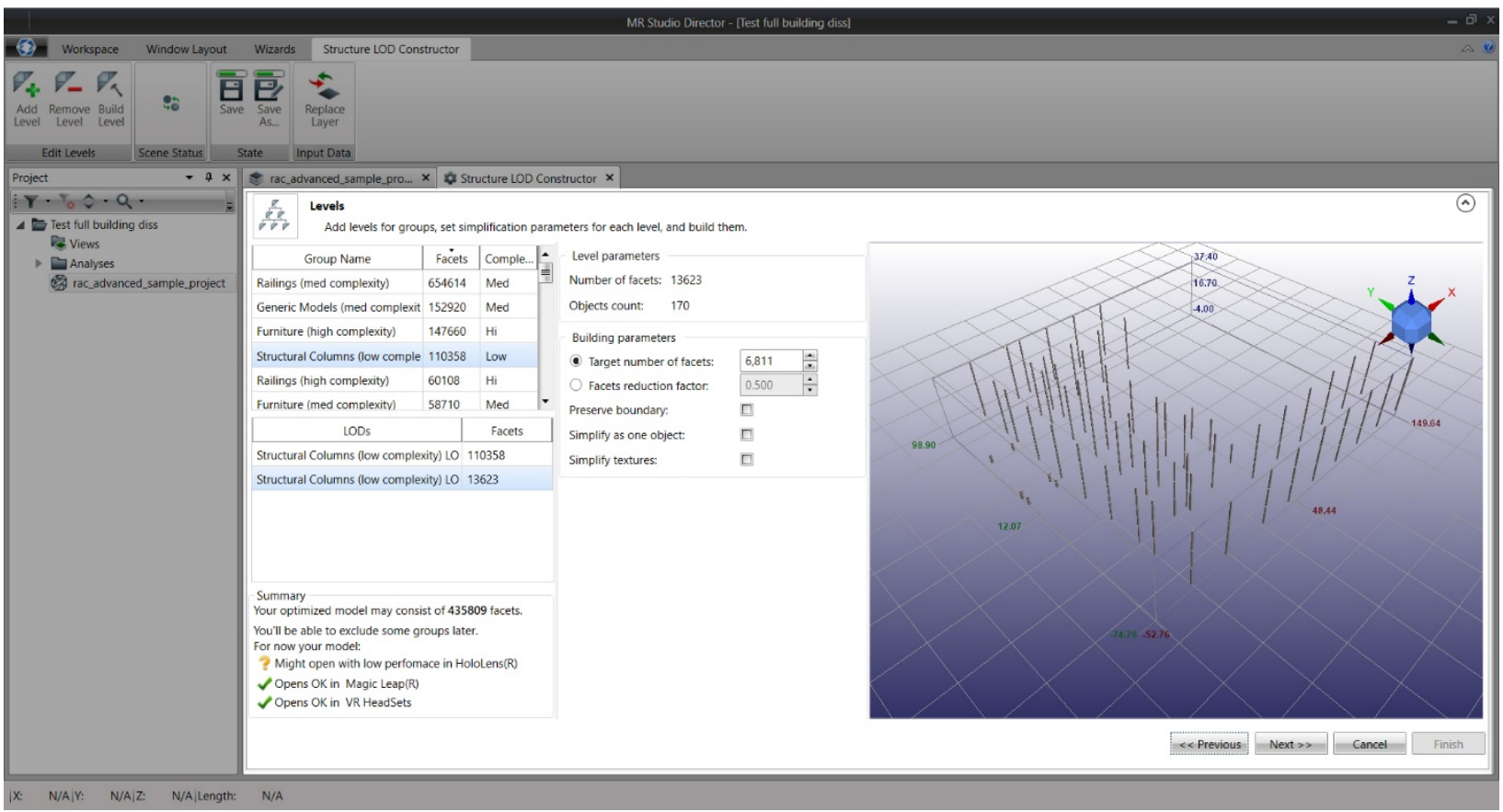

The Level of Details can be related to the targeted device:

LOD 0 highest number of facets. Ideal for VR Headsets.

LOD 1 medium number of facets. Ideal for Magic Leap.

LOD 2 lowest number of facets. Ideal for Microsoft HoloLens.

\section{Pyramid Construction}

- After pressing "Next" from previous page, another Wizard message will pop.

- This automated LOD construction feature creates simple optimized LOD structure for the entire project based on the levels created on the previous page for each group.

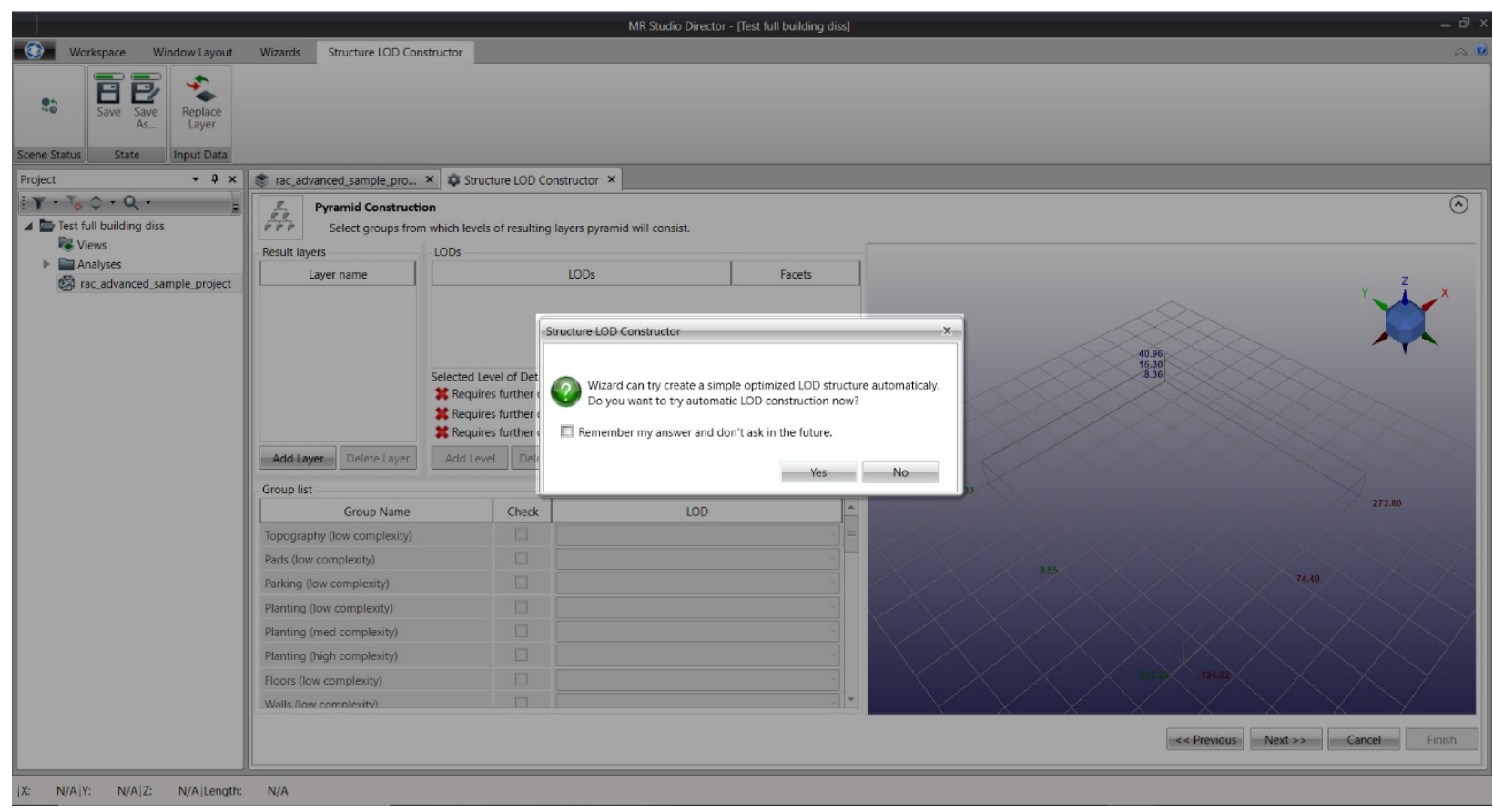




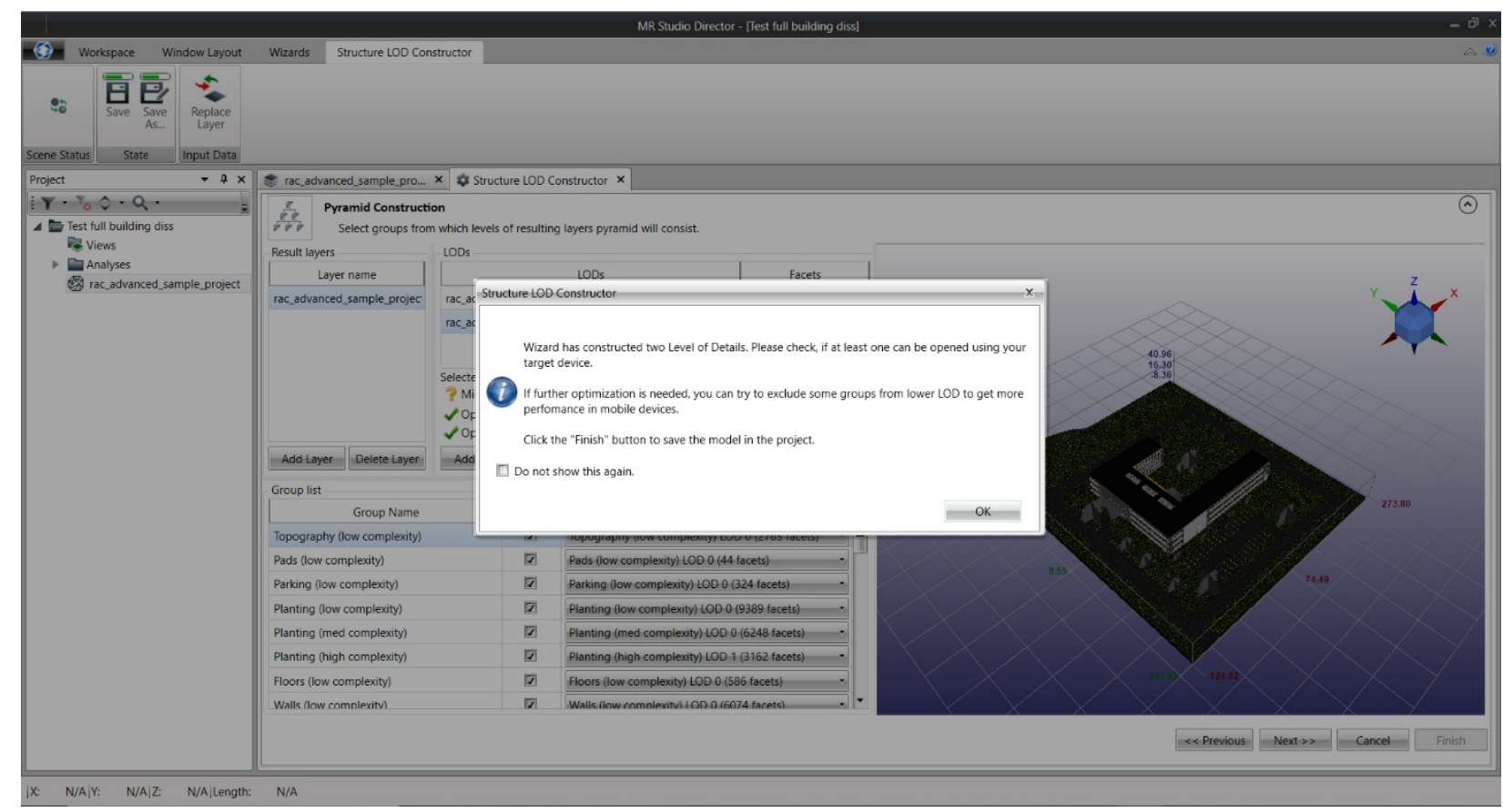

\section{Pyramid Construction" consists of:}

1. Result Layers: Allows the user to add secondary projects based on the primary one. This tool is useful if the user wishes to extract a part of the model (e.g only walls and HVAC System) that would be separate from the original project.

2. LODs: Results here will be embedded in the project and when shared with users wearing different headsets, the project will automatically accommodate the needs of each device based on the Level of Details it has in

3. Group List: helps the user select specific group LOD and move it to the general LOD list above.

4. Viewer: groups selected are represented visually in this screen

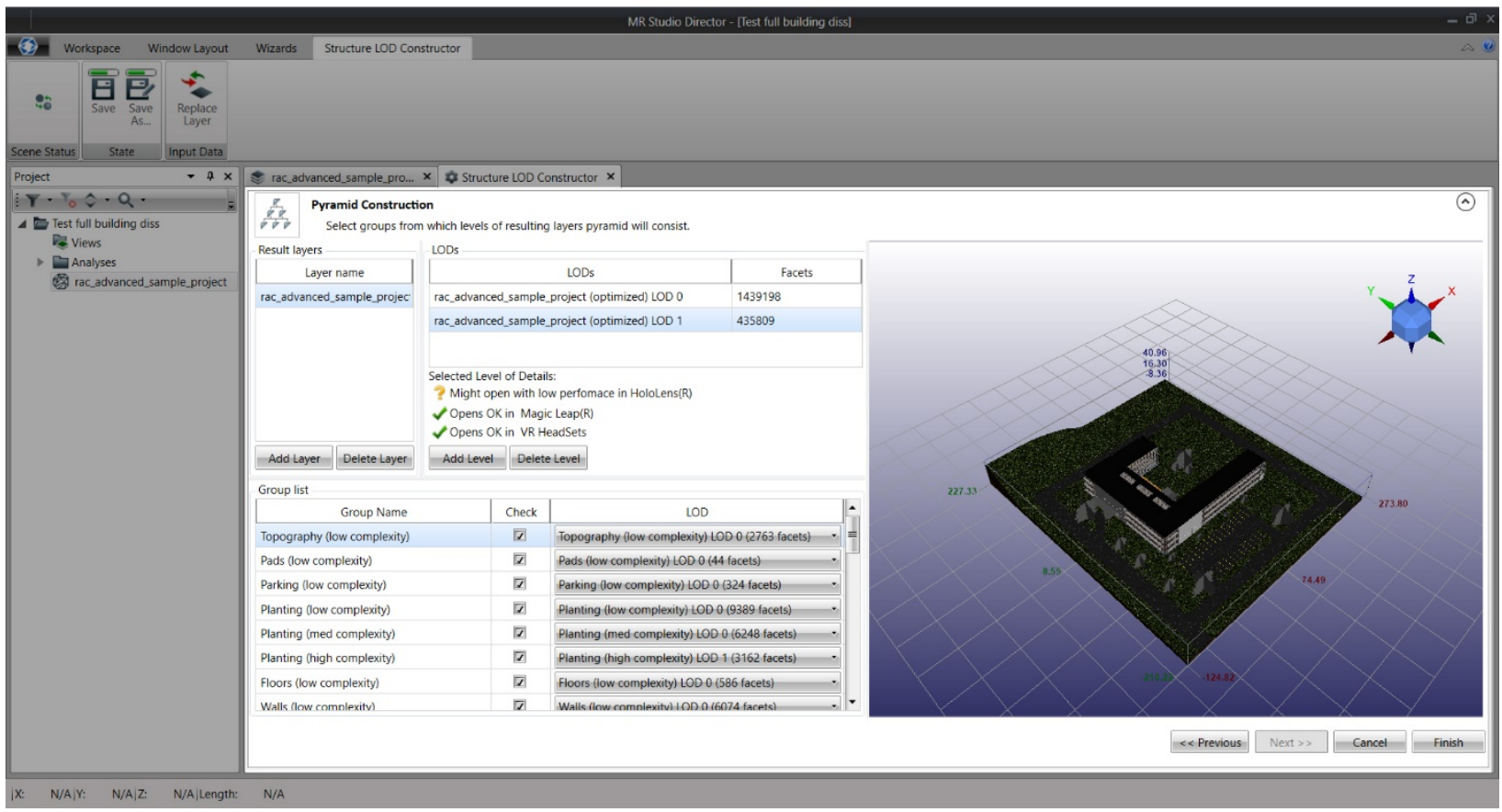




\section{- Add Level in "LODS" :}

1. Add Level

2. navigate in "Group List" to select lowest level of detail.

3. hide groups if necessary to reduce number of facets by unchecking the box next to them.

\section{The selected Level is now ready to work on Microsoft HoloLens}
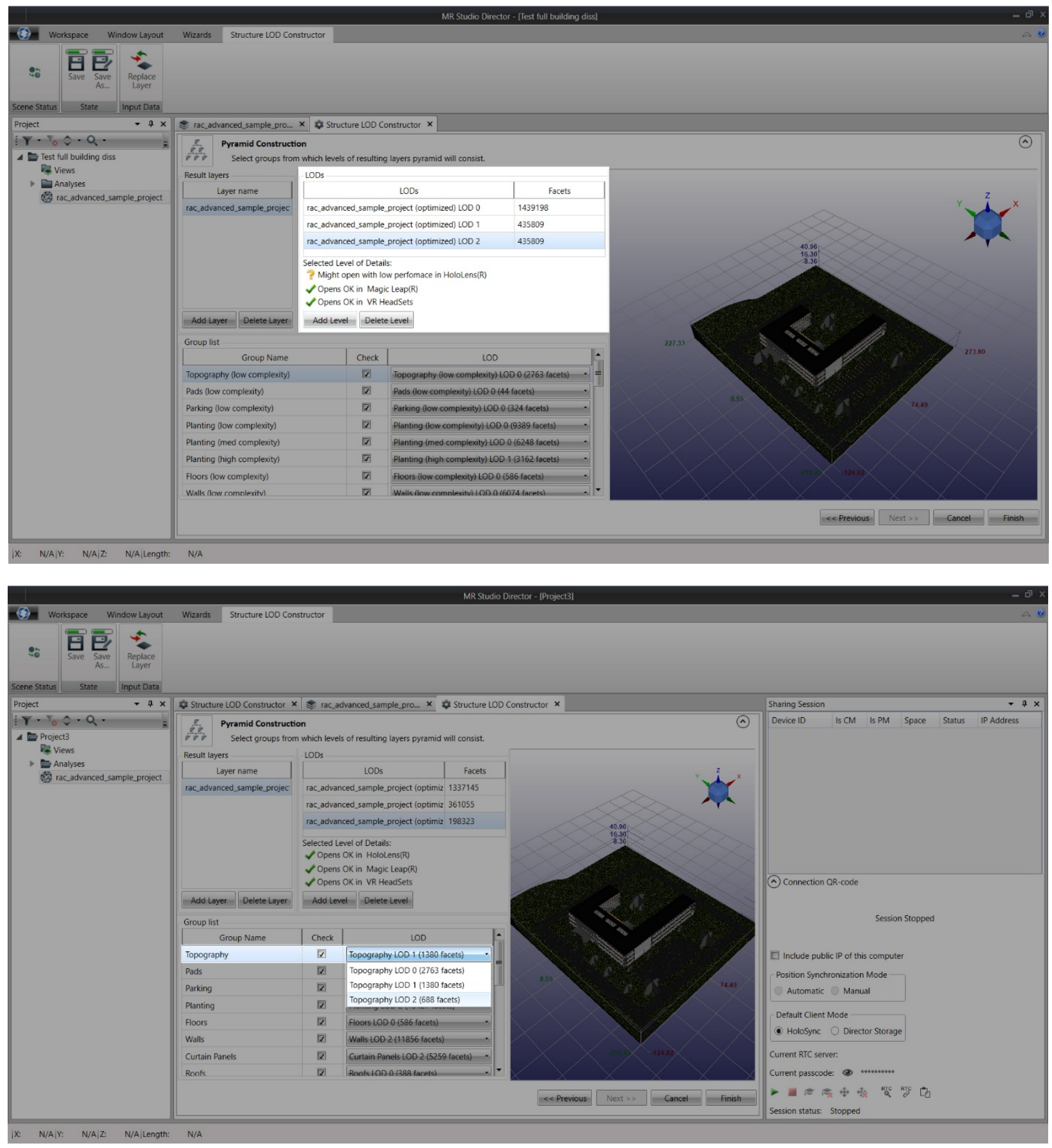


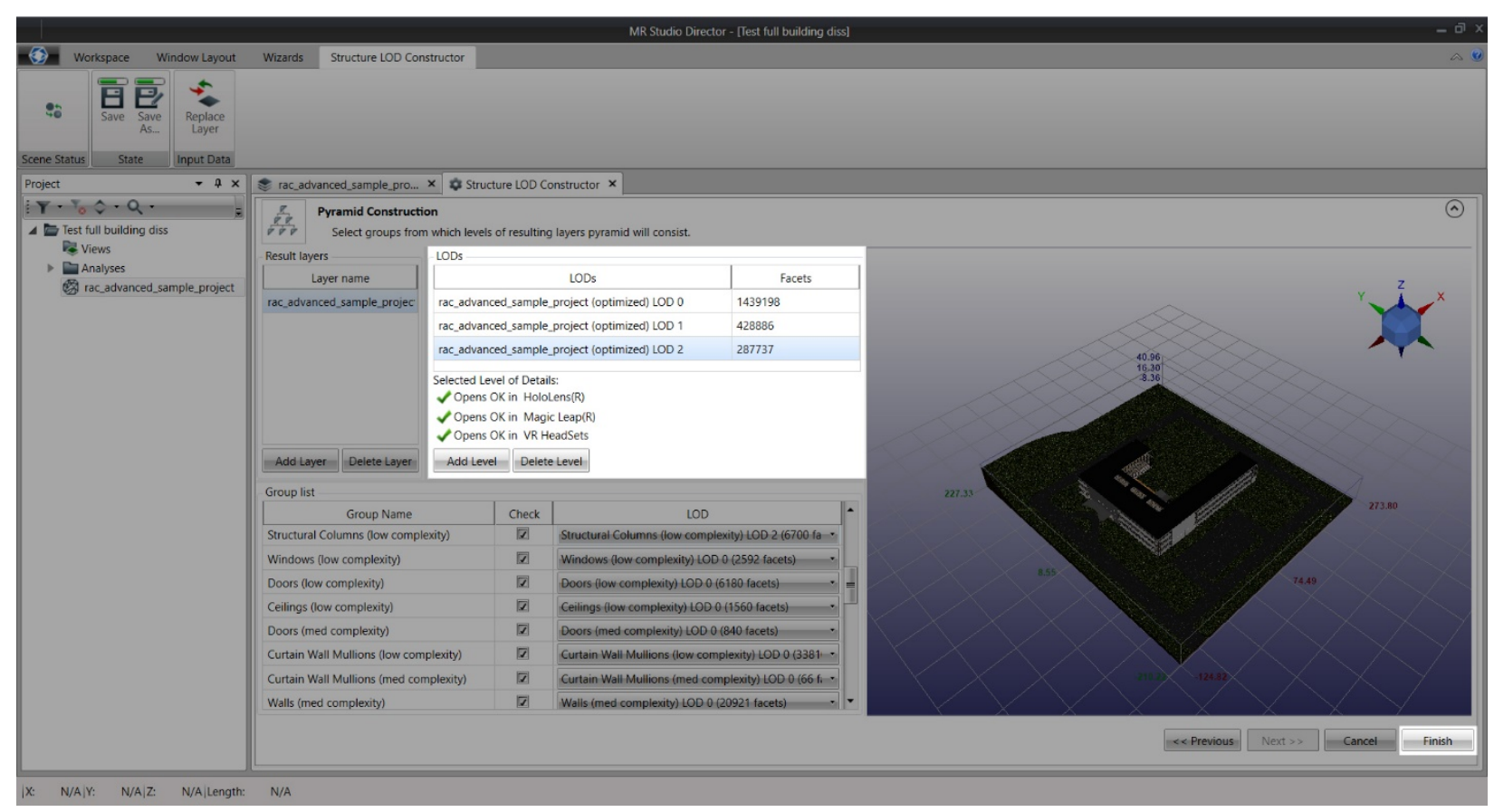

-Press "Finish" to end "Wizard" mesh optimization. 
BIBLIOGRAPHY 
"AEC Magazine. Mixed Reality: HoloLens on the Construction Site." AEC Magazine, 2018.

AIA National, and AIA California Council. "2007 Integrated Project Delivery: A Guide." 2007.

https://info.aia.org/SiteObjects/files/IPD_ Guide_2007.pdf.

Barfield, Woodrow, and Thomas A. Furness. Virtual Environments and Advanced Interface Design. New York: Oxford University Press, 1995.

Baxter, Mary. "IPD Shaping the Future of Canadian Construction Project Delivery Constructconnect.com." Daily Commercial News. September 15, 2017. https://canada.constructconnect.com/dcn/n ews/projects/2017/09/ipd-shaping-thefuture-of-canadian-construction-projectdelivery-1027185w.

Bernstein, Philip, and Peggy Deamer. Building the Future: Recasting Labor in Architecture. New York: Princeton Architectural Press, 2008.

Biocca, Frank, and Mark R. Levy. Communication in the Age of Virtual Reality. Florence: Taylor and Francis, 2013.

Bottazzi, Roberto. "Digital Architecture Beyond Computers." 2018.

Bowman, Doug A. "The Encyclopedia of Human-Computer Interaction, 2nd Ed." The Interaction Design Foundation. https://www.interactiondesign.org/literature/book/theencyclopedia-of-human-computerinteraction-2nd-ed.

Bray, Brandon, and Matt Zeller. "What Is Mixed Reality? - Mixed Reality." Mixed Reality | Microsoft Docs. March 2018. https://docs.microsoft.com/enus/windows/mixed-reality/mixed-reality.

Buchmann, Volkert, Stephen Violich, Mark Billinghurst, and Andy Cockburn.

"FingARtips." Proceedings of the 2nd International Conference on Computer Graphics and Interactive Techniques in Austalasia and Southe East Asia GRAPHITE 04, 2004. doi:10.1145/988834.988871.

Buick, Roz. "Microsoft Keynote HoloLens 2." In Mobile World Congress. Proceedings of Mobile World Congress, Barcelona. 2019.

Bulling, Andreas, Ozan Cakmakci, Kai Kunze, and James Rehg. "Eyewear Computing Augmenting the Human with Head-Mounted Wearable Assistants." Dagtsubl Seminar 16042, January 2016.

Bush, Vannevar. "As We May Think." The Atlantic, July 01, 1945.

Cadazz. "CAD Software - History of CAD CAM." CAD Software History CAD CAM Computer Aided Design. 2004. http://cadazz.com/cad-softwarehistory.htm.

Carpo, Mario, and Francesco Furlan, eds. Leon Battista Albertis Delineation of the City of Rome (descriptio Urbis Romae). Translated by Peter Hicks. Tempe, AZ: ACMRS, Arizona Center for Medieval and Renaissance Studies, 2007.

Carpo, Mario. The Alphabet and the Algorithm: Form, Standards and Authorship in times of $V$ ariable Media. Cambridge, MA: MIT Press, 2011.

Carpo, Mario. Digital Turn in Architecture 19922012: AD Reader. Somerset: Wiley, 2013.

Carreiro, Miguel B., and Pedro D. Pinto. "The Evolution of Representation in 
Architecture." Future Traditions, Regional International Workshop, 2013.

Caudell, T.p., and D.w. Mizell. "Augmented Reality: An Application of Heads-up Display Technology to Manual Manufacturing Processes." Proceedings of the Twenty-Fifth Hawaii International Conference on System Sciences, 1992. doi:10.1109/hicss.1992.183317.

Coons, Steven Anson. "An Outline of the Requirements for a Computer-aided Design System." AFIPS '63 (Spring), May 1963, 299304.

Dauben, Prof. Joseph. "Galileo Galilei." Khan Academy. 2015. https://www.khanacademy.org/humanities/ renaissance-reformation/high-ren-florencerome/beginners-guide-high-ren/a/galileogalilei.

Davis, Fred D. "Perceived Usefulness, Perceived Ease of Use, and User Acceptance of Information Technology." MIS Quarterly13, no. 3 (1989).

Do, Ellen Yi-Luen, and Mark D. Gross. "Drawing Analogies: Supporting Creative Architectural Design with Visual References." Proceedings of Association of Computer Aided Design In Architecture (ACADLA), 1995, 35-52.

Exploring New Uses for the Monastery Lands at 210 Laurier: Monastery Public Consultation Report. Report. National Capital Commission. 2018.

Featherman, Mauricio S., and Paul A. Pavlou.

"Predicting E-services Adoption: A Perceived Risk Facets Perspective." International Journal of HumanComputer Studies59, no. 4 (2003): 451-74.

Fitzgerald, Devinee. "Architecture vs.

Engineering: Collaborate Despite Differences [Updated]." Redshift EN. June 12, 2018. https://www.autodesk.com/redshift/archite cture-vs-engineering/.

Gänshirt, Christian. Tools for Ideas: Introduction to Architectural Design. De Gruyter, 2012.

Hendley, Nate. "Lean Construction Puts down Roots in Canada with Graham Construction." February 22, 2017.

Hendriks, Charlotte. "The Physical Architectural Model: The Architect's Most Important Tool." Reading, The Architecture of the Interior, 2015.

Hewitt, Mark. "Representational Forms and Modes of Conception; an Approach to the History of Architectural Drawing." Journal of Architectural Education39, no. 2 (1985): 2-9.

"HoloLens 2-Overview, Features, and Specs | Microsoft HoloLens." -Overview, Features, and Specs | Microsoft HoloLens. https://www.microsoft.com/enus/hololens/hardware.

Ilozor, Benedict D., and David J. Kelly. " Building Information Modeling and Integrated Project Delivery in the Commercial Construction Industry: A Conceptual Study." Journal of Engineering, Project, and Production Management2, no. 1 (2012): 23-36.

"Infographic: The History of Augmented Reality." Huff Post. October 25, 2016. https://www.augment.com/infographiclengthy-history-augmented-reality/.

Ishii, Hiroshi, and Minoru Kobayashi. "ClearBoard." Proceedings of the SIGCHI Conference on Human Factors in Computing Systems - CHI 92, 1992. doi:10.1145/142750.142977.

"Join the Mixed Reality Partner Program | Microsoft HoloLens." Join the Mixed Reality 
Partner Program | Microsoft HoloLens. https://www.microsoft.com/en-

us/hololens/partner-program.

Jung, Timothy Hyungsoo, and Tom Dieck M. Claudia. Augmented Reality and V irtual Reality: Empowering Human, Place and Business. Cham: Springer International Publishing, 2018.

Kruijff, Ernst, Joseph J. LaViola, and Doug A. Bowman. 3D User Interfaces: Theory and Practice. Edited by Doug A. Bowman. Boston, MA: Pearson Education, 2004.

Larena, Alejandro Larena. Proceedings of Origin of the Collaboration between Engineers and Architects in Great Britain in the Thirties. 2006.

Lehtinen, Tyler, and Anne Kokkonen. "Collaboration and Contracts in Integrated Project Delivery - Exploring the Roles of Owners and Architects." Proceedings of COCREATE 2013 - The Boundary-Crossing Conference on Co-Design in Innovation. 2013.

Macdonald, Jennifer A. "A Framework for Collaborative BIM Education Across the AEC Disciplines." Proceedings of 37th Annual Conference of the Australasian Universities Building Educators Association (AUBEA), The University of New South Wales, Australia. 2011.

"Magic in the Making." Magic Leap. https://www.magicleap.com/.

"Magic Leap One: Creator Edition | Magic Leap." https://www.magicleap.com/magicleap-one.

Murray, Peter. "The Saga of Sydney Opera House." 2003.

Myers, Brad A. "A Brief History of Humancomputer Interaction
Technology." Interactions5, no. 2 (1998): 4454.

Nadella, Satji. "Microsoft Keynote HoloLens 2." Proceedings of Mobile World Congress, Barcelona. 2019.

"NCC Buys Century-old Gatineau Convent • OttawaStart.com." OttawaStart.com. November 26, 2016. https://ottawastart.com/ncc-buys-centuryold-gatineau-convent/.

Picon, Antoine. "The Ownership Revolution, Digital Culture and the Transformation of Architectural Practice and Ideals." Lecture, Princeton University School of Architecture.

Picon, Antoine, and Martin Thom. French Architects and Engineers in the Age of Enlightenment. Cambridge: Cambridge University Press, 2009.

Premaratne, Prashan. "Historical Development of Hand Gesture Recognition." Human Computer Interaction Using Hand Gestures Cognitive Science and Technology, 2014, 5-29. doi:10.1007/978-981-4585-69-9_2.

Pyfer, James. "Sketchpad." Encyclopedia of New Media.

Riahi, Pari. "Expanding the Boundaries of Architectural Representation." The Journal of Architecture22, no. 5 (2017): 815-24.

Riahi, Pari. "Expanding the Boundaries of Architectural Representation." The Journal of Architecture22, no. 5 (2017): 815-24.

Robertson, Adi. "AR Headset Company Meta Shutting down after Assets Sold to Unknown Company." The Verge. January 18, 2019. https://www.theverge.com/2019/1/18/181 
87315/meta-vision-ar-headset-companyasset-sale-unknown-buyer-insolvent.

Rwinj. "Gestures - Mixed Reality." Mixed Reality | Microsoft Docs. https://docs.microsoft.com/enus/windows/mixed-reality/gestures.

Sheng, Lee Xia, and Dr.Mohd Faris Khamidi. "Digital Adaptive Mass Customization for Building Design, Construction, and Performance." January 3, 2018.

Smith, Deke. "An Introduction to Building Information Modeling." BuildingSMART Alliance (National Institute of Building Sciences), January 01, 2007.

Sommer, Degenhard, Herbert Stöher, and Lutz Weisser. Ove Arup \&o Partners: Engineering the Built Environment. Basel: Birkhäuser Verlag, 1994.

Speicher, Maximilian, Brian D. Hall, and Michael Nebeling. "What Is Mixed Reality." 2019.

Sutherland, Ivan E. "Sketchpad a Man-Machine Graphical Communication System." Simulation2, no. 5 (1964).

Sutherland, Ivan E. "The Ultimate Display." Proceedings of IFIP Congress, 1965, 506-08.

Sutherland, Ivan E. "A Head-Mounted Three Dimensional Display." AFIPS '68, Fall Joint
Computer Conference, Part I, December 9, 1968, 757-64.

Sutton, Mark. "Mixed Reality Brings New

Dimension to Construction." Leading

Technology. June 19, 2018.

http:/ /www.itp.net/617346-mixed-reality-

brings-new-dimension-to-construction.

"The Arvizio Platform." Front Page. https://www.arvizio.io/our-platform-2/.

"U.S. Bureau of Labor Statistics." U.S. Bureau of Labor Statistics.

https://www.bls.gov/ooh/architecture-andengineering/architects.htm.

Waters, John K. Blobitecture: Waveform Architecture and Digital Design. Gloucester, MA: Rockport, 2003.

"What Is Mass Customization? Definition and Meaning." BusinessDictionary.com. http:/ /www.businessdictionary.com/definiti on/mass-customization.html.

Wong, Johnny, Xiangyu Wang, Heng Li, Greg Chan, and Haijiang Li. A Review of Cloud-Based BIM Technology in the Construction Sector. Journal of Information Technology in Construction, 2014.

Yorke, Simon. "Blending Realities in AEC Using Immersive Experiences." Speech, Autodesk University, Las Vegas, July 13, 2018. 